\title{
Acoustic and Afterload evaluation of Left Ventricular Assist Devices
}

\section{Per Sundbom}

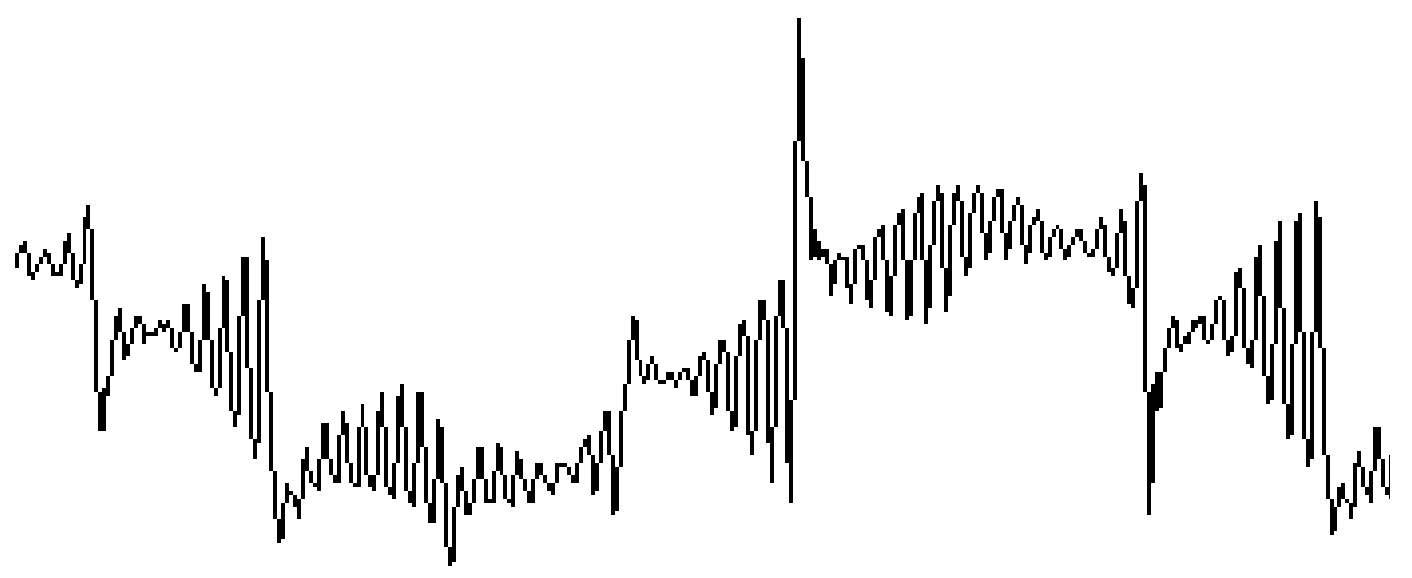




\title{
Acoustic and afterload evaluation of left ventricular assist devices
}

\author{
Per Sundbom
}

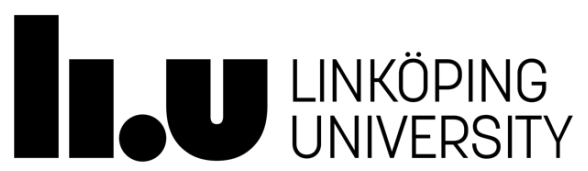

Department of Medical and Health Sciences

Linköping University, Sweden

Linköping 2019 
(C)Per Sundbom, 2019

Cover/picture/Illustration/Design: Soundwave from a HeartMate II.

Published articles have been reprinted with the permission of the copyright holder.

Printed in Sweden by LiU-Tryck, Linköping, Sweden, 2019

ISBN 978-91-7929-988-0

ISSN 0345-0082

Linköping University medical dissertation no 1707 
To Melker and Ellen, the light of my life!

It always seems impossible until it's done

-Nelson Mandela 


\section{Contents}

Abstract ............................................................................

List of original papers................................................................. 3

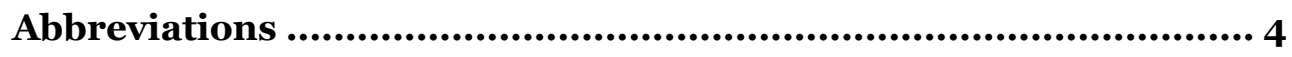

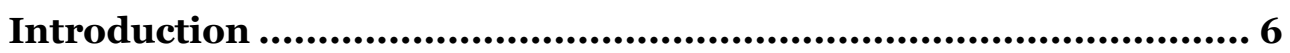

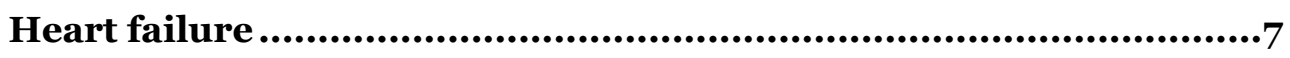

Epidemiology of heart failure ..................................................................... 7

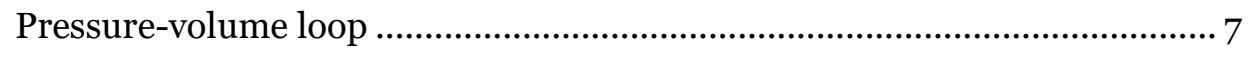

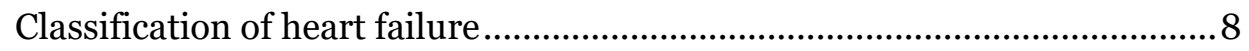

Pathophysiology of heart failure .................................................12

Introduction to pathophysiology …........................................................... 12

Ventricular remodeling ........................................................................ 12

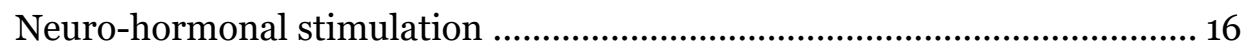

Calcium signaling dysfunction ................................................................17

Heart failure with preserved ejection fraction ..............................................17 
Pharmacological treatment .20

Angiotensin converter enzyme inhibitor .20

Angiotensin receptor blockers .20

Beta blockers 21

Mineralocorticoid/ aldosterone receptor antagonists 21

Angiotensin receptor Neprilysin inhibitor 22

Diuretics. 22

Other medical treatments 22

Combination Therapy 23

Device treatment for heart failure 24

Implantable cardioverter defibrillator 24

Cardiac resynchronization therapy 24

Advanced treatment for heart failure 25

Advanced pharmacological treatment 25

Short term assist devices 26 
Heart transplantation

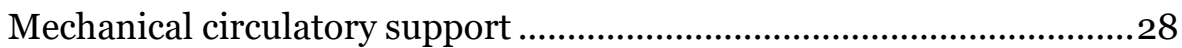

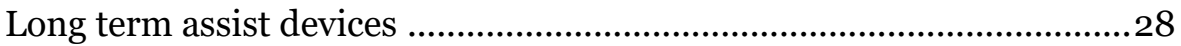

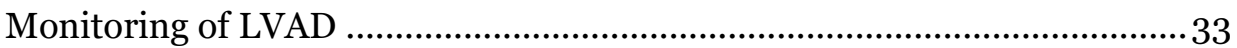

Adverse events during LVAD treatment .................................... 33

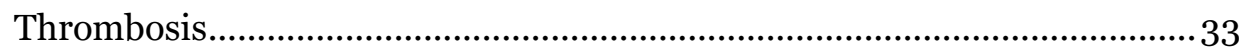

Assessment of pump thrombosis ............................................................ 35

Sound analysis of LVAD............................................................ 35

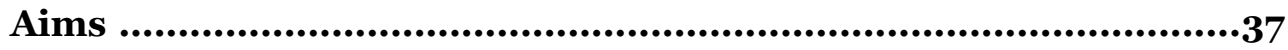

Methods........................................................................... 38

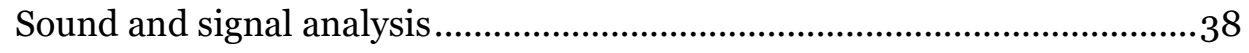

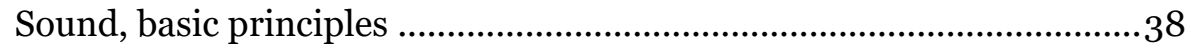

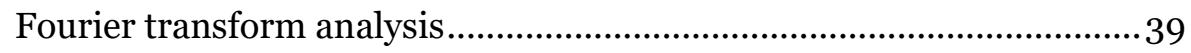

Power Spectral Density ......................................................................40

The Mock Loop Circuits ............................................................................... 41

Patient Characteristics ....................................................................... 42

Audio recordings and analysis.................................................................43 
iPhone/iPod

Shure microphones

Electronic stethoscope

Audacity

MATLAB

Statistical analysis

Sound analysis of a left ventricular assist device: A technical evaluation of iOS devices. Paper II.

Sound analysis of the magnetically levitated left ventricular assist device HeartMate $3^{\mathrm{TM}}$. Paper III.

In-vitro study of the impact of LVAD loading on mechanical performance.

Paper IV

Mock Loop

Recording devices and analysis 
Implication of the results .......................................................................... 56

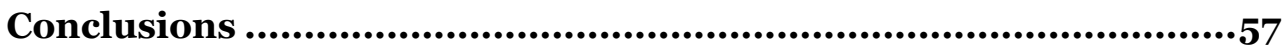

Future perspectives .................................................................57

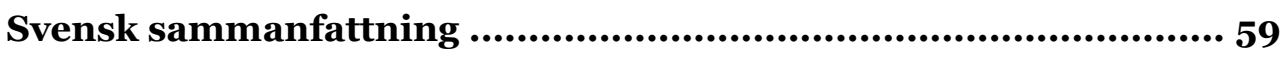

Acknowledgements.........................................................61

References ......................................................................... 63 


\section{Abstract}

Background: Heart Failure is a serious condition with consequences not only for the individual patient but also for the society with a 5-year mortality rate of $45-60 \%$, and a substantial economic burden. The estimated prevalence in Sweden is $2.2 \%$ and the age adjusted prevalence increases with higher age. The etiology of heart failure varies although with somewhat similar pathogenic mechanisms. The fundamental treatment for heart failure is pharmaceutical in combination with life-style changes, and physiotherapy. For some patients the implantation of cardioverter defibrillator, or resynchronization therapy might be an option.

For patients with advanced heart failure, the use of long-term circulatory support can be an option as a bridge to transplantation, or as destination therapy. However, this treatment entails a risk of multiple adverse events. The incidence of pump thrombosis increased as a clinical problem in 2012 and the need for diagnostic methods were desired. The aim of this thesis was to develop and to evaluate the use of a mock loop circuit to study the acoustics of left ventricular assist devices, to evaluate different recording devices and to study the effect of afterload on pump function.

Methods: Two different mock loops, with the possibility to insert artificial thrombus and to adjust preload and afterload were created to facilitate recording of the left ventricular assist devices. An iPhone/iPod ${ }^{\mathrm{TM}}$ was used as recording device since remote monitoring is desirable. The sounds from HeartMate $\mathrm{II}^{\mathrm{TM}}$ during different conditions were studied. The iPhone/iPod was evaluated in comparison to dedicated recording equipment, and the mock loop recordings to clinical situation.

The sound from HeartMate $3^{\mathrm{TM}}$ was studied, compared between in vivo and in vitro recordings, and the use of an electronic stethoscope was evaluated. The impact of afterload on left ventricular assist devices was studied in a mock loop circuit with different changes in preload and afterload.

Results: Mock loop circuit is a promising method to safely change the surrounding conditions as the pump is working. The sound from both HeartMate $\mathrm{II}^{\mathrm{TM}}$ and HeartMate $3^{\mathrm{TM}}$ can be recorded and analyzed in frequency and time domain. When inserting artificial thrombus in a HeartMate $\mathrm{II}^{\mathrm{TM}}$ the frequency spectrum is altered. The use of dedicated recording devices is superior to both electronic stethoscope and iPhone/iPod ${ }^{\mathrm{TM}}$, but these handheld devices can be used in clinical settings. The recordings from mock loop circuit and patients appear similar for both HeartMate II ${ }^{\mathrm{TM}}$ and HeartMate $3^{\mathrm{TM}}$. The flow of the devices is affected by the afterload. The HeartMate $3^{\mathrm{TM}}$ is more resistant to increased clot analogs within the pump. For both pumps, best efficacy is seen for clean circuits. The flow rate from the monitor might 
be misleading since the measured flow rate and the flow rate from monitor can differ due to surrounding conditions. The estimated flow might be adjusted by fitting a parabolic curve.

Conclusion: The use of mock loop circuit to study both flow and sound under different conditions is valid. It is possible to record and study the sound from both HeartMate $\mathrm{II}^{\mathrm{TM}}$ and HeartMate $3^{\mathrm{TM}}$. The sound holds information of pump function and appears similar in vivo and in vitro. All recording devices can be used, but dedicated equipment is superior to the more handheld devices, although these might have a function as a screening device. The flow measurement on the monitor might not be valid and optimization of fluid status and afterload can further increase pump efficiency.

Keywords: Afterload, Electronic stethoscope, Flow, HeartMate II, HeartMate 3, iOSdevices, Sound Analysis 


\section{List of original papers}

This thesis consists of 4 papers. Three of them are published in International, peerreviewed scientific journals. In the text, the studies are referred to by Roman numerals. Studies I-III are reprinted with the permission of the publisher. Study IV have been submitted for publication.

I. Hubbert L, Sundbom P, Loebe M, Peterzen B, Granfeldt H, Ahn H. Acoustic analysis of a mechanical circulatory support. Artificial organs. 2014;38:593-8.

II. Sundbom P, Roth M, Granfeldt H, Karlsson DM, Ahn H, Gustafsson F, et al. Sound analysis of a left ventricular assist device: A technical evaluation of iOS devices. The International journal of artificial organs. 2018;41:254-60

III. Sundbom P, Roth M, Granfeldt H, Karlsson D.M, Ahn H, Gustafsson F, et al. Sound analysis of the magnetically levitated left ventricular assist device HeartMate $3^{\mathrm{TM}}$. The International journal of artificial organs. 2019, doi: 10.1177/0391398819857443.

IV. Fuchs G, Sundbom P, Broman L.M, Hubbert L, Prahl Wittberg L. In-vitro study of the impact of LVAD loading on mechanical performance. 


\section{Abbreviations}

ACC/AHA American College of Cardiology/ American Heart Association

ACE Angiotensin converter enzyme

ACEI

AIDS

ANP

ARB

ARNI

ARVC

$\mathrm{BB}$

BNP

$\mathrm{BP}$

BPM

BTT

$\mathrm{Ca} 2+$

CMR

CO

CRT

DCM

DFT

DT

DTFT

EC

ECG

ECMO

$\mathrm{EF}$

ESC

ET1

FDA

FFT

$\mathrm{GH}$

$\mathrm{HCM}$

$\mathrm{HF}$ Angiotensin converting enzyme inhibitor Acquired immunodeficiency syndrome Atrial natriuretic peptides

Angiotensin receptor blocker Angiotensin receptor Neprilysin inhibitor Arrhythmogenic right ventricular cardiomyopathy Beta blockers

B-type natriuretic peptides

Blood pressure

Beats per minute

Bridge to transplantation

Calcium

Cardiac magnetic resonance imaging

Cardiac output

Cardiac resynchronization therapy

Dilated cardiomyopathy

Discrete Fourier transform

Destination therapy

Discrete-time Fourier transform

Excitation-contraction

Electrocardiogram

Extracorporeal membrane oxygenation

Ejection fraction

HFmrEF Heart failure with mid-range ejection fraction

HFpEF

HFrEF

HIV

European Society of Cardiology

Endothelin 1

Federal drug agency

Fast Fourier transform

Growth hormone

Hypertrophic cardiomyopathy

$\mathrm{HM}_{3}$

HMII

Heart failure with preserved ejection fraction

Heart failure with reduced ejection fraction

Human immunodeficiency virus

HeartMate 3

HeartMate II 


$\begin{array}{ll}\text { Htx } & \text { Heart transplantation } \\ \text { HVAD } & \text { HeartWare ventricular assist device } \\ \text { Hz } & \text { Hertz } \\ \text { IABP } & \text { Intra-aortic balloon pump } \\ \text { ICD } & \text { Implantable cardioverter defibrillator } \\ \text { INR } & \text { International normalized ratio } \\ \text { INTERMACS } & \text { Interagency Registry for Mechanically assisted } \\ & \text { Circulatory Support } \\ \text { ISHLT } & \text { International Society for Heart and Lung } \\ & \text { Transplantation } \\ \text { L } & \text { Liter } \\ \text { LBBB } & \text { Left bundle branch block } \\ \text { LDH } & \text { Lactate dehydrogenase } \\ \text { LV } & \text { Left ventricular } \\ \text { LVAD } & \text { Left ventricular assist device } \\ \text { LVEDD } & \text { Left ventricular end diastolic diameter } \\ \text { LVEF } & \text { Left ventricular ejection fraction } \\ \text { MAP } & \text { Mean arterial pressure } \\ \text { MCS } & \text { Mechanical circulatory support } \\ \text { MI } & \text { Myocardial infarction } \\ \text { Min } & \text { Minute } \\ \text { MRA } & \text { Mineralocorticoid /aldosterone receptor antagonist } \\ \text { MRI } & \text { Magnetic resonance tomography } \\ \text { NEP } & \text { Natriuretic peptide c-receptor } \\ \text { NP } & \text { Natriuretic peptides } \\ \text { NT-Pro-BNP } & \text { N-terminal of brain natriuretic peptide } \\ \text { NYHA } & \text { New York Heart Association } \\ \text { PSD } & \text { Power spectral density } \\ \text { PWM } & \text { Pulse width modulation } \\ \text { RAAS } & \text { Renin-Angiotensin Aldosterone system } \\ \text { ROS } & \text { Reactive oxygen species } \\ \text { RPM } & \text { Revolutions per minute } \\ \text { RV } & \text { Right ventricular } \\ \text { TGF- } \beta & \text { Transforming growth factor- } \beta \\ \text { vWf } & \text { Von Willebrand factor } \\ & \end{array}$




\section{Introduction}

Heart failure (HF) is a clinical condition characterized by symptoms caused by reduced cardiac output $(\mathrm{CO})$ and/ or elevated intra-cardiac pressures at rest, or during exercise. ${ }^{1}$ The classical symptoms include peripheral edema, shortness of breath, and fatigue. These symptoms can be accompanied by other signs such as elevated jugular venous pressure and pulmonary crackles. The reduction of $\mathrm{CO}$ is caused by a functional, or structural, cardiac abnormality with neurohormonal activation, and complex pathophysiology. ${ }^{1}$ The diagnosis of HF carries substantial risk of mortality and morbidity. For patients that deteriorate in their disease, despite optimal medication, heart transplantation (Htx) or mechanical circulatory support (MCS) might be an option. For patients treated with a left ventricle assist device (LVAD), adverse events can occur with devastating effects. One of these events is pump thrombosis. The relatively high incidence of pump thrombosis implies the need for non-invasive methods to assess the presence of pump thrombosis. This resulted in the start of this thesis.

To understand the concept of LVAD-treatment, an understanding on the basic epidemiology, physiology, pathophysiology, and treatment of HF is necessary. The proportion of patients eligible for advanced treatment is small but might be higher if patients were referred to HF-centers to a larger extent. Most of the patients that are treated with LVAD are amongst the sickest of the HF-population and are, despite LVAD treatment, in need for adequate pharmacological treatment.

The first four chapters within this thesis summarize the current knowledge of HF and HF-treatment. This alone can help to minimize mortality and morbidity, if used in every-day clinical practice. The remaining chapters focus on the acoustic and afterload evaluation of LVAD. 


\section{Heart failure}

\section{Epidemiology of heart failure}

It is estimated that 23 million humans worldwide suffer from HF. From 1970-1990 the prevalence of HF increased due to ageing population, to some extent increased incidence and improvements in the treatments of acute cardiovascular disease resulting in more patients surviving the initial event. ${ }^{2}$ In 2010, the estimated prevalence of HF within Sweden was $2.2 \%$, and the mean age of $77 \pm 13$ years. The prevalence has lightly increased for women whilst overall prevalence has plateaud. ${ }^{3}$ The prevalence and incidence increase with age and constitute a substantial financial burden, consuming approximately $1-2 \%$ of total health care expenditure. ${ }^{4}$ The total annual cost for HF in Sweden has increased from the estimation of 2.6 billion in 1996 to 5.0-6.7 billion in 1999, of which hospital admissions accounted for the main proportion (47\%) of total cost. ${ }^{5,6}$

The diagnosis of HF carries substantial risk of mortality and morbidity. The 30-day mortality is around $10 \%, 1$-year mortality is $20-30 \%$, and 5-year mortality is $45-60 \%$. $^{2}$ $\mathrm{HF}$ is mainly categorized according to different aspects depending on left ventricular (LV) or right ventricular (RV) function calculated by objective means, or symptoms addressed by the patient. ${ }^{1} \mathrm{HF}$ is a multi-organ disease where advanced HF with inadequate end-organ perfusion results in physiological derangements, neurological complications, metabolic wasting and subsequently death.

\section{Pressure-volume loop}

The maintenance of cardiovascular homeostasis requires ability to adapt cardiac function to different hemodynamic conditions. ${ }^{7}$ The basis for this adaptation is the Frank-Starling mechanism named after the work of Starling in 1914 and Frank in 1959. ${ }^{8,9}$ The mechanism state that an increase in arterial resistance or venous return lead to increased end-diastolic volume and subsequently increased contractility/stroke volume. $^{7}$ The end-diastolic volume, also known as preload, generates an increased pressure in the LV. When the pressure exceeds the intra-aortic pressure, also known as afterload, the mitral valve closes and the aortic valve opens. This process can be measured and plotted as a pressure-volume loop. See figure 1. The increased contractility is mainly attributed to the response of Calcium $\left(\mathrm{Ca}^{2+}\right)$ released on the sarcomere. Elongated sarcomere results in increased sensitivity for $\mathrm{Ca}^{2+}$ stimulus. Phosphorylation of multiple cardiomyocyte proteins and receptors participate in the 
myocardial response to stretch of which many affect $\mathrm{Ca}^{2+}$ levels (see Pathophysiology; Calcium signaling dysfunction) ${ }^{7}$

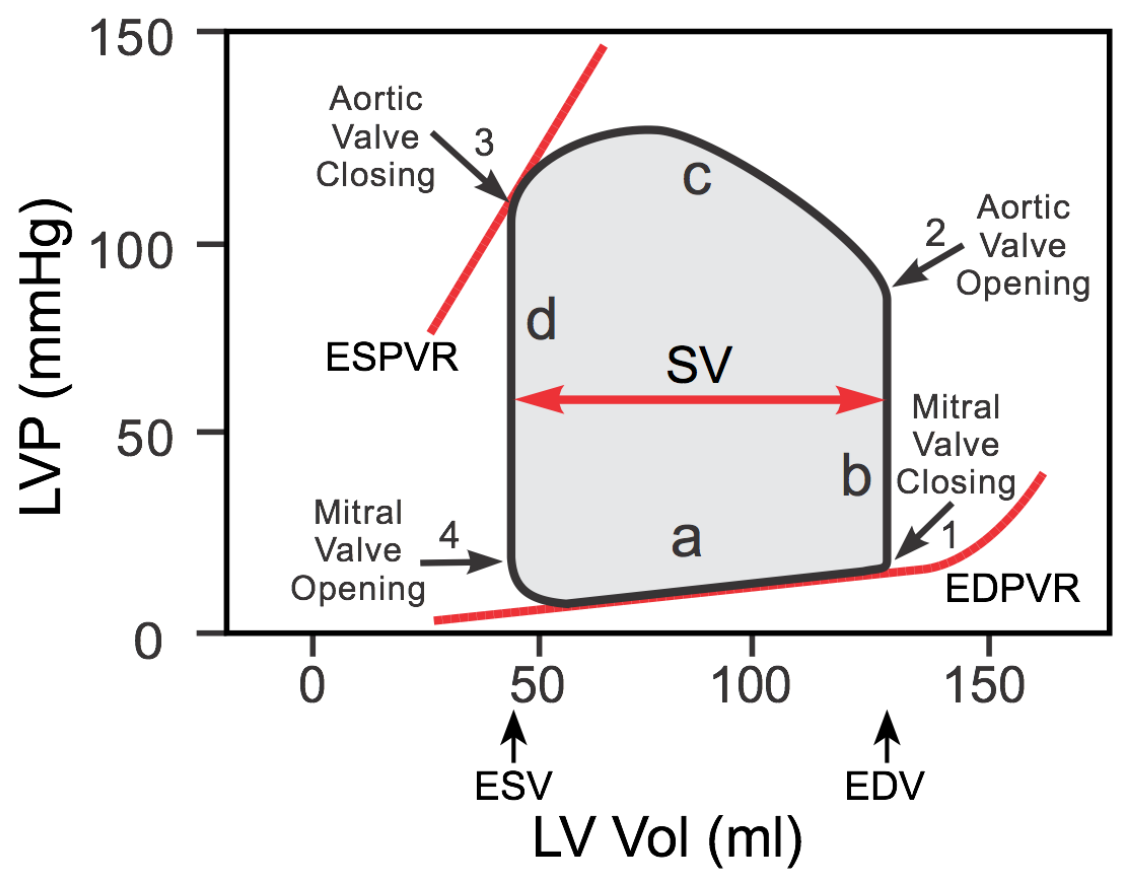

Figure 1. The figure shows a pressure volume loop of the left ventricle. Ventricular filling (phase a, diastole), isovolumetric contraction (phase b systole), ejection phase (phase c, systole), isovolumetric relaxation (phase d, diastole) EDPVR; End-diastolic pressure-volume relationship, ESPVR: End-systolic pressure volume relationship, LVP: Left ventricular pressure, LV Vol; Left ventricular volume, SV; Stroke volume. (Reprinted with permission from Richard E. Klabunde, www.cvphysiolgy.com)

\section{Classification of heart failure}

HF can be predominantly affecting left or right ventricle or both (biventricular). Historically, the classification is based on LV function measured by ejection fraction (EF), ((Systolic volume-Diastolic volume)/Diastolic volume). Due to the multifactorial etiology, HF can occur without impact on EF. Consequently, and in lack of studies of patients with $\mathrm{EF}>40 \%, \mathrm{HF}$ is now described in three categories. This categorization is: heart failure with reduced ejection fraction (HFrEF) with an EF below 40\%, heart failure with mid-range ejection fraction (HFmrEF) with an EF between 40 and $50 \%$ and heart failure with preserved ejection fraction (HFpEF) with an EF above 50\%. ${ }^{1}$ 
Most clinical studies are performed on patients with HFrEF whilst patients with HFpEF acquired scientific interest during recent years. ${ }^{1}$ However, there is low evidence of effective therapies yet available for $\mathrm{HFpEF}$, but further research is ongoing. Previously patients with HFmrEF was classified HFrEF, but the European society of cardiology (ESC) states in their latest guidelines from 2016 that these patients represent an entity of its own that needs further scientific investigation. In order to classify patients to the correct group, an objective assessment is necessary. This assessment could be by either echocardiography or and cardiac magnetic resonance imaging $(\mathrm{CMR}){ }^{1}$

Another approach in classification of HF is based upon functional status and severity of symptoms. The New York Heart Association (NYHA) classification has been used for a long time, and it categorizes patients in one of four groups based upon selfreported physical limitations. See Table 1. The NYHA-classification is often used when communicating the severity of $\mathrm{HF}$, and can also be used as a prognostic marker in which patients in NYHA class IV have the highest mortality. ${ }^{10}$ The American college of cardiology / American heart association (ACC/AHA) classifies HF in four stages depending on risk factors and abnormalities that are associated with HF. The scale constitutes of four progressive stages, A-D, and once a patient reaches a higher stage there is no moving backwards to previous stages. Progression in stages is associated with reduced 5-year survival and increased biomarker. ${ }^{11}$ The Interagency Registry for Mechanically Circulatory Support (INTERMACS) classify patients with advanced HF in 7 clinical categories depending on symptoms and the use of inotropic treatment. This classification further divides patients in functional classes, NYHA IIIbIV. ${ }^{12}$ See Table 1 . A portion of patients with HF will progress to advanced HF. Advanced HF is defined as patients that, despite optimal treatment fulfil the criteria below 13

1. Severe and persistent symptoms. (NYHA III-IV)

2. Severe cardiac dysfunction defined by a reduced LVEF $\leq 30 \%$, isolated RV failure, or non-operable severe valvular abnormalities or congenital abnormalities or persistently high (or rising) Brain natriuretic peptides (BNP) or $\mathrm{N}$-terminal of brain natriuretic peptide (NT-proBNP) values and diastolic dysfunction or LV structural abnormalities according to the ESC definition of HFpEF and HFmrEF

3. Episodes of pulmonary or systemic congestion requiring high-dose intravenous diuretics (or diuretic combinations) or episodes of low output requiring inotropes or vasoactive drugs or malignant arrhythmias causing $>1$ unplanned visit or hospitalization in the last 12 months. 
4. Severe impairment of exercise capacity with inability to exercise or low 6minute walk distance $(<300 \mathrm{~m})$ or peak exercise oxygen consumption $(<12-$ $14 \mathrm{~mL} / \mathrm{kg} / \mathrm{min}$ ) estimated to be of cardiac origin. 


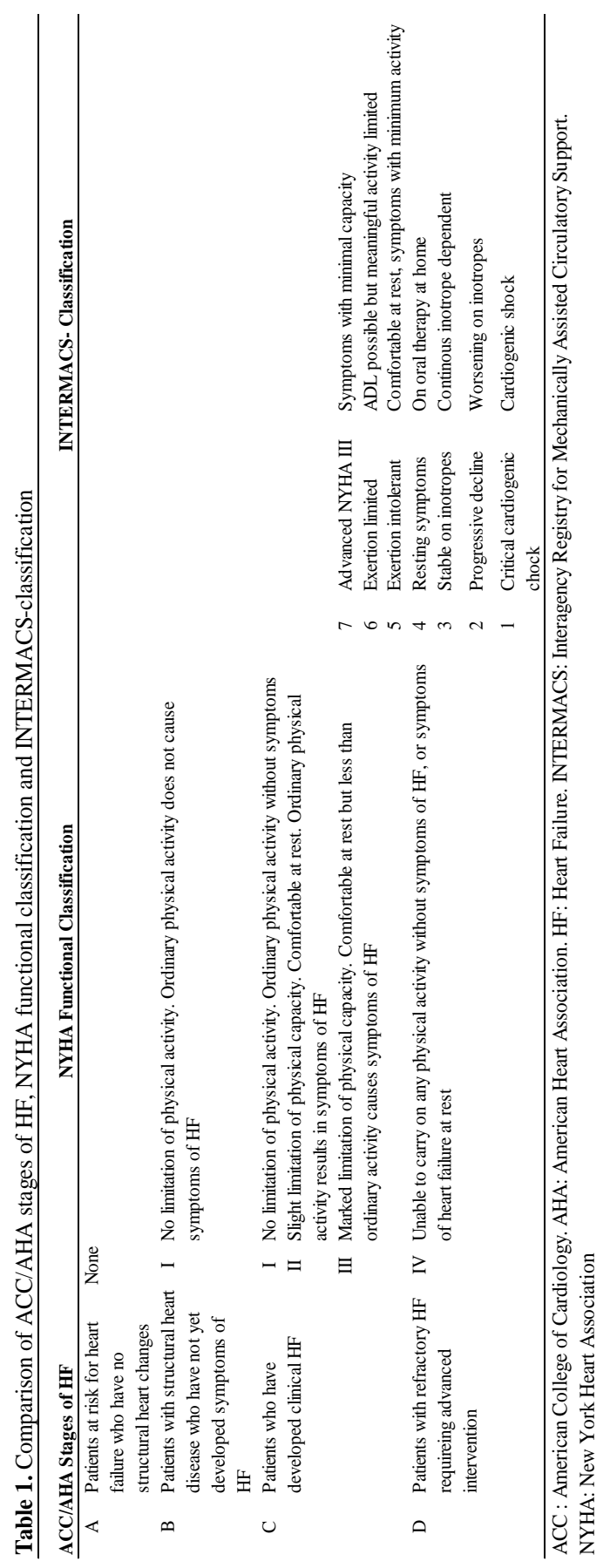




\section{Pathophysiology of heart failure}

\section{Introduction to pathophysiology}

The aim for the healthy heart is to deliver nutrients and oxygen to the multiple organs within the human body. To be able to perform this important task the heart contract in both longitudinal and circumferential way with a rhythm of 50-70 beats per minute (bpm). A numerous of diseases can affect the normal physiology of the heart and cause an impairment of the possibility to maintain normal hemodynamics. These diseases result in impairment of the ejection or of the ventricular filling. The initial disease affects the myocytes that will lead to subsequent structural changes leading to HF. A summary of etiologies of HF is presented in table 2. The major pathogenic mechanism is ischemic dysfunction within myocytes, ventricular remodeling, increased hemodynamic overload, excessive neuro hormonal stimulation, abnormal myocyte calcium cycling, accelerated apoptosis, excessive or inadequate proliferation of the extracellular matrix and genetic mutations. Occasionally patients may suffer from HF that resolves completely, examples of these etiologies are viral myocarditis, Takutsubo cardiomyopathy, and peripartum cardiomyopathy. ${ }^{14-16}$

\section{Ventricular remodeling}

In the presence of myocardial infarction (MI) which is the predominant etiology of $\mathrm{HF}$, often 1 billion or more cardiomyocytes die within 20 minutes. The inner layer of myocardium is affected first, and the wave of cell death moves towards the outer layer reaching all affected cells (including nerves, fibroblasts and vascular cells) within 3$6 \mathrm{~h} .{ }^{17}$ Consequently, since the cardiomyocytes are not able to regenerate, this generates a massive inflammatory response, recruiting neutrophils and macrophages that subsequently results in a fibrotic scar. ${ }^{18,19}$ Thereafter, early and late remodelling occur, including hypertrophy and fibrosis of the surrounding myocardium eventually leading to impaired cardiac function. ${ }^{19}$ The fibrosis is mediated by fibroblasts and myofibroblasts, and causes both the pivotal scar formation (to prevent rupture of cardiac wall) and the reactive fibrosis in the surrounding tissue. ${ }^{20}$

The healing after heart-damage is complex and involves numerous hormonal and paracrine mediators that can induce increased remodeling in the remote uninjured myocardium. ${ }^{18}$ The remodeled myocardium, and mainly the scar, will act as a nonexcitable area that can cause re-entrant arrhythmia and sustained ventricular arrhythmia. ${ }^{21}$ The equilibrium of immune response to infarction has a deleterious effect on adverse remodeling but is also important for proper infarction healing. ${ }^{21}$ The reactive fibrosis is accompanied by hypertrophic growth of cardiomyocytes as they try to compensate the increased workload. They do so by expand in size, which will 
decrease wall tension and increase cardiac function. However, the increased mechanical stress will sustain fibroblast activation and continued collagen deposits, leading to interstitial fibrosis that influence the diastolic function and increase wall tension. ${ }^{18} \mathrm{~A}$ route to $\mathrm{HF}$ has emerged.

The model of fibroblast activation by induced mechanical stress can be applied to other etiologies as well. Multiple pro-fibrotic cytokines are involved in control of fibrosis. The best characterized pro-fibrotic cytokine is Transforming growth factor- $\beta$ (TGF- $\beta$ ) that can rapidly be released and activated in the response to reactive oxygen species (ROS). ${ }^{18}$

For dilated cardiomyopathy (DCM) the etiology is multifactorial with familial transmission in $20-35 \%$ of the cases with a wide variety of genetic disorders. Alcohol abuse accounts for a substantial number of patients with LV-dilatation in high-income countries. These are often referred to as alcoholic cardiomyopathy. ${ }^{22-24}$ Most of the genetic disorders, or acquired etiologies, affect one or more genes that encode the sarcomere, cytoskeleton, nuclear envelope, transcriptional pathways, or mitochondrial proteins. ${ }^{25}$ For example, one commonly affected gene is the TTN gene that encodes the protein Titin, a component of the sarcomere structure. ${ }^{26}$ As DCM progress, the LV will dilate and assume a spherical shape. This results in a decreased stroke volume and CO, impaired ventricular filling and increased end-diastolic pressure. See figure 2. The compensatory effects in the vascular system includes a decreased arterial compliance, increased systemic vascular resistance, increased venous pressure, and increased circulating blood volume. ${ }^{27} \mathrm{DCM}$ is often accompanied by diastolic dysfunction in both the active and passive compliance phase that leads to rapid ventricular filling. The increased preload and afterload affect the wall stress and results in activation of secondary neuro-hormonal systems, see section of neuro-hormonal stimulation. ${ }^{25}$

Hypertension is another common etiology of HF. Hypertension cause a structural effect on the myocardium that starts with hyperplasia of fibroblasts and hypertrophy of vascular smooth muscle layer which in turn results in expansion of interstitial collagen. ${ }^{28}$ All combined, the changes contribute to ischemia at the micro and macrovascular level. The ischemia and the remodeling events result in up-regulation of hypertrophic genes and a LV hypertrophy. The LV hypertrophy leads to concentric remodeling (increased wall thickness to cavity diameter) or concentric hypertrophy (increase in absolute LV thickness). ${ }^{29}$ The hypertrophy results in increased distance between epicardial and endocardial layers, inadequate coronary growth, increased perivascular fibrosis, and medial thickening. ${ }^{27,28,30}$ All these mechanisms impair the myocardial perfusion and result in ischemia and increased LV-pressure that in turn result in secondary neuro-hormonal activation, see section of neuro-hormonal stimulation. $^{31}$ 


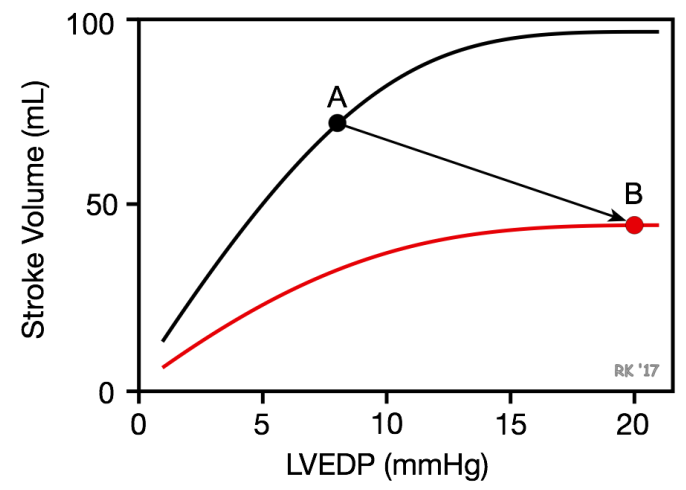

Figure 2. In Heart Failure the impaired ventricular contraction (inotropy) cause a decreased stroke volume that generates a downward shift (a to b) in the Frank-Starling curve which results in a compensatory rise in preload, shown as end diastolic pressure, to maintain stroke volume. (Reprinted with permission from Richard E.

Klabunde, www.cvphysiology.com) 
Table 2. Etiologies to heart failure

\begin{tabular}{|c|c|c|}
\hline Etiology & Sub-group & Specific diseases \\
\hline Ischemic heart disease & & $\begin{array}{l}\text { Myocardial scar after infarction } \\
\text { Endothelial dysfunction } \\
\text { Epicardial coronary artery disease } \\
\text { Myocardial hibernation/stunning } \\
\text { Defect coronary microcirculation } \\
\end{array}$ \\
\hline $\begin{array}{l}\text { Inflammatory and immune- } \\
\text { mediated }\end{array}$ & $\begin{array}{l}\text { Infections } \\
\text { Inflammatory }\end{array}$ & $\begin{array}{l}\text { Bacterias, HIV/AIDS, fungi, protozoa, spirochaetes, } \\
\text { Ricketssia, parasites etc } \\
\text { Autoimmune diseases, Systemic lupus } \\
\text { erythematosos, Churg-Strauss vasculitis }\end{array}$ \\
\hline Metabolic & $\begin{array}{l}\text { Nutritional } \\
\text { Hormonal }\end{array}$ & $\begin{array}{l}\text { Obesity, Deficiences in thiamine, selenium, } \\
\text { phosphates, calcium, iron, L-carnitine. } \\
\text { Addisons disease, thyroid diseases, parathyroid } \\
\text { diseases, metabolic syndrome, } \\
\text { Phaeochromocytoma, diabetes, GH defiencey States } \\
\text { related to pregnany and peripartum }\end{array}$ \\
\hline Infiltrations & $\begin{array}{l}\text { Malignancy } \\
\text { Not related to malignancy }\end{array}$ & $\begin{array}{l}\text { Infiltrations and metastases } \\
\text { Amyoloidosis, lysosomal storage disease, } \\
\text { sarcoidosis, haemochromatosis }\end{array}$ \\
\hline Toxic & $\begin{array}{l}\text { Substance abuse } \\
\text { Medications } \\
\text { Radiation } \\
\text { Heavy metals }\end{array}$ & $\begin{array}{l}\text { Alcohol, amphetamine, anabolic steroids, cocaine } \\
\text { Cytostatic drugs, immunomodulating drugs, } \\
\text { antidepressants, anti-inflammatory drugs, } \\
\text { Copper, iron, lead, cobalt }\end{array}$ \\
\hline Genetic abnormalities & Diverse forms & $\begin{array}{l}\text { DCM, Left ventricular non compaction, } \\
\text { ARVC,HCM, Muscular dystrphies and } \\
\text { laminopathies, restrictive cardiomyopathy }\end{array}$ \\
\hline \multicolumn{3}{|l|}{ Hypertension } \\
\hline Arrythmias & $\begin{array}{l}\text { Tachyarrythmias } \\
\text { Bradyarrythmias }\end{array}$ & $\begin{array}{l}\text { Atrial and ventricular arrythmias } \\
\text { Sinus node dysfunction, conduction disorders }\end{array}$ \\
\hline Valve disease & $\begin{array}{l}\text { Congentinal } \\
\text { Acquired }\end{array}$ & $\begin{array}{l}\text { Atrial and ventricular septum defects } \\
\text { Aortic, mitral, pulmonary and tricuspid valve disease }\end{array}$ \\
\hline High output & & Anemia, pregnancy, thyreotoxicosis, sepsis \\
\hline Volume overload & & Renal failure, iatrogen volume overload \\
\hline Others & $\begin{array}{l}\text { Pericardial } \\
\text { Endomyocardial }\end{array}$ & $\begin{array}{l}\text { Constrictive pericarditis, pericardial effusion } \\
\text { hypereosinophilic syndrome, endocardial } \\
\text { fibroelastosis, endomyocardial fibrosis }\end{array}$ \\
\hline
\end{tabular}

HIV: Human immuno defiency virus. AIDS: Aquired immunodefiency syndrome. GH: Groeth hormone. DCM: Dilated cardiomyopathy. ARVC: Arrythmogenic right ventricular cardiomyopathy. HCM: Hypertrophic cardiomyopathy 


\section{Neuro-hormonal stimulation}

Angiotensin II (Ang II) is expressed and activated by fibroblasts within the initial infarction scar and have multiple effects on the cardiac remodeling. ${ }^{32}$ Ang II is also the central signal molecule of the Renin-Angiotensin Aldosterone System (RAAS) that is a central part of the excessive neuro hormonal response. When the $\mathrm{CO}$ decreases, the renal perfusion will be affected, and Renin will be produced to induce sodium retention and increase blood pressure (BP). Renin will cleave angiotensinogen, produced by the liver, to angiotensin that will be converted to Ang II by Angiotensin converting enzyme (ACE). Ang II will then bind to one of its 2 receptors, primarily AT1R, that results in secretion of aldosterone, vasopressin secretion, and vasoconstriction within small vessels resulting in increased BP. It is suggested that stimulation of AT2R counteract the effect of AT1R. ${ }^{33}$ Ang II also promotes fibroblast proliferation, myofibroblasts differentiation, secretion of pro-inflammatory cytokines, Extracellular matrix turnover, and up regulation of TGF- $\beta$ within the myocardium.

Endothelin 1 (ET1) is also reported as a pro-fibrotic paracrine signal released downstream of Ang II and TGF- $\beta .^{32}$. Both Ang II and ET1 affect the intracellular levels of $\mathrm{Ca}^{2+}$ and the inotropic effect of the heart. ${ }^{7}$ In the presence of low $\mathrm{CO}$, arterial baroreceptors and ventricular reflexes will try to increase $\mathrm{CO}$ by increased heart rhythm, heart wall contraction (inotropy), vascular tone and increased sympathetic renal nerve activation leading to additional water retention. The physiological response is an intravascular increase in volume that for the patient with HF results in congestion. ${ }^{34}$

To counteract the Renin induced sodium retention, primarily the heart secretes natriuretic peptides (NP) that aim to protect the heart from volume overload by induced natriuresis, vasodilatation, heart wall relaxation and, diuresis. There are two forms of NP, Atrial NP (ANP) and B-type, BNP. The ANP is dominantly produced in the atria whilst BNP mostly is produced in the ventricle. BNP is synthesized when increased wall tension occurs whilst ANP is stored in granule and released with minor triggers. BNP is cleaved from its inactive state, pro-BNP, to active state, BNP, and NT-Pro-BNP. The peptides are degraded by neutral endopeptidase and cleared by natriuretic peptide c-receptor (NEP). Both are present in kidneys, vascular wall, and lungs. ${ }^{35}$ All the peptides can be measured as a biomarker for volume overload, but with different specific features depending on degradation habitus of the patient and renal function. ${ }^{36}$

For patients with chronic or acute HF the level of NT-pro-BNP is a prognostic marker for morbidity and mortality. ${ }^{37,38}$ However, in patients with severe HF a relative state of deficiency and resistance to NP might be present due to an overwhelmed system and downregulation of receptors as well as an increased clearance of peptides by NEP. ${ }^{35}$ 


\section{Calcium signaling dysfunction}

Another mechanism that is central for HF is altered excitation-contraction (EC) coupling. This derives from a maladaptive redistribution of intracellular $\mathrm{Ca}^{2+}$, altered expression and function of $\mathrm{Ca}^{2+}$ handling proteins, and changes in the architecture of the cell membrane.

Depolarization of the cardiomyocyte requires complex membrane with t-tubular network that is situated close to the sarcoplasmic reticulum and leads to rapid diffusion of $\mathrm{Ca}^{2+}$. This induces $\mathrm{Ca}^{2+}$ release on the sarcomere and facilitate muscle contraction. Multiple channels (L-type, SERCA2a) and receptors (RyR2) facilitate this transport and reabsorption of $\mathrm{Ca}^{2+}$ and their function is impaired in HF. Another altered part of intracellular $\mathrm{Ca}^{2+}$ is the increment within mitochondria that impairs mitochondrial function and increases ROS and induces apoptotic pathways. The changes in $\mathrm{Ca}^{2+}$ signaling results in remodeling of t-tubule architecture, alteration in handling proteins that promotes slowed relaxation, spontaneous $\mathrm{Ca}^{2+}$ release, increased apoptotic pathways, reduced and delayed force of contraction. All these effects are essential parts of the pathophysiology of $\mathrm{HF}^{39}$

\section{Heart failure with preserved ejection fraction}

Approximately $50 \%$ of all patients with HF suffer from HFpEF where the primary dysfunction is within the relaxation phase. ${ }^{1,40-42}$ The relaxation phase is equally important as contraction phase for normal cardiac function. Diastolic dysfunction mostly affects exercise function when cardiomyocytes cannot be elongated in response to higher demand of CO. Diastolic dysfunction can occur regardless of, or in combination with, reduced EF. The prevalence of HFpEF is rapidly rising, up to 1 in 10 elderly individuals is affected. Patients with HFpEF, in comparison with those with $\mathrm{HFrEF}$, are more likely to be older, female, and have diabetes, atrial fibrillation, hypertension, and other co-morbidities. ${ }^{40,42,43}$

The ventricular remodeling that occurs as a result of cardiac insult or inflammation worsens the diastolic dysfunction. The pathophysiology for the diastolic dysfunction is multifactorial and includes chronic pro inflammatory state, collagen deposition, oxidative stress, chronotropic incompetence, RV dysfunction, systolic abnormalities not seen in echocardiography, and hypo-phosphorylation of titin. ${ }^{40,41,44-48}$

Titin is a large muscle filament protein that acts as a scaffold for the sarcomere, and is a major component in myocardial elasticity and passive stiffness. ${ }^{49}$ Titin acts both as a mechanic-sensor and molecular target by modulating the active force development due to length-dependent activation. ${ }^{7,50}$ The activation of titin is regulated by 
phosphorylation and adapts quickly to changes in hemodynamic requirements. ${ }^{7}$ The phosphorylation facilitates by different kinases that are affected by stimulation by NP, nitric oxide and the sympathetic nerve system, thus linking titin to multiple pathways affected by HF. Titin is also related to numerous inherited conditions, especially DCM. ${ }^{49}$ ESC require clinical symptoms, EF> 50\% combined with exclusions of valvular and non-cardiac causes and elevated NP for diagnosis. Echocardiographic measurements are additional criteria and if uncertainty, a stress test or invasive measurement of LV filling pressure may be needed. ${ }^{1}$

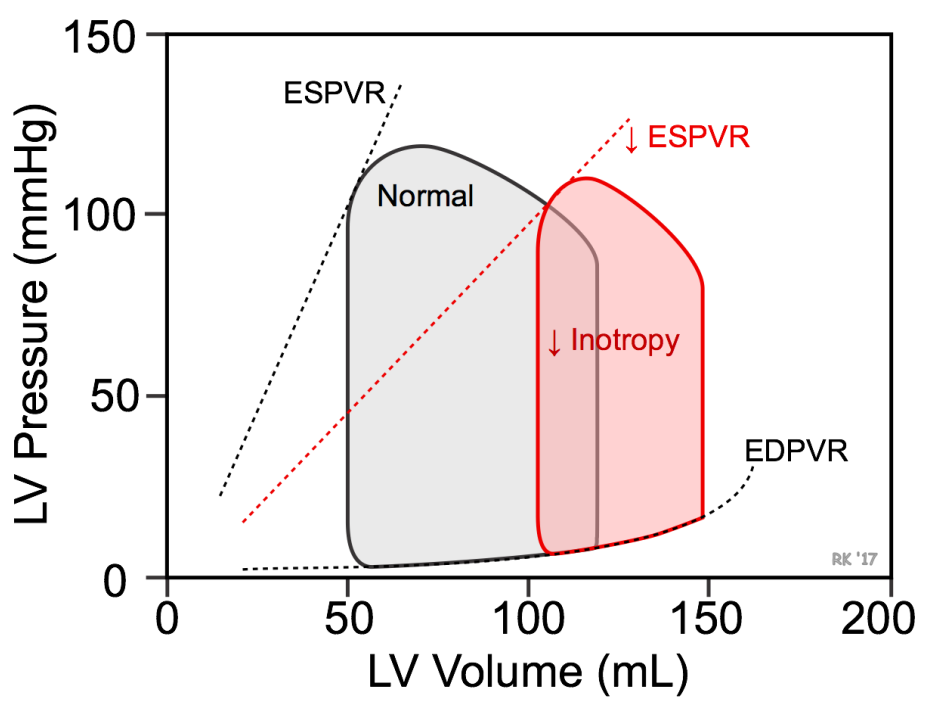

Figure 3. The PV-Loop of HFrEF. The loss of contraction (inotropy) results in increased end-systolic volume and end-diastolic volume which results in decreased stroke volume. As the heart remodels, the EDPVR shifts downwards and right due to increased ventricular compliance. In diastolic heart failure, the EDPVR shifts upwards and left. EDPVR; End-diastolic pressure-volume relationship, ESPVR: End-systolic pressure volume relationship, LV: Left ventricle. (Reprinted with permission from Richard E. Klabunde, www.cvphysiolgy.com) 


\section{Diagnosis of heart failure}

The symptoms of HF are often non-specific, hence the clinical diagnosis might be hard.$^{51}$ In patients with obesity or pulmonary disease, the symptoms might be even harder to detect. ${ }^{52,53}$ For patients presenting with symptoms of HF, the probability of HF should be evaluated based on the patients clinical history and status. If something in the history or clinical status indicate HF, the concentration of BNP or NT-pro-BNP can be assessed as a first diagnostic step. Patients with normal levels are unlikely to have HF, therefor the test is used to rule-out HF, not to establish the diagnosis. ${ }^{1}$ Multiple factors, such as age, renal failure, atrial fibrillation and obesity might affect the levels of NP. ${ }^{53-55}$ The diagnostic cut off values set by the ESC have excellent ability to exclude HF, when used in combination with clinical condition. ${ }^{1,56}$ For patients with HF, the symptoms and signs should be assessed at each visit to monitor the response to treatment and to assess stability. Worsening of symptoms indicates progression of the disease and should result in additional treatment. Worsening also place the patient at high risk for hospital admission.

Combined with NP, the electrocardiogram (ECG) can provide information of potential etiology of $\mathrm{HF}$ and is recommended as routine use. In patients with normal ECG, the diagnosis of HF is unlikely but might occur. ${ }^{1,51}$

If the ECG is abnormal or the NPs are elevated, the patient should be examined by echocardiography to diagnose HF. ${ }^{1}$ Echocardiography is the method of choice for the accuracy, availability, safety, and cost. ${ }^{57}$ Gold standard for assessment of LV/ RV volumes, EF and cardiac mass is CMR. The CMR also provides information of tissue characterization but holds multiple contraindications and is relatively expensive. ${ }^{1}$ In comparison, echocardiography can provide information on cardiac structure and function by using 2-dimensional, 3-dimensional, contrast, spectral, and color flow Doppler. ${ }^{57}$ For measurement of the LVEF, the modified biplane Simpson's rule is recommended. ${ }^{1}$ If $\mathrm{HF}$ is confirmed, appropriate treatment are initiated and determination of etiology assessed. 


\section{Treatment for heart failure}

The fundamentals of the treatment for HF are pharmaceuticals that inhibit or affect one or more pathological pathways. The aim is to reduce mortality, improve physical capacity, physical status and quality of life whilst hospital admission is reduced. ${ }^{1}$ For patients with $\mathrm{HFrEF}$, a treatment that inhibits the excessive neuro-hormonal response is recommended whilst the treatment for $\mathrm{HFpEF}$ is more uncertain and mostly focuses on minimizing the effects of comorbidities. Most often, a combination of pharmaceuticals at an optimal level is required. If the patient remains symptomatic or deteriorates, despite optimal medical treatment, the use of additional compounds might be indicated. Unfortunately, an optimal dose is not always achieved and the prescription of ACE-inhibitors (ACEI) is inequitable. ${ }^{58,59}$ Below, the ways to treat $\mathrm{HF}$ is described. For all patients, including advanced HFrEF, the first step is to assess if the current medication is appropriate and, if possible, optimize the medical treatment.

\section{Pharmacological treatment}

\section{Angiotensin converter enzyme inhibitor}

ACEI is the foundation of the treatment for HF. ${ }^{60-63}$ Multiple substances are known for having similar effect but variations in side effects. ACEI is recommended for HFrEF unless the substance is not tolerated by the patient or the substance is contraindicated. ${ }^{1}$, ${ }^{63}$ ACEI is considered "first line" treatment. ACEI is also used for patients with asymptomatic LV dysfunction to minimize the progression to HF. ${ }^{60}$ ACEI inhibits the conversion from angiotensin I to Ang II, which results in blockage of RAAS. This inhibits some of the sodium and water retention resulting in lowered BP, afterload, and congestion. ${ }^{64,65} \mathrm{By}$ using ACEI, the excessive fibrotic response is inhibited and the subsequent remodeling minimized. ${ }^{65}$ ACEI significantly reduces both morbidity and mortality in HFrEF. ${ }^{66-69}$ The effect is not as clear for patients with HFpEF but ACEI might improve functional class and lower hospitalizations. ${ }^{70,71}$ For patients with a high risk for cardiovascular events, ACEI reduces stroke, nonfatal MI, cardiovascular, and overall mortality. 1,72

\section{Angiotensin receptor blockers}

Angiotensin receptor blockers (ARB) exerts its effect by blocking the AT1R and thereby inhibit the effect of Ang II. ${ }^{65}$ This results in an effect similar to the one for ACEI and reduces both morbidity and mortality for patients with HFrEF. ${ }^{73}$. However, the effect is only seen for AT1R and angiotensin can still bind to AT2R which might facilitate additional positive effects. ARB is used for patients with contradictions to, or 
cannot tolerate ACEI. ${ }^{1,63}$ In the ESC guidelines the use of ARB is equal to ACEI. ${ }^{1}$ ARB is associated with lower adverse events than ACEI, but this do not effect mortality or morbidity in head to head comparison to ACEI. ${ }^{74-76}$ The addition of ARB might be considered in symptomatic patients that can't tolerate mineralocorticoid/aldosterone receptor antagonists (MRA). ${ }^{1}$ For patients with HFpEF, ARB treatment has been shown to have a moderate impact on hospitalization but no effect on mortality. ${ }^{71,77,78}$

\section{Beta blockers}

Beta blockers (BB) are complementary to ACEI, and should be administered in patients with a clinical stable condition with a low dose that is slowly titrated to maximum tolerated dose. ${ }^{1,63}$ BB block the $\beta$-receptor and thereby inhibit excessive sympathetic response, reduce afterload, decrease plasma renin levels, and renal-nerve signaling. The $\mathrm{BP}$ is lowered and the $\mathrm{CO}$ is enhanced due to enhancement of the diastolic filling time ${ }^{65,79} \mathrm{BB}$ have shown to reduce mortality and morbidity for symptomatic patients with HFrEF. This effect is seen regardless of ACEI-treatment. ${ }^{80-}$ ${ }^{84} \mathrm{BB}$ should also be considered for rate control for patients with HFrEF and atrial fibrillation. Furthermore, BB should be administered for those patients with asymptomatic systolic dysfunction to prevent progression, prevent remodeling, and improve survival, especially if there is a $\mathrm{MI}$ in the medical history. ${ }^{1,80}$ Evidence of effect of $\mathrm{BB}$ in $\mathrm{HFpEF}$ is ambiguous, but pooled analysis indicates a reduction in cardiovascular mortality. However, the reduction disappears when the studies are limited to those with low bias. ${ }^{71}$

\section{Mineralocorticoid/ aldosterone receptor antagonists}

Since evidence that ACEI does not effectively suppress the production of aldosterone in approximately $40 \%$ of the patients with HF, the studies on MRA started.$^{85}$ MRA exert its effect by inhibit the binding of aldosterone to its receptor. ${ }^{86}$ Corticosteroid and androgen receptors might also be inhibited with variation in affinity, resulting in side effects. MRA minimizes the retention of water and sodium, decreases preload, and might suppress cardiac remodeling. ${ }^{86}$ In addition to ACEI or ARB treatment, MRA has

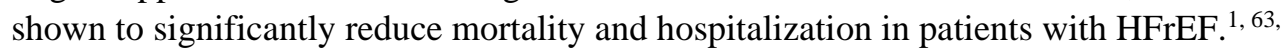
65, 86-88 For patients with HFpEF, treatment with MRA has shown a reduction of hospitalizations, but there is no impact on mortality or morbidity. ${ }^{71,89}$ Post-Hoc analysis for the use of spironolactone shows a wide regional difference in outcome, which makes the result ambiguous. ${ }^{90}$ Spironolactone is associated with gynecomastia whilst Eplerenone is not. Both compounds improve endothelial function in nondiabetic patients, but spironolactone might increase the levels of glycated hemoglobin and does not improve endothelial function in patients with diabetes. ${ }^{86}$ 


\section{Angiotensin receptor Neprilysin inhibitor}

Angiotensin receptor Neprilysin inhibitor (ARNI) is a relatively new therapeutic agent that combines an ARB (Valsartan) and a compound (sacubitril) that inhibits degradation of NP, bradykinin, and other peptides by inhibiting NEP, Neprilysin. This results in both inhibition of RAAS, remodeling, and myocardial hypertrophy. ${ }^{91}$ ARNI has shown to be superior to ACEI in reducing overall mortality, cardiovascular mortality, and hospitalizations in patients with HFrEF with LVEF $\leq 35 \% .{ }^{92,93}$ ARNI has also shown to create a greater reduction in NT-ProBNP than an ACEI (Enalapril) with a significant difference as early as one week after initiation. ${ }^{94}$ The effect is seen over the whole perspective of LVEF. ${ }^{95}$ The therapy is withheld for those with severe HF. However, the risk of hypotension and angioedema is increased. ${ }^{1}$ The use of ARNI in HFpEF has not shown any reduction in mortality or hospitalizations. ${ }^{71,96}$

\section{Diuretics}

Diuretics are recommended to reduce symptoms in patients with HF. Diuretics increase physical capacity and reduce risk of death in patients with HFrEF. ${ }^{1}$ The aim of diuretic medication is to maintain euvolemia with the lowest achievable dose, higher doses are related to worse prognosis. ${ }^{97}$ The dose is changed over time, and to individual needs, and preferably self-adjusted according to symptoms and weight. A good adherence to self-monitoring and adjustments results in fewer hospitalizations and emergency visits due to HF. ${ }^{98}$ Diuretics also alleviate signs of HF in patients with HFmrEF and HFpEF. 1,63, 99 There are different types of diuretics (loop-diuretics, thiazides and potassium sparing) that exert effect on different receptors but the net effect is the same. Use of multiple diuretics needs careful monitoring. ${ }^{1}$

\section{Other medical treatments}

Ivabradine exert its effect by inhibit the $\mathrm{I}_{\mathrm{f}}$-channel in the sinus node, reducing heart rate. ${ }^{100}$ Ivabradine has shown to reduce mortality and hospitalization for patients with symptomatic HFrEF despite optimal medical treatment. The effect is seen for patients with $\mathrm{LVEF} \leq 35 \%$, heart rate $\geq 70 \mathrm{bpm}$, and prior hospitalization within 12 months. ${ }^{101}$, ${ }^{102}$ Ivabradine has also shown to reverse cardiac remodeling. ${ }^{103}$ Ivabradine should only be used in patients with sinus rhythm. ${ }^{1}$

For patients with $\mathrm{HF}$ and an indication for anticoagulation should maintain on ongoing anticoagulation therapy. Addition of a low dose rivaroxaban to standard HF therapy shows no benefit in terms of mortality or morbidity ${ }^{104}$ There is no evidence that any other oral anticoagulation reduces mortality or morbidity compared to Aspirin or placebo in patients with both HFrEF and HFpEF. A small reduction in ischemic stroke can be seen but this is counteracted by the increased rate of bleeding. 105,106 
The combination of hydralazine and isosorbide di-nitrate, results in dilatation, both peripherally and within cardiac muscle. The treatment shows beneficial effect in small, specific groups and may only be considered for symptomatic patients with $\mathrm{HFrEF}$ unable to tolerate ACEI or ARB. ${ }^{1,63,65}$ The effect is inferior to that of ACEI. ${ }^{107}$

Digoxin exerts its effect by elongating the conduction within AV-node, increasing contraction, and reducing heart rate. Combined, this leading to positive inotrope and negative chronotropic effect. ${ }^{65}$ It may be considered for patients with symptomatic HFrEF and sinus rhythm, and for patients with HF and rapid rate atrial fibrillation for frequency control. ${ }^{1}$ Digoxin does not show any reduction of mortality or morbidity in patients with HF but can improve symptoms. Some studies report increased mortality in patients using digoxin due to atrial fibrillation. This indicates that if the drug is to be used, the digoxin level must be monitored. ${ }^{108}$

Renin inhibitors reduce biomarkers of HF but no effect have been seen on cardiovascular deaths or hospitalization for patients with HFrEF. ${ }^{109-111}$

\section{Combination Therapy}

In the current guidelines on HFrEF a combination of BB and ACEI/ARB is the first line treatment with an add-on of MRA if the patient is still symptomatic. ${ }^{1}$ Combination therapy with BB and ACEI/ARB is well studied in large trials and has proven to reduce both mortality and morbidity. ${ }^{82,83,112}$ Combination of ACEI/ARB with BB and MRA results a further reduction in mortality and hospitalization..$^{87,88}$

Combining ACEI with Carvedilol (BB and $\alpha-1$ receptor blocker) shows a $65 \%$ lower risk for death in patients with moderate decreased LVEF, and for patients with severely decreased left ventricular function, addition of Carvedilol reduces the rate of death by $35 \% .{ }^{82,112}$ The initiation of monotherapy with BB or ACEI/ ARB shows no difference in mortality or hospitalization whilst the combination further reduces mortality and hospitalizations. ${ }^{113}$

The studies of combining ACEI, BB and ARB in patients with HFrEF shows ambiguous results. The combination has shown both increased mortality, increased adverse cardiac events, and a reduction of cardiovascular death ${ }^{76,114,115}$ The different studies cannot be compared because of non-comparable cohorts. Specific groups of patients might benefit from the combination

For patients with HFpEF, the studied effect of combination therapy is inconclusive. In one study the combination of ARB and BB shows a lower rate of all-cause death, but this finding is not supported in two other trials on the same subject. ${ }^{77,78,116}$

In summary, combination therapy with ACEI/ARB and BB for HFrEF is widely studied and hold multiple evidence of increased survival. Addition of MRA to 
previous therapy further decreases mortality in patients with $\mathrm{HFrEF}$ and might have an impact on mortality for HFpEF patients. Add-on of ARB to previous treatment with ACEI and BB is most likely related to increased cardiovascular death in patients with HFrEF but might be indicated for patients with HFpEF. Further studies on HFpEF treatment are necessary.

\section{Device treatment for heart failure}

\section{Implantable cardioverter defibrillator}

A major proportion of death amongst patients with $\mathrm{HF}$ is due to ventricular arrhythmias, bradycardia, and asystole. Pharmaceuticals decrease risk of mortality, but the risk remains high. For patients with ventricular arrhythmia that causes hemodynamic effect, the implantation of an Implantable cardioverter defibrillator (ICD) is indicated, if the patients estimated lifetime exceeds one year with good physical capacity. ${ }^{1}$ For patients with HFrEF after MI, implantation is indicated if the reduced $\mathrm{EF}(\leq 35 \%)$ is sustained, despite optimal medical treatment, 3 months after the infarction. ${ }^{117,}, 118$ The time delay is due to the fact that, despite decrease in sudden cardiac death, the total mortality remains unchanged within the first month. ${ }^{119,}{ }^{120}$ The mortality can also be reduced for selected patients with HFrEF of non-ischemic etiology, but the evidence is ambiguous. ${ }^{121-124}$ However, current guidelines recommend implantation of an ICD since the evidence is more in favor for implantation than withholding ICD. ${ }^{1}$ ICD is not indicated for patients with severe symptoms, such as physical status of NYHA IV that is refractory to medical therapy, not eligible for MCS or Htx. ${ }^{1}$

\section{Cardiac resynchronization therapy}

For some patients with HFrEF the electrical conduit of the heart is affected leading to dys-synchronous contraction of the ventricles. Cardiac resynchronization therapy (CRT) is a pacemaker that corrects this delay for LV and restores synchronous contraction. The CRT holds the same features of normal pacemakers and can control heart rate (CRT-P) and can, in special cases, stop lethal arrhythmia if the CRT also holds an implantable defibrillator (CRT-D). CRT reduces mortality and morbidity whilst increasing quality of life for symptomatic patients with LVEF $\leq 35 \%$ despite optimal medication. ${ }^{125-128}$ However, the effect on reversed remodeling is not seen among all patients fulfilling these criteria. Those with ischemic etiology have scar tissue that impact improvement in LV function but these patients might obtain the same prognostic benefit. ${ }^{129}$

ECG predicts the outcome of the CRT-treatment and the most favorable effect is seen in patients with left bundle branch block (LBBB) or QRS width greater than 130ms, and especially for those over $150 \mathrm{~ms} .{ }^{1,128,130}$ Newer methods are developing and his- 
bundle pacing might be an alternative in patients for whom left ventricular-lead placement is not possible. ${ }^{131}$ His-bundle pacing and CRT in combination with atrioventricular ablation can increase functional status and reduce the use of diuretics for patients with HFrEF, HFpEF and atrial fibrillation. It and can also decrease the number of HF hospitalizations. ${ }^{132,133}$

\section{Advanced treatment for heart failure}

\section{Advanced pharmacological treatment}

For patients that deteriorates to INTERMACS 3-4 despite optimal medical therapy, and for patients with cardiogenic shock due to acute HF, the use of inotropic or vasoactive agents can facilitate improvement. These agents acutely increase $\mathrm{CO}$ but should only be used in patients with hypotension and hypoperfusion. ${ }^{1}$ The inotropic agents all aim to increase cardiac contractility by affecting the $\beta$-adrenergic stimulation, the Frank-Starling mechanism, or the positive force-frequency relation (accumulation of intracellular $\mathrm{Ca}^{2+}$ at higher heart rates). ${ }^{134}$ However, some of the inotropic agents also increase cardiac work, myocardial oxygen consumption, myocardial toxicity, myocardial hypertrophy/remodeling, renin-angiotensinaldosterone activation, and renal sodium-water retention. These effects combined contribute to the process of HF and can explain why the use of inotropic therapy does not show any improved outcome, in some studies even worsened outcome. ${ }^{135-137}$

Vasopressors and inotropic agents, such as epinephrine, norepinephrine, dopamine, and dobutamine stimulates the $\beta 1$ receptors and to various extent also $\beta 2, \alpha 1, \alpha 2$, and dopaminergic receptors 1 and 2 resulting in different effects on the cardiovascular system. Inodilators such as milrinone and levosimendan have a different effect on the myocardial tissue than the inotropic agents. ${ }^{138,139}$ The use of inotropes generates an increase in $\mathrm{CO}$ and for some inotropes, increased blood pressure. For vasopressin and norepinephrine the effect is increased blood pressure whilst the inodilators increasing $\mathrm{CO}$ leading and act as a peripheral vasodilator which lead to lower blood-pressure. ${ }^{139}$ Norepinephrine is preferred over dopamine sine the use of dopamine shows more arrhythmic events and increased death at 28 days. ${ }^{140}$ In patients with cardiogenic shock after myocardial infarction, epinephrine shows unfavorable metabolic changes such as increased lactic acidosis and higher incidence of refractory shock than norepinephrine. ${ }^{141}$ Dobutamine improves cardiac contractility by being a $\beta 1$ and $\beta 2$ adrenergic agonist. Due to its effect on $\beta 2$, the drug also induces peripheral vasodilatation. Dobutamine can be used to obtain a moderate, rapid and short-acting effect due to the short half-life. ${ }^{139}$

Milrinone is a phosphodiesterase inhibitor that increases contractility and improves diastolic function by increasing influx of $\mathrm{Ca}^{2+} .{ }^{139}$ Along with the increased contractility, milrinone also generates a vasodilatation in both the peripheral and 
pulmonary vasculature. ${ }^{142}$ Milrinone can be used for patients on betablockers in combination with dobutamine for synergic effect. Milrinone has a longer half-life than dobutamine. ${ }^{139}$ Milrinone, as well as dobutamine, is however associated with higher mortality and more frequent cardiac arrhythmias when compared to placebo, and should therefore only be used in selected patients. ${ }^{143}$

Levosimendan increases contractility by increasing the sensitivity for intracellular $\mathrm{Ca}^{2+}$ by binding to troponin $\mathrm{C}$. Levosimendan also cause peripheral vasodilation by opening adenosin triphosphate-sensitive potassium channels in vascular smooth muscles. ${ }^{139}$ Levosimendan has shown to cause improvement in hemodynamics and decreased HF symptoms. Levosimendan also show lower mortality compared to dobutamine and placebo. ${ }^{144,145}$ However in other trials levosimendan failed to show any benefit compared to dobutamine regarding mortality and secondary outcome. ${ }^{146}$ In metaanalysis in 2012 and 2016, levosimendan was associated with a reduction of mortality by $20 \%$, but these meta-analyses had both elective and acute patients enrolled. ${ }^{147,148}$ For patients undergoing surgery, the use of vasopressors $24 \mathrm{~h}$ after surgery were lower for those treated with levosimendan but there was no difference in 30-day mortality. ${ }^{149}$, ${ }^{150}$ Levosimendan has also been shown to increase diuresis and improve renal function in patients with advanced $\mathrm{HF}^{151}$

\section{Short term assist devices}

\section{Intra-aortic balloon pump}

For patients with cardiogenic shock and inotrope dependence, a short-term assist device might be an alternative as bridge to recovery, bridge to Htx or bridge to LVAD. The intra-aortic balloon pump (IABP) is a short-term assist device that increases CO by approximately $20 \%$ by counter pulsation in the descending aorta. The counter pulsation results in an increase of myocardial perfusion and a reduction of the aortic, end-diastole and systolic pressures. The use of IABP may be associated with major complications such as systemic infections, stroke and major bleeding. ${ }^{152}$ In the SHOCK II trial, in which patients with cardiogenic shock caused by acute myocardial infarction were randomized to either IABP or control, the use of IABP did not increase survival at 30 days, 6 or 12 months. ${ }^{153,154}$ After the presentation of this study the recommendation for IABP were lowered. ${ }^{1}$ There might however be a place for IABP for patients with chronic HF with an acute episode, at an early phase of cardiogenic shock. ${ }^{155}$

\section{Impella}

In recent years, new short-term assist devices have been presented. Another commonly used, short term assist device is the Impella (Abiomed Inc., Danvers, MA, USA) that comes in different sizes. The Impella is a catheter-mounted axial flow pump that is placed over the aortic valve and unload the LV by continuously displacing blood from 
LV to the ascending aorta. The Impella 5.0 requires a surgical procedure to gain access to the femoral or the axillary artery, whilst the Impella $2.5 \mathrm{LP}$ and Impella CP can be placed percutanously. ${ }^{156}$ Compared to the IABP the Impella reduces LV pressure and causes a reduction in LV stroke work, myocardial oxygen demand, as well as it provides a superior hemodynamic support. ${ }^{157,158}$ However, these devices have not yet been able to show any effect on mortality compared to IABP. ${ }^{158-161}$ The most common adverse events are stroke, hemolysis, device related vascular complications, and nondevice-related bleeding. ${ }^{162}$

\section{ECMO}

Extracorporeal membrane oxygenator (ECMO) system consists of a centrifugal pump, membrane oxygenator, and a heat exchanger. The ECMO is mostly positioned with the inflow cannula in the superior vena cava or the right atrium. The outflow cannula may be positioned in either the femoral or subclavian artery. The system provides gas exchange, oxygenation, circulatory support, and may be used in patients with impaired oxygenation or cardiogenic shock. ${ }^{156}$ When ECMO is used in patients with cardiogenic shock, the LV afterload may be increased and can worsen the myocardial ischemia, cerebral ischemia, and cause pulmonary oedema. For these patients, a combination of ECMO and Impella or IABP might be an option. ${ }^{163}$ Compared to ECMO alone, the combination therapy results in lower in-hospital mortality and a higher rate of successful bridging to recovery or long term treatment options. ${ }^{164,165}$ The most common adverse events are bleedings, stroke, kidney failure, and limb ischemia. The development of adverse-events, preimplant serum creatinine, and hypoalbuminemia are risk factors for mortality. ${ }^{166}$ In a meta-analysis in 2016, survival for patients in cardiac arrest was increased when ECMO was used. For patients with cardiogenic shock, the use of ECMO showed a greater 30 day survival compared to IABP but not compared to Impella. ${ }^{167}$

\section{Surgical treatment for heart failure}

\section{Heart transplantation}

Htx, the only curative therapy of HF is a surgical replacement of a patient failing heart with a normal functioning heart from a donor. ${ }^{168}$ The first orthotropic Htx was performed in 1967, but survival was limited due to ineffective immunosuppression. Development of immunotherapy since the 80-ies increased survival, and Htx is now widely accepted. In Sweden approximately $50 \mathrm{Htx}$ are performed every year. ${ }^{169}$ The vast majority of Htx are due to DCM and coronary artery disease. ${ }^{168}$ The basal principles for a successful Htx are that the heart function is so poor that no other intervention could be beneficial, the function causes the patient substantial limitations in their quality of life and that the patient otherwise is strong, healthy enough to have long-term benefits from the surgery. ${ }^{169}$ There are a numerous criteria and relative 
contraindications to Htx and before acceptance for transplantation, the patient must undergo thorough examination. ${ }^{170} \mathrm{After} \mathrm{Htx}$, the patient maintains strict immunosuppression regimes and periodically undergoes cardiac biopsy to assess graft rejection. ${ }^{168}$ Survival after heart transplantation has improved; in 2002-2008 the 1 year survival rate was $84 \%$ and $2009-201486 \% .{ }^{168}$ In Sweden, the 1 year survival rate was $92 \%$ in 2011 and 10 year survival rate was $71 \%{ }^{169}$

\section{Mechanical circulatory support}

The low number of donor organs available is still a major issue, and is one of the driving forces for the development of MCS. During the 20th century, the use of MCS as a bridge to transplant (BTT) has increased from $22.2 \%$ in 2002 to $43 \%$ in 2013 . The most used MCS are LVAD. ${ }^{168}$ Previously, the use of LVAD pre-transplant, was associated with worse post-transplant prognosis but this is not seen for the continuous flow LVAD. ${ }^{168}$

\section{History of Mechanical circulatory support}

The thought of replacing the human native heart with a mechanical pump has been tempting to generations of cardiologists and cardiothoracic surgeons. The first device for temporary left-heart assist (DeBakey blood pump) was implanted in 1963 and used for adequate support for 4 days. Unfortunately, the patient died due to pre-implant injury. The pump was improved and successfully used in 1966 when a patient recovered after cardiac surgery and 10 days treatment with MCS. In the following years, driven by clinical developments and American initiatives, multiple assist devices were developed. Most of them trying to simulate pulsation and were pneumatically driven. In the 80-ies, due to deaths while awaiting Htx, the previously developed pumps were approved as investigational devices and their use as BTT hence increased. ${ }^{171}$ In 1994, Thermo cardiosystems got their HeartMate 1000IP, pneumatically driven, approved by the federal drug association (FDA) for clinical use. ${ }^{171,172}$ The sequel, electrical driven, HeartMate 1000VE were approved in 1998, showing good clinical results with a patient surviving 604 days on support, awaiting Htx. ${ }^{172}$

\section{Long term assist devices}

Linköping university hospital was the first center in Sweden to implant a long-term assist device in 1993. In the recent decades, multiple manufactures have presented their solution to MCS but the most successful is HeartMate II (Abbott, Lake Bluff, IL, USA)(HMII) that was the one used at Linköping University hospital prior to adaptation to HeartMate3 (Abbott, Lake Bluff, IL, USA)(HM3) and therefore most reported in this thesis. 
The approval for MCS as BTT resulted in more patients receiving the pumps and numerous studies were performed. The studies showed that short term use of these devices improved end-organ dysfunction, exercise intolerance, with a reasonable quality of life. The patient can also be discharged with a relatively low rate of adverse events. ${ }^{173,174}$ REMATCH trial, 2001, shows a 48\% reduction of death in the group randomized to device compared to optimal therapy, therefore indicating that long-term treatment is efficient. The survival rate in this study, $52 \%$ at one year for the device group and $25 \%$ for the medical therapy. ${ }^{175}$ The beneficial effect continued in extended follow up. ${ }^{176}$

The first generation of LVAD, no longer used, were large and limited in construction due to the pulsatile mode involving multiple moving parts. The HMII, LVAD, uses axial flow, started evolving in 1991 and came to clinical trials in 2000. ${ }^{177}$ The subsequent generation were already designed as the first clinical trials started. ${ }^{178}$ Multiple other LVADs were developed during the same decade. ${ }^{179,} 180$ The first European study of HMII ended early due to poor outcome related to pump design, and the first implantation of the redesigned LVAD occurred in 2003 with more than 6 months without adverse events. ${ }^{181}$ The initial design of HMII consisted of a fully integrated system with transcutaneous energy transmission system, but this was never adopted and the use of externally placed batteries is still an issue for all available LVADs. ${ }^{181,182}$

Since the new generation of LVADs was smaller, more patients, including children could be eligible for treatment. The first clinical results of HMII showed improved end-organ function, great longevity, and reached a 1- year survival rate of $80 \%$. Adverse events such as stroke, gastrointestinal bleeding, and arrhythmia were still noted. ${ }^{183}$ A larger, observational trial, involving 133 patients resulted in a 6-month survival rate of $75 \%$ and 1 -year survival rate of $68 \%$. The previously noted adverse events such as stroke and bleeding were still present within this study. During the trial, $2 \%$ of the patients had a pump thrombosis that needed pump exchange. ${ }^{184}$ The extended survival, longevity of the device, and superiority of pulsatile pumps, have been shown in multiple studies worldwide and are widely accepted. ${ }^{185-198}$

For those treated with LVAD as BTT the post Htx survival is equivalent to that of patients with conventional transplantation. The time with HMII does not affect outcome. ${ }^{199}$ HMII improves functional capacity and HF related quality of life for both BTT and destination therapy (DT). ${ }^{200}$ MCS as DT is used for patients with contradiction to Htx, the patient will live as long as possible with their device. With the favorable outcome of the axial flow devices, the adverse events that occur during treatment started to consume more scientific interest. ${ }^{187}$ To further increase outcome, major adverse events such as neurological, thrombo-embolism, pump thrombosis, gastro intestinal bleeding, arrhythmias, and hemodynamics were addressed..$^{201,202}$ The success of HMII resulted in approval as DT in 2010. ${ }^{203}$ 
The centrifugal, continuous flow pump, HeartWare (HVAD) received approval as BTT in 2012. ${ }^{203}$ The HVAD is a smaller centrifugal pump that is implanted in the pericardium. ${ }^{204}$ The outcome of HMII as DT has been improved mostly due to a decrease in adverse events. ${ }^{205}$

The increasing use of MCS resulted in the start of INTERMACS in 2006. Between the start and 2017, approximately 25.000 patients received an FDA-approved device. Of these, approximately 18.000 were continuous flow LVAD. The major proportion was an axial flow LVAD (HMII). The survival rate has continued to improve and has reached a 1 year survival rate of $83 \%$ and 5 year survival rate of $50 \%{ }^{206-208}$ It has been proven that timing of implantation LVAD is a factor for survival and risk of adverse events, with survival being best for those patients who were not inotrope dependent at implantation (INTERMACS profile 4-7). ${ }^{193,197,206}$

The use of HMII and other MCS are related to severe costs for society, and the use is frequently challenged due to the low cost-effectiveness, of which the device is the major proportion of the cost. ${ }^{209-211}$ The overall effect is still considered a success. There are individual case reports that show the long-term benefits and life-saving ability of these devices. ${ }^{212,213}$ The adverse events have triggered further improvements in minimizing moving parts that can cause pump failure and minimizing shear stress that leads to platelet activation.

The HM3 differs significantly from its precursor in achieving these features. ${ }^{214}$ The experimental studies started in 2007 and the first implantation in man occurred in 2015. ${ }^{215}$ HM3 takes a further leap in LVAD design as it optimizes the physiological features by simulating an artificial pulse. The first trial, to achieve CE-mark showed non-inferiority in survival at 6 months (92\%) compared to HMII and no pump thrombosis was reported in 50 patients. ${ }^{216}$ Survival rates are 98\%, 92\%, 81\% and $74 \%$ at 1 month, 6 months, 1 year and 2 years post-implantation, respectively. The HM3 is superior to an axial flow device with respect for survival free of disabling stroke, or reoperation for removing or replacing a malfunctioning device. In the studies, most patients received the device as DT. ${ }^{216-220}$

\section{HeartMate II}

The HMII (figure 4) consists of an implantable housing, control device and batteries that provide a functional time about $8-12 \mathrm{~h}$. The device is cradled in a surgical pump pocket, below the cardiac margin. A titanium cannula is sutured to the cuff placed in the apical left ventricle. From the titanium cannula, a Dacron graft protected by silicone sheathing, leads the blood flow to the titanium inflow curve that is directly attached to the pump. The pump weight is $290 \mathrm{~g}$, displacing $124 \mathrm{ml}$ and has a diameter of $12 \mathrm{~mm}$. In the titanium body of the pump, magnets are fixed radially, and consecutive charging makes the titanium impeller spin. At the inflow, a three bladed 
inflow stator produces a linear flow whilst suspending the impeller with a ruby bearing. Distal to the ruby bearing, the spinning three, curved bladed impeller rotates and creates radial flow through the pump. The distal part of the impeller is suspended by mechanical bearing at the outflow stators creating the axial velocity. The outflow is connected to a Dacron graft that is sutured, end-to-side anastomosis at the ascending aorta. The material in the pump is designed to create biocompatibility.

Before placing the pump in the prepared pump pocket, a trocar is used to cannulate the driveline at the right side of the abdomen. The pump typically operates in ranges of $8600-10000$ revolutions per minute (rpm) generating a flow of 3-7Liters (L) / minute (min). The fixed speed can be read on the controller, where also the calculated flow, Pulsatility Index (PI), and power consumption is displayed. ${ }^{221}$ Guidelines from the manufacturer recommend anti-coagulation with warfarin in addition to anti-platelet therapy with acetylic salicylic acid at a dose of $81 \mathrm{mg}$ daily. The international normalized ratio (INR) is recommended to keep between 2.0 and 3.0. ${ }^{221}$

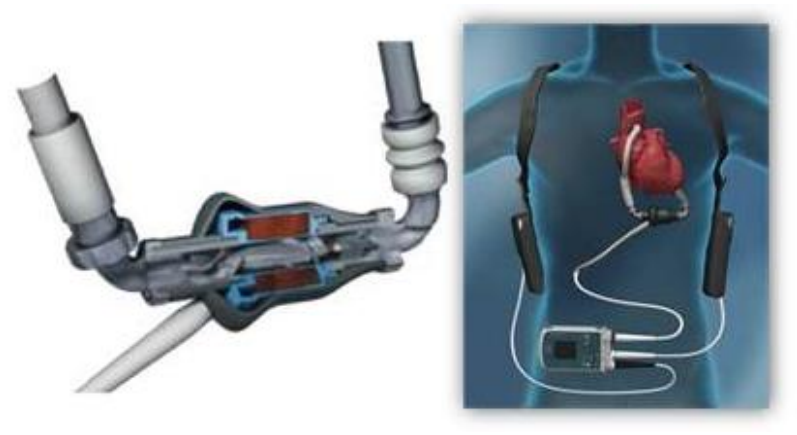

Figure 4. The HeartMate $\mathrm{II}^{\mathrm{TM}}$ LVAD. The figure to the left shows the HMII with the impeller and magnetic stators visible. The image to the right shows the position in which the HMII is placed and the attached part of the system. Reprinted with permission from Thoratec corporation.

\section{HeartMate 3}

HM3 (figure 5) was first introduced in 2001 and was continuously developed until the first implantation occurred in 2015. ${ }^{178,214,215} \mathrm{HM} 3$ is implanted in the pericardial space and consists of a compact intra-pericardial housing, control device, and batteries. The integrated inflow cannula consists of titanium with fused titanium microspheres to enhance biocompatibility and create a new intima. The inflow cannula is inserted in the apical region of the native heart and fixed by a built-in locking mechanism in the suture apical cuff. The pump weighs $200 \mathrm{~g}$ and displaces a volume of $80 \mathrm{ml}$. The rotor is magnetically suspended and rotates centrifugally creating a flow through the gelatinimpregnated woven polyester outflow graft. The outflow graft is sutured end-to-side 
anastomosis at the ascending aorta. The magnetic levitation and the controlled rotation allowing wider gaps in the blood flow than previous pumps. The increased gaps minimize shear stress, resulting in stable coagulation and less von Willebrand factor (vWf) degradation. ${ }^{215,216,222}$ The driveline is placed in the same manner as for HMII and all the outer products are similar to HMII.

The pump typically operates in ranges 4000-6000rpm generating a flow of 3-7 L/min and can deliver up to $10 \mathrm{~L} / \mathrm{min}$ if the speed is increased. When pump speed is fixed above 4000rpm, the system creates an artificial pulse by a rapid decrease in speed followed by a rapid increase above fixed speed. According to the manual, the increase and decrease are 2000rpm. The artificial pulsation minimizes stasis in LV, allowing flow over the aortic cusps, and rinses out the pump housing, all factors to minimize the risk of thrombosis. ${ }^{216} \mathrm{In}$ an analysis of the fluid dynamics, the artificial pulse showed no additional benefit on scalar washout performance but could be relevant for removal of deposits in the pump. The viscous stress proved lower in the HM3 than in previous pumps but the artificial pulse substantially increased turbulence and total stress which could activate platelets. ${ }^{223}$
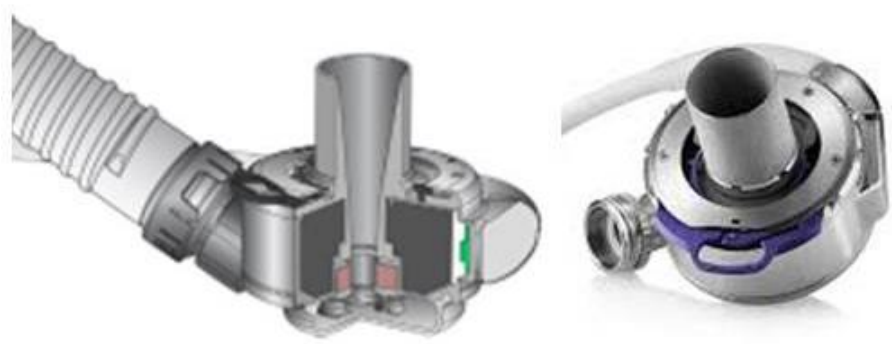

Figure 5. The HeartMate $3^{T M}$ which is the newest of LVAD. Reprinted with permission from Thoratec Corporation/ Abbot Laboratories 


\section{Monitoring of LVAD}

Continuous monitoring of LVAD parameters is of importance to detect problem at an early stage. Normally, the patient is followed by routine outpatient visits with documentation of pump parameters. The patient and caregiver should be trained to observe changes in these parameters. Between these routinely scheduled visits, frequency depending on clinical stability, the patient may have monitoring phone calls. ${ }^{224}$ The effect of a standardized telephone intervention with focus on pump parameters, blood pressure, alarms, INR, and the status of the patients is associated with reduced Mean Arterial Pressure (MAP) and also has impact on the survival. The impact on survival is due to early detection of high MAP and other upcoming problems. ${ }^{225}$ Echocardiography should be performed at regular intervals to evaluate optimal pump function and potential signs of recovery. In addition, Echocardiography should be performed to evaluate sub-optimal pump function. ${ }^{224}$ Echocardiography is a key element in assessing the hemodynamic of the LVAD patients, in which the LV should remain unloaded whilst the RV should remain loaded. ${ }^{226}$ For patients waiting heart transplantation, additional right heart catherization could be performed to assess and document pulmonary artery pressure. Right heart catherization can be useful to assess persistent or recurrent symptoms of HF after LVAD implantation. ${ }^{224}$

\section{Adverse events during LVAD treatment}

Despite the progress of MCS, the treatment withholds multiple risk factors that can cause the patient harm, or subsequently death. The most common adverse events of the treatment are stroke, bleeding, pump thrombosis, and infection. Stroke is becoming more and more outcome-defining, but the others still have impact on mortality. In this next section, the one most relevant for this thesis, thrombosis will be discussed.

\section{Thrombosis}

During the initial trials of HMII, the event rate of thrombosis was low. In the first clinical experiment, there were no reports of thrombosis and in the European study; there were one event of thrombosis. ${ }^{183,184}$ In 2008 , the first case report of thrombosis showed association between sudden increase in power consumption and thrombosis forming in HMII. The thrombus occurred after withdrawal of anticoagulation due to 
gastrointestinal bleeding. ${ }^{227}$ However, thrombus formation can occur without any alarm or apparent change in power, flow, or PI ${ }^{228}$ The rate of thrombotic events reported to be lower than the risk of bleeding which created massive morbidity, despite INR, and a lowering of recommended INR were suggested in 2009. ${ }^{229,230}$ Anti-platelet therapy might be reduced without generating any increase in thromboembolic events if the INR of 2.3 can be maintained. ${ }^{231}$ Pump, patient, surgery technique and management-related factors are associated with the risk of thrombosis and the frequency of this condition increased during 2011-2012, resulting in alarming studies in 2014. ${ }^{232-238}$ Compared to 2008-2009, pump thrombosis in 2011-2012 increased 6fold with a decrease in freedom from thrombosis at 6 months at $99 \%$ in 2009 to $94 \%$ in $2012 .{ }^{234}$

The studies in 2013-2014 revealed total incidence of confirmed or suspected thrombosis in 11-13.4\% of HMII recipients. ${ }^{236,239,240}$ The risk of thrombosis is highest between 1-3 months post implantation. ${ }^{234,236,241}$ One of the major contributors to the increase in pump thrombosis might be inadequate anticoagulation, in which small changes can be of great importance. ${ }^{234}$ Patient-related factors that can increase the risk for pump thrombosis are atrial fibrillation, pre-existent ventricular thrombus, infection, left sided mechanical prosthesis, low-flow, hypercoagulable state, and patient compliance to medical treatment. ${ }^{232}$ There is also a correlation between modification (sealed inflow graft) of the pump and increase in pump thrombosis, if this is a statistical phenomenon is uncertain. ${ }^{242}$ Minimization of risk factors by uniform implant techniques and consistent post-op management such as heparin bridging between implantation and adequate INR, pump speeds $>9,000 \mathrm{rpm}$, may reduce the number of pump thrombosis and maintain the incidence at low levels. ${ }^{243,} 244$

In a study where the flow of HMII was analyzed by computational fluid dynamics, specific regions within the pump were highly thrombogenic since the flow formed entrapped circular patterns that can activate platelets. The circular patterns were found in the same places as the thrombosis was found in pumps explanted due to pump thrombosis. ${ }^{245}$

For HVAD the rate of thrombosis is about $8,1 \%$ and is associated with INR $<2$, INTERMACS profile 3 or higher at implant, and aspirin doses $<81 \mathrm{mg} .{ }^{246}$

After responding to the alarm, the abrupt increase in thrombosis plateaued in 2014 with a freedom of pump thrombosis at 6 months of $95 \%{ }^{241}$ The risk of death after a pump thrombosis reported as high as, $24 \%$ at 3 months after thrombosis, and the incidence of neurological events and infections are greater than those patients without pump thrombosis. ${ }^{207,234,247}$ For HM3, all publications on follow-up have shown low incidence of pump thrombosis. ${ }^{216-220,248-252}$ There is one reported case of outflow graft occlusion..$^{253}$ 


\section{Assessment of pump thrombosis}

The presence of abnormalities in the system performance data (power consumption, Flow, Speed, PI) displayed at the system monitor is indicative of pump thrombosis; however, there are reports of pump thrombosis in lack of increased power consumption or low flow. ${ }^{227}$ Suspicion of thrombosis is a composition of multiple causes, for instance, a transient or gradually increase in pump power consumption, increased lactate dehydrogenase (LDH) in conjunction with low haptoglobin and/or high free hemoglobin and worsened HF-symptoms. ${ }^{232}$ If the increase in power consumption is above $10 \mathrm{~W}$, or an increase of $>2 \mathrm{~W}$ from baseline over $24 \mathrm{~h}$, LDH level increased 3 times over the normal upper limit, there should be a high suspicion of pump thrombosis. Chest computed tomography can be of value for finding mechanical etiology such as inflow malposition or kinked outflow graft. ${ }^{232}$ Clinical ramp-studies of the HMII have been performed to further detect device thrombosis. During echocardiography the pump-speed is sequentially increased and measurement (amongst others) of Left Ventricular End Diastolic Diameter (LVEDD) is performed. A LVEDD slope that shows that the pump is not sufficient to unload the ventricle, is an indication of thrombosis. ${ }^{254}$ Most of these methods are somewhat invasive and do not fully verify or rule out thrombosis. Algorithms for the treatment of suspected thrombosis has been developed. Depending on pump power consumption, LDH, Chest Computed tomography, and ramp study, they results in increase of the anticoagulation, thrombolytic therapy, or urgent pump exchange/ $\mathrm{Htx} .{ }^{232}$

\section{Sound analysis of LVAD}

The use of a method with a high sensitivity to detect malfunction or thrombosis within the LVAD is desirable, especially a non-invasive method. The non-invasive method of acoustics was tested on animals in 2006, and the results indicated that experimental design could identify and detect initial signs of deterioration in the pump function. ${ }^{255}$ In 2007, nine patients with HeartMate XVE were monitored for any acoustic findings indicating end of life or mechanical failure. An aquatic hydrophone was used for recordings and the sound was interpreted on a laptop. All patients had their devices exchanged due to device failure, and the acoustics could differentiate between inflow valve incompetence and bearing wear, thus indicating that monitoring of LVAD can be an alternative to waiting until symptoms appear. ${ }^{256}$

In 2009, the rotary blood pumps had been applied to clinical practice, and they were studied for their acoustic profile by using an electronic stethoscope. The results shows that the frequency spectrum contains information of rotation rate, device design, and LV/LVAD interaction. ${ }^{257}$ In an abstract presented at the meeting of International 
Society of Heart and Lung Transplantation (ISHLT) in 2011, the presence of thrombus within HVAD resulted in change in spectral peaks at $125-175 \mathrm{~Hz}$ due to unbalanced impeller motion. Normalization of the frequency spectrum was associated with resolution of the thrombus. ${ }^{258}$

In a patient with HMII, included in the multicenter- SoundMate study, acoustic recordings prior to a thromboembolic event showed a change in the frequency spectrum, similar to the findings in the abstract presented at ISHLT. Another patient, free from events showed little or no change in amplitude or peaks in the frequency spectrum over time. These recordings were made with an iPhone, recorded at home and transferred electronically for distance monitoring. ${ }^{259}$

Further studies on HVAD in small settings showed that alteration in peak amplitude was associated with outflow occlusion and changes in MAP. ${ }^{260}$ Acoustic spectral analysis of HVAD was analyzed in 105 patients of whom 8 had signs of pump thrombosis which also was confirmed after surgical pump exchange. In this study, they normalized the spectrum towards the fourth harmonic and thereafter compared the spectrum to the normal. The study concluded that all 8 patients had a presence of a third harmonic, that was not seen for the controls, and an increase in amplitude of first and second harmonic. ${ }^{261}$ According to a small study, the opening of aortic cusps can also be seen in acoustic analysis. ${ }^{262}$

Except from the studies from our group, only a few others have been performed on HMII. A two-tiered approach was used when both mock loop and clinical data from 10 stable patients and 2 patients with pump thrombosis were studied to detect changes in acoustics, speed, and pressure. For sampling, an electronic stethoscope was used, however, no normalization was conducted. The change in fluid viscosity, inflow and outflow pressure affected flow rates, and power consumption, but no changes in the sound spectrum could be seen. There was no imminent structural resonance within the pump. In presence of a thrombus, the spectral energy is reduced, resulting in lower amplitudes and lower area under the curve. ${ }^{263}$

To evaluate if the location and mass of the thrombus have an impact on the acoustics, an artificial thrombus model with silicone simulating thrombosis in HVAD were developed. Both acoustics and vibration analysis were performed. The results showed that the third harmonic was visual in $62.5 \%$ of the pumps at baseline and 4 dominant spectral peaks were observed in $75 \%$. Most spectral peaks were harmonics to the fundamental frequency. The power consumption was only significantly increased when the thrombi were located on the tilted pad, and the mass exceeded $4 \mathrm{mg}$, but the numbers of spectral peaks was significantly increased when the thrombus mass was 2 and $5 \mathrm{mg}$ and located in the primary flow path, or located in the tilted pad (all masses). The findings of impact on the third harmonic amplitude found in Kaufmann et al. could not be confirmed, but an assessment of the total number of peaks and that an 
acoustic method might find thrombosis prior to elevation of power consumption was suggested. ${ }^{264}$

The ECMO-system, CentriMag (Thoratec, Pleasanton, CA, USA) is somewhat like the HM3 in design. One common adverse event in CentriMag is formation of thrombosis. In a small number of patients with ECMO- treatment, and in mock loop circuit, a peak at $3 \mathrm{~Hz}$ were significant for the build-up of thrombosis, and the amplitude being gradually increased depending on the mass of thrombus. ${ }^{265}$

\section{Aims}

The overall aims of this thesis were to develop and evaluate the use of a mock loop circuit to further characterize and study the acoustics of LVAD. Another aim was to evaluate different recording devices and to study the effect of afterload on pump function.

The specific aims of the four studies presented in this thesis were to:

- design an experimental in vitro model to register and analyze acoustic signals from the HMII continuous flow Mechanical circulatory support, and to detect changes in sound correlating to artificial and blood clot/thrombosis, using modern telecom techniques.

- characterize the sounds of the HMII using signal processing methods in time (waveforms) and frequency (spectra) domains. Furthermore, cheap and readily available handheld recording devices suitable for use at home (iPhone and iPod) were compared with dedicated audio equipment.

- evaluate if the sounds from HM3 can be recorded and if in vivo and in vitro acoustic analyses are comparable. Also to evaluate whether an electronic stethoscope may be used for recording audio signals from the HM3.

- investigate the effects of inflow and outflow resistance of the pump on performance and the impact on the estimated flow rate indicated by the LVAD monitor.

Additionally, we consider the impact of clot-analogs on the efficiency of the HMII and HM3 ventricular assist devices, their impact on the algorithm for flow monitoring and the risk for retaining clot-analogs in the LVAD. 


\section{Methods}

This thesis consists of four papers with similarities between the methods used. In this section, the fundamentals of sound and signal analysis, the patients studied, the two different mock loops, characteristics of the different recording devices, software (audacity and MATLAB) used, and statistical analysis will be presented.

\section{Sound and signal analysis}

\section{Sound, basic principles}

Sound is a product of air pressure disturbances in an elastic medium due to vibration. If an object is set into motion it will begin an upward and downward oscillation until the internal resistance causes the vibration to stop. This format of vibratory motion is called a simple harmonic motion and the pattern that it creates if we plot the motion towards the baseline (before set into motion) is a sine wave, sinusoid, a pure tone that is rarely encountered in nature. The speed of sound is depending on the medium density and compressibility. The speed of sound in air is $343 \mathrm{~m} / \mathrm{s}$ whilst in the human body it is $1540 \mathrm{~m} / \mathrm{s}$. When the sound passes through different mediums, the sound might be damped and could impact analysis.

The time to perform a cycle (baseline to baseline) can be measured, and the number of cycles completed in one second is called Hertz $(\mathrm{Hz})$. The normal hearing range for young humans is 20 to $20.000 \mathrm{~Hz}$. Simple vibratory systems can differ in three dimensions: amplitude, frequency, and phase Amplitude refers to the magnitude of displacement or the power within the vibration, and is normally measured between maximum positive and maximum negative peak within the signal. The phase is determined by the initial direction of the vibration, resulting in different starting points for the sinusoid. For example, if a string starts its movement from baseline with a positive sinusoid, the phase is 0 . If the string instead starts with a downward movement, the phase is $180^{\circ}$. The frequency is affected by the mass and stiffness of the vibrating part, a stiffer part will have a higher frequency and a larger mass will have a lower frequency. Aperiodic sound shows no repeating pattern in time domain and can be divided in to transient and continuous aperiodic sounds. The continuous is also called noise and the frequency spectrum is often relatively flat.

Sound is created by a deformation of the air particles that are connected, creating a chain reaction of particle density. The deformation of air particles can also affect a membrane. The membrane starts to move due to the deformation of air particles. The membrane movement can be turned into electrical components, generating a microphone. 
Sound often consists of multiple sinewaves at different frequencies, at different time, and is called complex signals. If the frequencies can be determined they can be shown in regard to their amplitude, or power within an amplitude spectrum, or power spectrum. Most complex signals have energy at the multiples of the fundamental frequency, called harmonics. To determine how the power, or amplitude of the sound, is distributed over the frequencies, multiple techniques of signal analysis can be performed. The most common is Fourier transform analysis.

\section{Fourier transform analysis}

Fourier transform analysis was developed in $19^{\text {th }}$ century by the mathematician Joseph Fourier, and is based on the theory that all complex waves can be derived by adding sinusoids together. The method has widespread applications in engineering, physics, and medicine. Fourier transform analysis takes a signal in time domain and determines the amplitude of each sinusoidal component that is present within the signal, and also determines the phase of the signal, see figure 6 . A major assumption for this method is that the signal is stationary over time. The Fourier transform analysis was further developed to handle discrete time signals and with an output that is continuous in time and periodic. This is called a discrete-time Fourier Transform (DTFT). Since computers only can handle a finite number of values, the Discrete Fourier Transform (DFT) was developed from the DTFT. It can be seen as the DFT is the sampled version in frequency domain of DTFT. The methods to calculate DFT, are multiple and all algorithms that can calculate the DFT in an efficient way is called a Fast Fourier Transform (FFT). This method is often integrated into different sound handling software. ${ }^{266}$ 

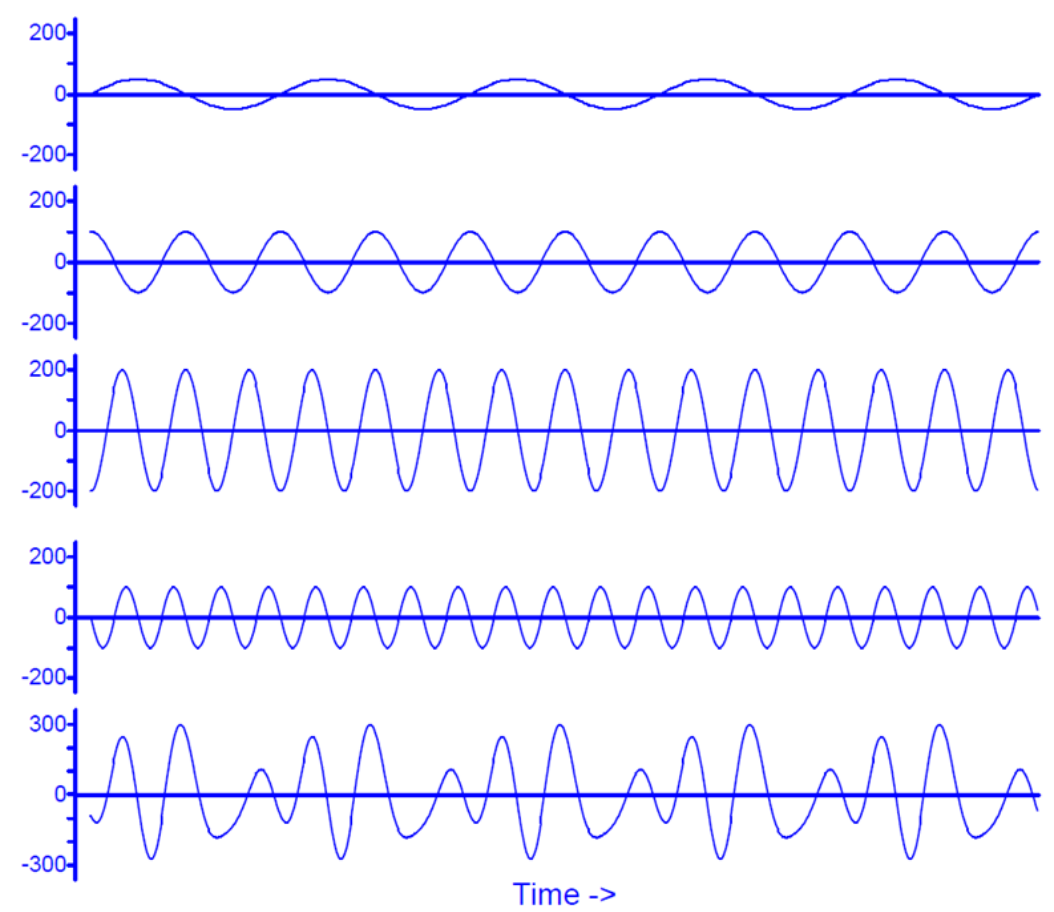

Figure 6. Illustration of principle underlying Fourier transforms analysis. The complex signal in panel e is derived by point for point summation of the sinusoidal signals shown in panel a-d. Thereafter the sum of amplitude is calculated at each time generating the instantaneous amplitude of the complex signal in panel e. As example, at time zero, the sum of a-d are, $0,+100,-200$ and 0 , producing a sum of -100 which is equal to the starting sum of panel e. Adopted from 267

\section{Power Spectral Density}

One essential part of determining differences between recordings is normalization. The distance from the object, and the sensitivity of the microphone, may result in different amplitude within the frequency spectrum regarding the different recordings. To ensure that all recordings analyzed with FFT can be compared to each other power within the signal is set to 1 . To determine the amount of power that is in different regions within the frequency spectrum, power spectral density (PSD) can be performed. PSD refers to the spectral energy distribution that will be found per unit time and is normally used for continuous signals. By calculating PSD within a signal, the area under the segment of the curve corresponds to the power within that frequency range, and can be used for determining differences between signals. ${ }^{266}$ 


\section{The Mock Loop Circuits}

The mock loop circuit, described below, was used in the simulations (paper I-II) with modulations to be able to insert artificial thrombotic materials. The model was developed by testing inputs that might affect the recording. The development started with the HMII, described earlier in this thesis, connected to the heart and lung machine within the Thoracic Intensive Care Unit to facilitate a pulsation. Multiple recordings were performed, as well as simulations with different viscosity and pulsation. These recordings were analyzed without, to our knowledge, any effect on the sound.

Thereafter a mock loop circuit without pulsations was created. The LVADs were lowered into a saline bag to facilitate a dry surface for audio recording with different devices, and to mimic the location within the human thoracic cavity. The outflow of the LVAD was connected to a container filled with water by $50 \mathrm{~cm}$ long plastic flexible tubing with a diameter of $1.25-1.5 \mathrm{~cm}$. The container was connected to the inflow by $50-\mathrm{cm}-$ long flexible vinyl tubing. The distance from the LVAD to the recording device was $3 \mathrm{~cm}$. In the first study, ball valves on the tubing were used to create in and outflow obstructions by $50 \%$. A specific location on the surface of the saline bag were marked at which the recordings were to be performed. Multiple recordings were made at different speed levels and sent to a computer as file attachment in e-mail for analysis. For paper III, the mock loop circuit was modulated to fit the HM3 with $50 \mathrm{~cm}$ plastic tubing, $2 \mathrm{~cm}$ in diameter connecting the water chamber (2L) to the pump inflow. The graft from HM3 connected the pump outflow and the water chamber. Forceps were applied to change inflow and outflow obstruction. See figure 7 for schematic drawings of the two mock loop settings used in paper I-III.
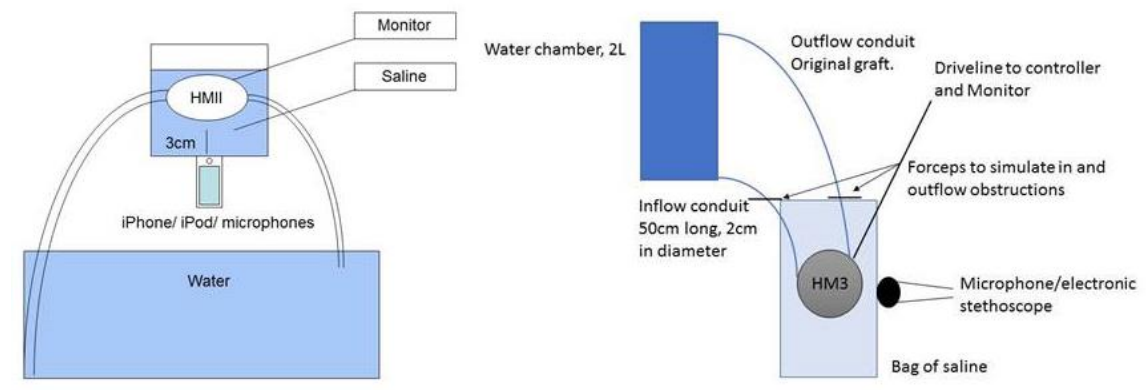

Figure 7. A schematic figure of the mock loop circuit. To the left; the mock loop circuit used in paper I and paper II. To the right; The mock loop circuit used in paper III

In paper IV the two different LVADs were connected in a mock loop composed of a water reservoir, 3/8" PVC tubing, valves to adjust resistance (inflow and outflow of 
the pump) and the possibility to include or exclude the oxygenator from the circuit by two valves. Ultrasound flow probe (Transonic H9XL, Transonic Inc., Ithaca, NY, USA) and pressure transducers (CODAN DPT-6000 system, Codan Triplus AB, Kungsbacka, Sweden) were adapted at the inlet and outlet section of the pump. This setup conveys the possibility to change the pre and afterload by different means, constrictions, circuit of different lengths, and by inserting clot analogs. See figure 8 .

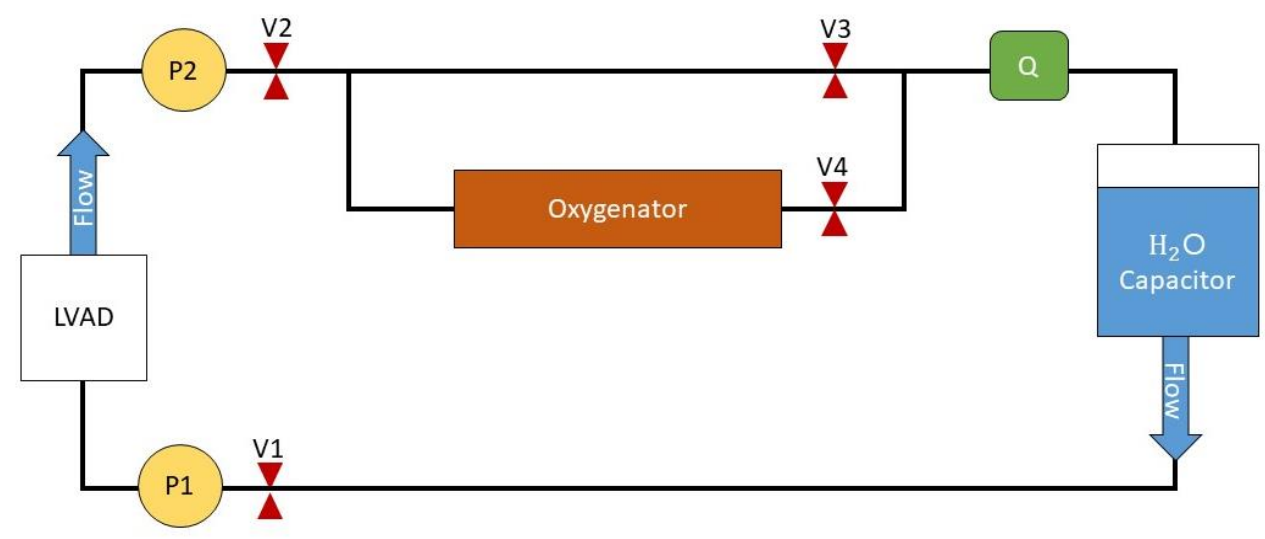

Figure 8. A sketch of the circuit, with possibility to adjust the pump operating conditions. The pressure gauges (P1 and P2) were placed at the inflow and outflow of the pump (LVAD). The valves V1 and V2 regulate the down-and up-stream resistance, respectively. The flow meter $(\mathrm{Q})$ was placed further downstream from the oxygenator. The oxygenator could be by-passed altogether by using the valve V4. The blue arrow shows the flow direction.

\section{Patient Characteristics}

In paper II and III we included patients to be able to compare the sounds from implantable LVADs and LVADs in mock loop circuit. In paper II a male 52 years old, with dilated cardiomyopathy had the sound recorded. He received his HMII as a bridge to transplantation. No alterations in settings of the patients HMII were performed. The patient was sitting down, and by placing all audio recording devices over the lower left chest the sound was recorded. Participation of the patient was approved by the local ethics committee (2014/14-32). In paper III, the recordings from 4 patients ( 3 males and 1 female) with different etiologies (dilated cardiomyopathy, acute ischemic cardiomyopathy, and congenital aortic stenosis) to heart failure, were performed. Their ages varied between 24-64 years old. The patients had received their HM3 as BTT. The recordings were performed with the patients lying down with an electronic stethoscope, and microphones placed over the pump for sound recording. No changes 
in any of the patients pump settings were performed. The study was approved by the local ethics committee (2019-00415).

\section{Audio recordings and analysis}

\section{iPhone/iPod}

In paper I and II, iPhone $4^{\mathrm{TM}}$ and $\mathrm{iPod}^{\mathrm{TM}}$ (Apple, Inc., Cupertino, CA, USA) with the commercially available stethoscope application iStethPro (Dr. Peter J Bentley, London, UK) was used for audio recordings, and the recordings were then transferred via telecommunication to a laptop for analysis. For the iPhone, the built-in microphone was used and lightly pressed towards the surface of the saline bag. The iPod was equipped with an external microphone, Thumbtack ${ }^{\mathrm{TM}}$ (SwitchEasy, Tracy, CA, USA) since the built-in microphone is located on the back of the device, making it impossible to handle the application without generating disturbances while positioning the device towards the underlying surface. The decision to use iPhone and iPod as recording devices was to facilitate a method for home monitoring. The sampling frequency was set to $44.1 \mathrm{kHz}$ for all devices, and all recordings were $8 \mathrm{~s}$ long.

\section{Shure microphones}

In paper II and III, dedicated recording equipment as a reference device was used. Two identical microphones were used and the recordings were made at the same time with both devices to exclude impact of the specific device. The microphones used were a Shure PG58 (Shure Inc., Niles, IL, USA). The microphone provides a relatively linear frequency response over the frequencies $60-15.000 \mathrm{~Hz} .{ }^{268}$ This means that above or under these frequencies attenuation or amplification might occur, and the results are then not completely valid. The microphones were connected to a commercial laptop by an external sound card, Behringer FCA1616 (Behringer, Germany). ${ }^{269}$ The sampling frequency for the microphones was set at $44.1 \mathrm{kHz}$ and the recordings were performed with MATLAB (MathWorks, Natick, MA, USA). ${ }^{270}$

\section{Electronic stethoscope}

In paper III, evaluation of the electronical stethoscope, Littman ${ }^{\mathrm{TM}} 3200$ (3M, St. Paul, MN, USA) as a recording device was performed. The electronical stethoscope is a clinical tool and can be used for both routine auscultation and for audio recordings. The electronic stethoscope is capable of recording sounds in the frequency range 20$2000 \mathrm{~Hz}$, with 30 second clips. Three filters may be applied to amplify different regions within the frequency range. The recordings were transferred by Bluetooth to a laptop with the Littmann Stethassist (3M, St. Paul, MN, USA) software and converted to .WAV files within the software. The sampling rate for the electronic stethoscope was set to $4 \mathrm{kHz}$. 


\section{Audacity}

In paper I, the frequency analysis software program, Audacity 1.3.13-beta (Unicode, Ash, Chinen and Crook, Pittsburgh, PA, USA) was used for analysis of the recordings. The software has a built-in function that calculates FFT of the signal. The software presents the frequency spectrum in a Hanning-window that can be exported. When exported, the frequency amplitudes at different, pre-specified levels are numerically presented. In our study, these values were exported to Microsoft Excel and in that software, comparisons between different spectrums could be created

\section{MATLAB}

MATLAB (Mathworks, Natick, MA, USA) is software that is developed for mathematical and technical variables. It is built of matrixes and can be used to calculate multiple algorithms automatically by using scripts. The software has multiple built-in functions and algorithms. MATLAB is frequently used by engineers to perform and to visualize complex calculations. Multiple customized algorithms have been used within our different studies.

\section{Statistical analysis}

All statistical analysis was performed using commercially available software programs, $\mathrm{p}<0.05$ was regarded as significant.

Paper I. In paper I, Statistica ${ }^{\mathrm{TM}}$ (StatSoft, Tulsa OK, USA) was used for comparison between the different recordings. The values within the stated region and peaks were summarized and student t-test were used for statistical analysis.

Paper II. In paper II, the difference between the specific devices was shown by visualization which is common within engineering resulting in no specific statistical analysis.

Paper III. In paper III, IBM SPSS version 23 was used for statistical analyzes. To determine the correlation between measured and estimated frequencies the Pearson correlation coefficient was used. To determine the statistical differences in power distribution the two-tailed student t-test was used to compare the different groups of recordings.

Paper IV. In paper IV, the difference between the specific LVADs was evaluated with visualization in multiple graphs. No specific statistical analysis was used. 


\section{Summary of results}

\section{Acoustic analysis of a mechanical circulatory support. Paper I}

The acoustics from the HMII could be recorded by an iPhone and transferred to a computer for further analysis. A frequency spectrum consisting of clear peaks and regions were found and to facilitate statistical analysis, the spectrum was divided in these regions and the sum of amplitudes was calculated. Changes with increase in speed resulted in significant changes in multiple regions and peaks. See figure 9 and table 3 .

When simulating different clot situations with both ball valves and artificial thrombus masses from gelatin the frequency spectrum was significantly changed. The most significant changes were in the lower regions of the frequency spectrum. See figure 9 and table 3 . 


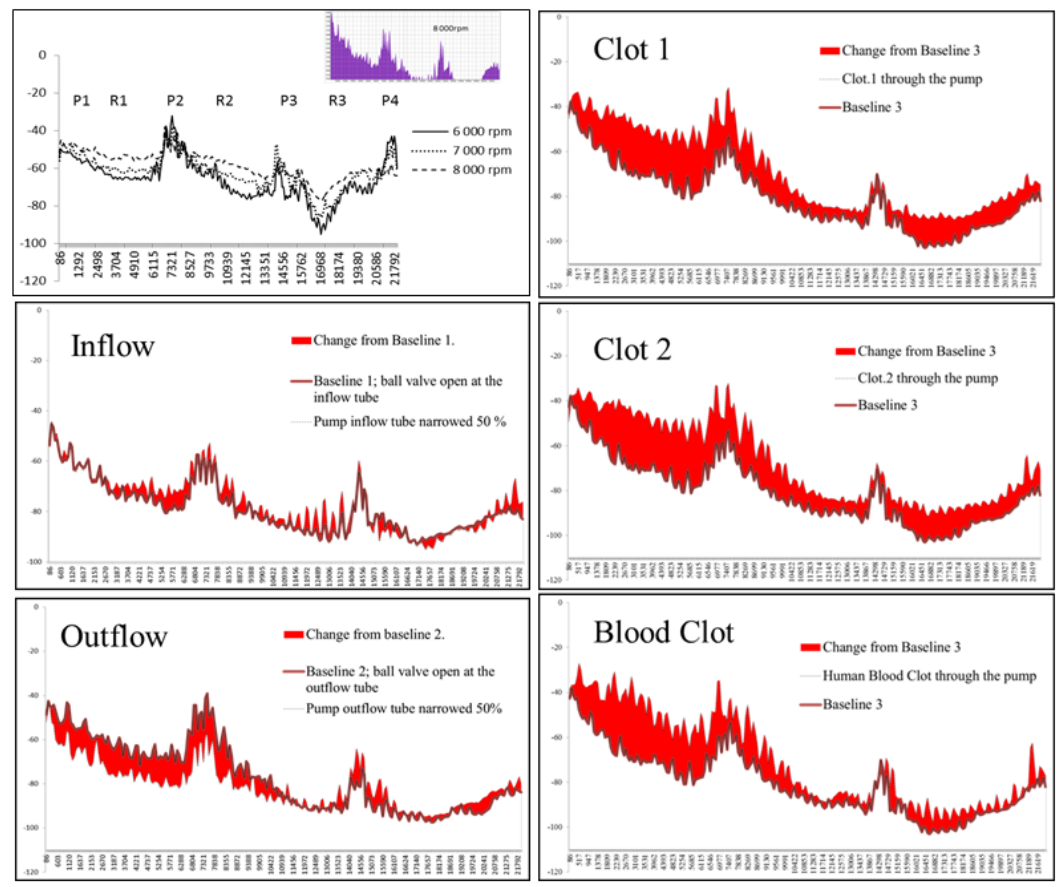

Figure 9. Change in the frequency spectrum at increased pumps speed curves (upper left panel) shows example of change in acoustic fingerprint when pump speed increased from 6000 to 700 to $8000 \mathrm{rpm}$. The spectrum in the software audacity imprinted in the right corner. Acoustic changes in red when narrowing the inflow and outflow tubes with 50\% respectively (left panel), and at different clots passed through the pump. R= Regions (R1:10006500; R2: 8500-14000; R3 15000-21000) Hz. P=Peaks (P1:0-1000; P2: 6500-8500; P3: 14000-15000; P4: 21000-23000) Hz. Frequency (x-axis) in $0-23000 H z$, and amplitude (y-axis) in -dB. Figure from ${ }^{271}$

When controlling the pump monitor, a decrease in power consumption and flow occurred when the in-and out-flow tubing was narrowed. Compared to baseline (Power: 4.0, 3.9, 4.2W; Flow: 3.8, 3.8, $3.8 \mathrm{~L} / \mathrm{min}$ ) the power was decreased to $3.2 \mathrm{~W}$ and $2.1 \mathrm{~L} / \mathrm{min}$ when the inflow tubing was reduced by $50 \%$. When the outflow tubing was narrowed the power decreased to $2.7 \mathrm{~W}$ and flow to $2.1 \mathrm{~L} / \mathrm{min}$. The artificial clots resulted in a decrease in power $(2.7 \mathrm{~W}, 2.4 \mathrm{~W})$ whilst the blood clot resulted in a $48 \%$ increase to $7.4 \mathrm{~W}$. The monitor showed no estimation of the flow while the clots were passing thru the pump. Uncertainty of the adequacy of the iPhone as a device for audio collection arose. The background for different peaks within the frequency spectrum could not be determined. 
Peaks and Regions (no. of Frequencies)

Change in noice level dB: mean (SD) and mean \%

\begin{tabular}{|c|c|c|c|c|c|c|c|}
\hline \multirow{3}{*}{$\begin{array}{l}\text { Change at increased speed (rpm) } \\
6000 \text { to } 7000\end{array}$} & \multirow[b]{2}{*}{ P1 (11) } & \multirow[b]{2}{*}{ R1 (64) } & \multirow[b]{2}{*}{ P2 (23) } & \multirow[b]{2}{*}{ R2 (64) } & \multirow[b]{2}{*}{ P3 (12) } & \multirow[b]{2}{*}{ R3 (69) } & \multirow[b]{2}{*}{ P4 (12) } \\
\hline & & & & & & & \\
\hline & $2(2)^{*} \quad 4 \%$ & $3(2) * * 5 \%$ & $4(3) \mathrm{ns} \quad 0 \%$ & $5(3)^{* *} \quad 8 \%$ & $7(3) * * \quad 18 \%$ & $5(4)^{* *} 6 \%$ & $4(3) \mathrm{ns} \quad 7 \%$ \\
\hline 7000 to 8000 & $2(2)^{*}$ & $5(2) * * 10 \%$ & $4(2) \mathrm{ns}$ & $5(2)^{* *}$ & $5(3) \mathrm{ns}$ & $5(3)^{* *}$ & $7(5)^{* *} 14 \%$ \\
\hline 8000 to 9000 & $3(2)^{* *}$ & $3(2) * * 3 \%$ & $5(5) \mathrm{ns}$ & $5(2)^{* *}$ & $6(2)^{* *} 12 \%$ & $4(2)^{* *}$ & $9(4) * * 15 \%$ \\
\hline 9000 to 10000 & $3(2)^{* *}$ & $2(1) \mathrm{ns} \quad 2 \%$ & $3(3) \mathrm{ns}$ & $3(2)^{* *}$ & $3(2)^{* *} \quad 5 \%$ & $4(2)^{* *}$ & $3(2) \mathrm{ns} \quad 6 \%$ \\
\hline \multicolumn{8}{|l|}{ Change from baseline } \\
\hline Pump inflow tube narrowed $50 \%$ & $2(1) \mathrm{ns} 3 \%$ & $4(3) * * \quad 5 \%$ & $5(2)^{*}$ & $4(3) * *$ & $2(1) \mathrm{ns}$ & $2(8)^{*}$ & $6(4) * *$ \\
\hline Pump outflow tube narrowed $50 \%$ & $8(4) * 16 \%$ & $11(4) * * 19 \%$ & $16(4)^{* *} 31 \%$ & $4(3) \mathrm{ns}$ & $8(3) * * \quad 10 \%$ & $3(3)^{* *}$ & $3(2) * *$ \\
\hline Clot 1 & $9(5)^{* *} 19 \%$ & $20(5) * * 29 \%$ & $19(5)^{* *} 29 \%$ & $8(5)^{* *} \quad 10 \%$ & $7(3) \mathrm{ns} \quad 8 \%$ & $10(3) * * 10 \%$ & $7(3)^{* *} \quad 9 \%$ \\
\hline Clot 2 & $10(5) * * 20 \%$ & $22(6) * * 32 \%$ & $20(6)^{* *} 31 \%$ & $10(5)^{* *} 12 \%$ & $8(4)^{*}$ & $10(3)^{* *} 10 \%$ & $10(4)^{* *} 12 \%$ \\
\hline Blood Clot & $\mid 12(7) * * 24 \%$ & $22(7) * * 31 \%$ & $\mid 16(7)^{* * *} 24 \%$ & $6(5)^{* *} \quad 7 \%$ & $7(6)^{* * *}$ & $\mid 5(4)^{* *} \quad 5 \%$ & $6(7)^{* *} \quad 8 \%$ \\
\hline
\end{tabular}

Table 3. R= Regions (R1:1000-6500; R2: 8500-14000; R3 15000-21000) Hz. P=Peaks (P1:0-1000; P2: 65008500; P3: 14000-15000; P4: 21000-23000) Hz.** $\mathrm{P}<0.005$. * $\mathrm{P}<0.05$. ns, no significant change. Rpm, revolutions per minute. A significant change in frequencies from the baseline acoustic fingerprint was detected in all experimental settings. Significant acoustic changes and the largest numeric change were seen in low frequencies when artificial clots and blood clots passed through the pump. Table from ${ }^{271}$

\section{Sound analysis of a left ventricular assist device: A technical evaluation of iOS devices. Paper II.}

The recordings from HMII within mock loop circuit and implanted in a patient appear similar in both time and frequency domain. Ambient and background noise affects the recordings. When the recordings were analyzed in time domain, a sine wave with an overlying saw-tooth signal became visible for the HMII in both patients and in mock loop circuit, see figure 10. The overlying "saw-tooth" signal is a high frequency signal at $7,2 \mathrm{kHz}$ due to the pulse width modulation (PWM) and disappears when the pump is suddenly turned off. The PWM also generates harmonics seen as a peak at $14.4 \mathrm{kHz}$. This is a system parameter that was also visible in paper I. The fundamental frequency is located at the set speed appearing as a clear peak within the spectrum and frequency peaks appear by its side, side lobes. These peaks might stem from slowly changing amplitude of the low-frequency oscillations. The low-frequency component can be reproduced by parametric models that clearly apply to the underlying, fundamental frequency. 


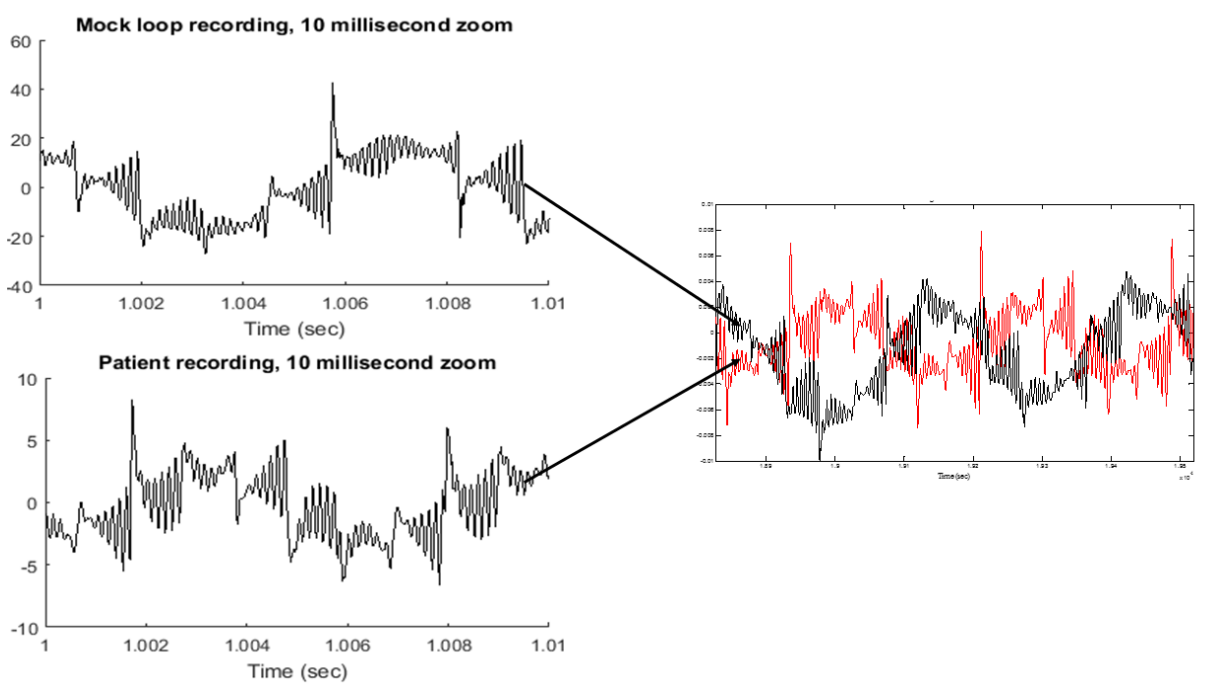

Figure 10. The figure shows the recordings from mock loop and patient with HMII. A periodicity, underlying sine wave with an overlying high frequency, saw-tooth signal can be seen. The overlying, high frequency signal originates from Pulse Width Modulation. The signal from mock loop and patient appear similar. Figure from ${ }^{272}$

The iOS-devices appeared to pick up more ambient noise and were lower in sound volume. The oscillation that is seen with the dedicated equipment is not as clear for the iOS-devices, but a periodicity could often be asserted and the underlying, low frequency sine wave can be reconstructed, see figure 11. The low-frequency spectra revealed visible but not prominent peaks at the pump frequency and its harmonics. The frequency spectrum of HMII is complex and holds multiple peaks and harmonics that make the use of sound analysis for thrombosis detection challenging. The use of iOSdevices needs further evaluation and should benefit from a high-end microphone. 


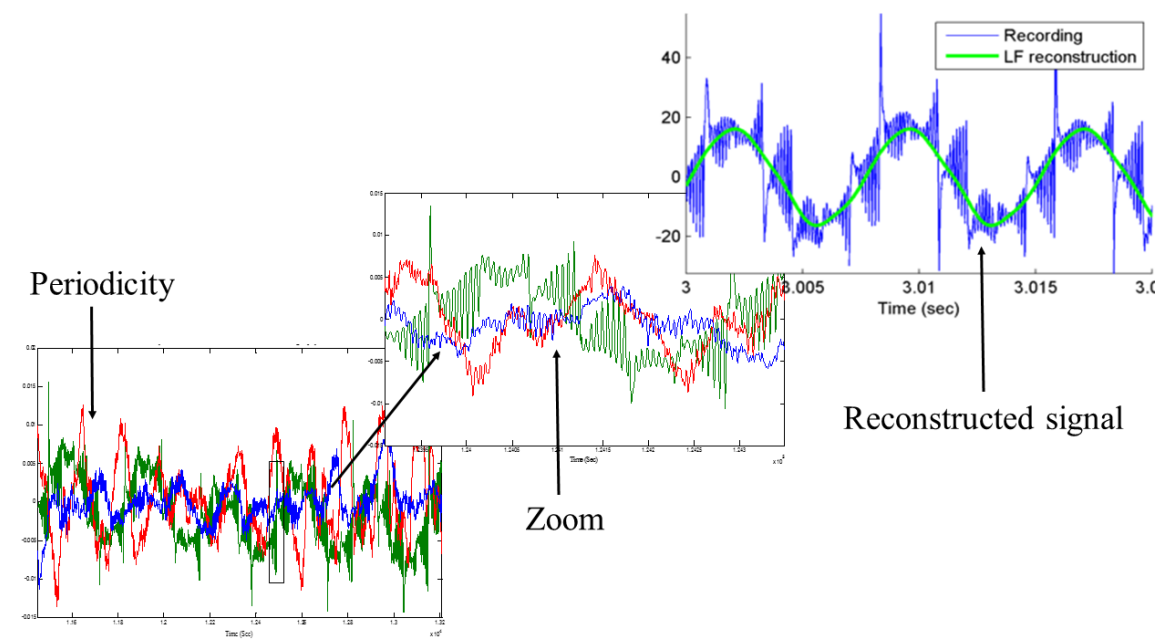

Figure 11. A comparison of the dedicated equipment, iPhone and iPod in time domain show that all of them are periodic (left). The PWM can be seen for all devices as a superimposed saw-tooth signal. The underlying sine wave, representing impeller rotation, can be reconstructed (right; dedicated recording equipment (green), iPhone (red), and iPod (blue)). Figure from ${ }^{272}$

\section{Sound analysis of the magnetically levitated left ventricular assist device HeartMate $3^{\mathrm{TM}}$. Paper III.}

The HM3 holds different properties compared to other LVAD due to the absence of mechanical bearings. The sound from HM3 can be recorded with both dedicated and an electronic stethoscope. The sound appears similar in vivo and in vitro. When the sounds were plotted in time domain, an underlying sine wave and a shift in amplitude and frequency could easily be seen when the artificial pulse were active. These changes were not as clear with the electronic stethoscope as with the dedicated equipment, see figure 12 . The major proportion of signal power $(96.7 \%)$ is within pump frequency $\pm 40 \mathrm{~Hz}$ indicating that the signal of interest is in the low frequency range. When the artificial pulse was activated, peaks at $+29.5 \mathrm{~Hz}$ and $-30.5 \mathrm{~Hz}$ appeared in the frequency spectrum. These peaks correspond to an increase/ decrease of speed of approximately $1800 \mathrm{rpm}$. This finding differs from the manufacturers manual but were consistent for all recordings, see figure 13. The electronic stethoscope was not as good as the Shure microphones at finding the fundamental frequency and in some recordings with electronic stethoscope a peak with higher amplitude and more power were seen, most often corresponding to a harmonic. All patients showed similarities in 
the frequency spectrum with peaks at the fundamental frequency and harmonics, see figure 14. Dedicated microphone system is superior to the electronic stethoscope but both methods may be used for acoustic sampling.

Shure microphone, 5600rpm

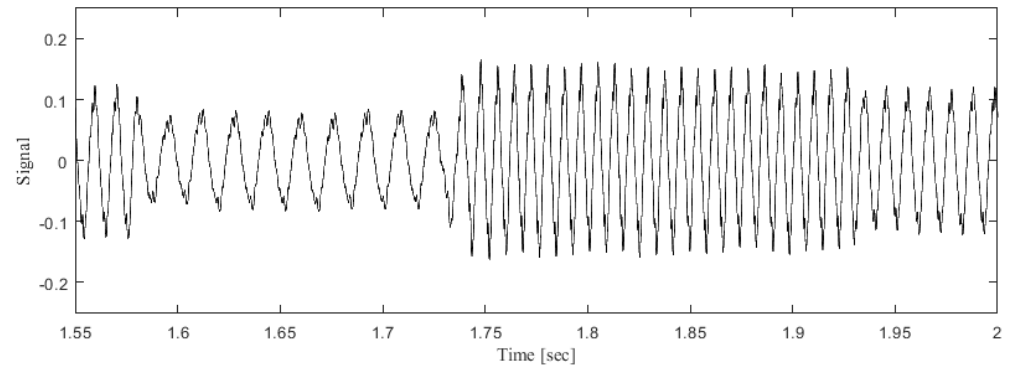

Littmann 3200, 5600rpm

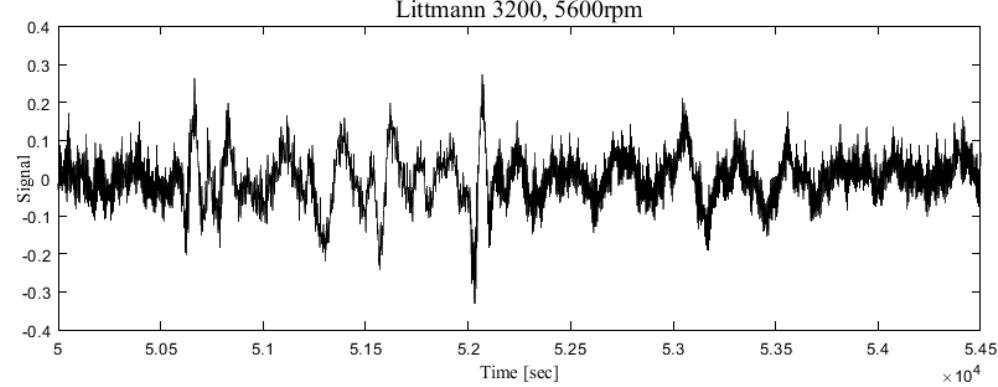

Figure 12. Recordings of the HM3 in a mock loop circuit with microphone and the electronic stethoscope. The change in frequency and amplitude due to artificial pulsation can easily be seen for the microphones. The changes are not as clear for the electronic stethoscope. Figure from ${ }^{273}$ 

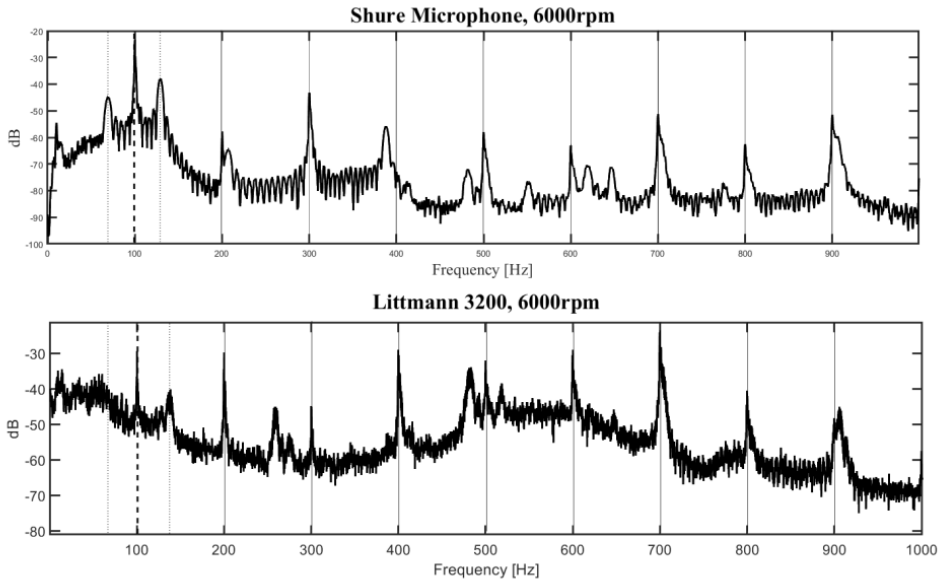

Figure 13. The sound from HM3 in a mock loop presented in frequency domain. The fundamental frequency $(100 \mathrm{~Hz})$ corresponds to the highest peak. This is not as clear for the electronic stethoscope but is visible and the harmonics are clearly seen. The peaks adjacent to the fundamental frequency corresponds to the increase/ decrease in speed that results in artificial pulsation. Figure from ${ }^{273}$

\section{In vivo and In vitro comparison}

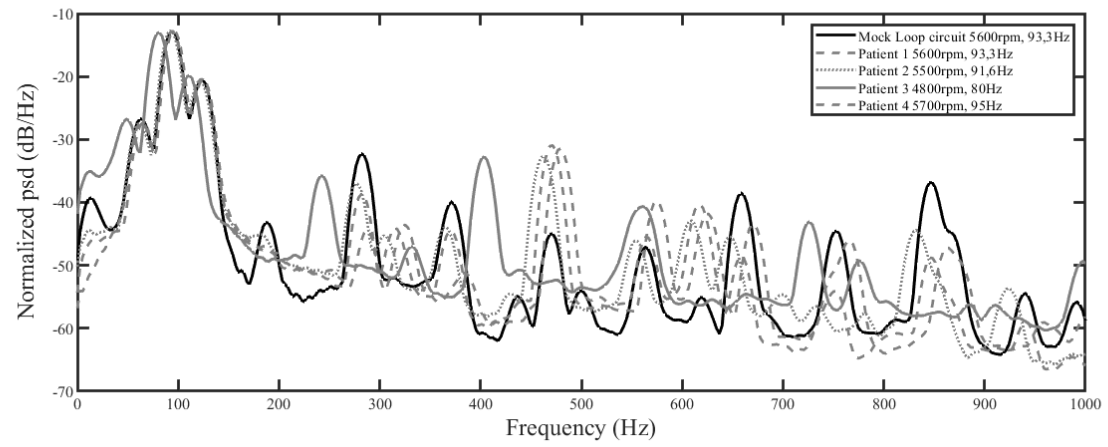

Figure 14. Recordings from the four in vivo recordings presented in a low frequency spectrum up to $1 \mathrm{kHz}$ after normalization (area under curve =1). Pump frequency and artificial pulsation peaks are clearly visible. Multiple harmonics can be seen. All recordings look alike with minor changes due to speed. $-20 \mathrm{db}$ equal to $0.01 \mathrm{~W} / \mathrm{Hz}$. Rpm=revolutions per minute. Figure from ${ }^{273}$ 


\section{In-vitro study of the impact of LVAD loading on mechanical performance. Paper IV}

The pump head, flow rate and data presented by the pump monitor were measured over a wide range of pump conditions. Acoustic signal was used to assess the time variations of the flow due to changes in rpm. For HMII the flow was steady and for HM3, quasi-steady. For both pumps, clot analogs remained within the pump housing. The linear relationship between flowrate and power consumption of both HMII and HM3 was valid in a limited range of operation and depended on the pump loading. Increment of afterload, by adjusting the piping length and outflow valve resistance affected the pump efficiency by decreasing the slope and the flow at specific rpm, see figure 15 .
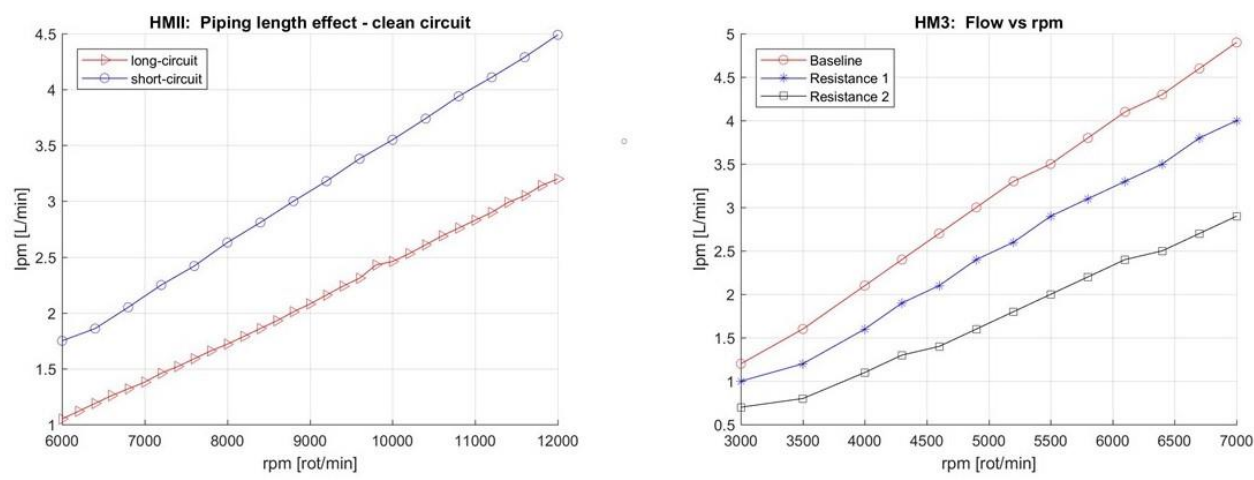

Figure 15. The measured flow-rate vs the pump speed in revolutions per minute (rpm) under different downstream conditions. HMII with a short and long circuit (a). HM3 pumping against three different downstream levels of resistance determined by the outflow valve seen in figure 8 .

For HM3, the in-and outflow constriction affect pump efficiency where an intermediary obstruction resulted in the highest efficiency, see figure 16. The insertion of clot analogues resulted in an increased pump head due to increments in rpm but the slope decreased. The HM3 showed better resistance to increased number of clot analogs. 

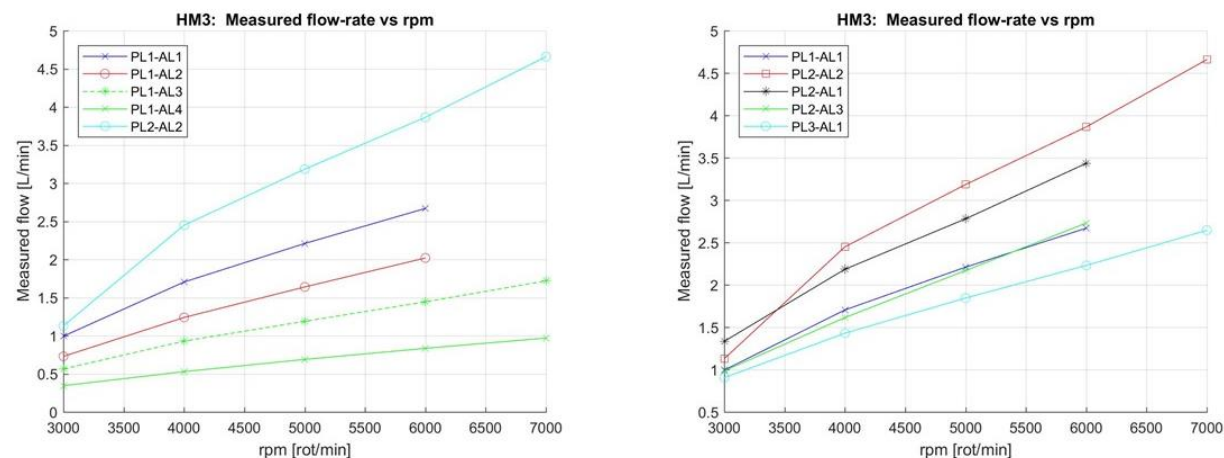

Figure 16. Measured flow vs pump speed in revolutions per minute (rpm) during mixed up-and down-stream levels of resistance for HM3. Minimum (1) to maximum (4) preload (PL) and afterload (AL) were altered. The highest efficacy is seen for intermediate in-and outflow restriction whilst the lowest flowrate is observed for higher outflow restriction.

Mechanical power output is defined as the total head in the circuit times the flowrate in $\mathrm{W}$. The mechanical power output can be used to determine pump efficiency by comparing mechanical power output towards power output measured from the monitor. The best efficiency is seen for clean circuits. HM3 is more efficient than HMII and less prone to be affected by clot analogues, see figure 17. Both pumps show the highest efficiency at the highest pump speed. The flowrate from the monitor might be misleading but might be adjusted by fitting a parabolic curve. For a specific power input, the flowrate from the monitor and measured flow rate can differ, this due to surrounding features such as different constriction. 

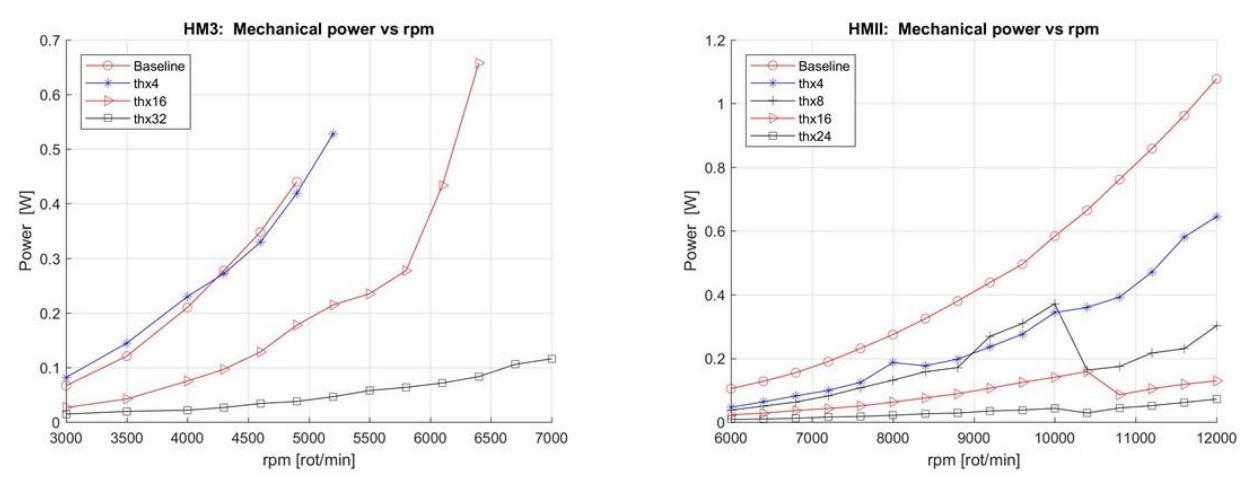

Figure 17. Mechanical power output vs pump speed in revolutions per minute (rpm) for HMII and HM3. Adding clot analogs to the circuit reduce the power output of both HM2 and HM3. HM3 seems to be less prone to be affected by clot analogs. Note that the scale is different for the two pumps.

\section{Discussion}

As the prevalence and incidence of $\mathrm{HF}$ increases, the number of patients that deteriorates to advanced HF with the need of advanced therapies is suggested to increase. This might also increase the number of patients in need for LVAD. The newest LVAD, HM3 has shown great results in the clinical studies, with both survival benefits as well as lower frequencies of adverse events. ${ }^{220}$ The number of pump thrombosis and malfunctions is low. This implies the need for further methods for detection of malfunction since the clinicians might not be aware of the risk as was the case for HMII.

\section{Mock Loop}

The mock loop circuits are a promising way to safely change the surrounding conditions as the pump is working. The mock loop can be constructed in multiple ways with different preload, afterload, and viscosity settings. This facilitates for studies on flow patterns, pump efficacy, and sound without the need of animals for implantation. On one hand, the use of water as medium results in a lower dissipation rate of turbulence. On the other hand, generation of flow instabilities and turbulence in the pumps is due to shear layer and centrifugal instabilities. Different viscosities of the fluid within the mock loop circuit and different acoustic positions have previously 
been studied by Yost. ${ }^{274}$ The power, flow, pulsatility and peak harmonic frequency were left unchanged as viscosity was increased. The results indicate that the use of water as a medium is sufficient to study the acoustics. The difference in preload and afterload does not seem to affect the amplitude for peak harmonic frequency, which also indicates that sound analysis might be a valid method with low disturbance from other factors that might affect pump function. ${ }^{274}$ The sound recordings from patients and mock loop are similar for both HMII and HM3, shown in paper II and III and by Yost. ${ }^{263,}{ }^{274}$ However, all studies, including ours, are mostly based on a small number of patients or clinical situations which impact the validity of the method. The first step to further assess the method could be to perform a larger scale simulation in mock loop circuit with daily recordings. The mock loop circuits allows for simulation at a larger scale with artificial thrombus at specific locations, for validation of the method, and examination of different recording devices as shown with HVAD by Feldman ${ }^{264}$

\section{Recording devices and analysis}

The use of handheld, easy to use recording devices is essential for developing the method so that in can be used in clinical settings. Different recording devices have been used in the different studies within the field. The iOS-devices, used within paper I, hold many features that are appealing, but the built-in high pass filter impacts the recordings. The HM3 and HVAD work in a lower speed than HMII, with a fundamental frequency, below $100 \mathrm{~Hz}$ which make the iOS-devices even more dubious as a recording device for these devices. In Yost et al. an electronic stethoscope, of the same brand as used in paper III, was used for sound recording. ${ }^{263,274}$ Validity of the electronic stethoscope was never discussed. As shown in paper III, the electronic stethoscope is more susceptible for disturbances and less efficient in determining the fundamental frequency. In Kaufman et al. a data acquisition device with a built-in microphone was used, the specification for the microphone is not however reported. ${ }^{261}$ In paper II and III we used microphones with a relatively linear frequency spectrum as a reference method. These recordings were clearer for both HMII and HM3 recordings, thus indicating the need for validation of the recording devices. If a specific, low-frequency peak, infrasound, as found for Centrimag, ECMO system is found to indicate thrombosis is yet to be determined ${ }^{265}$ For these low frequencies, a high end microphone or hydrophone is needed. In conclusion, further studies need to validate the easy to use, handheld devices before they are adopted as a clinical mean to evaluate pump function.

Within the studies, different ways and software have been used to analyze the sounds from the LVAD. A critical approach is the use of normalization so that the different peaks are not based on differences in volume. This has been performed in paper II and III, as well as Kaufman et al. ${ }^{261}$ In paper I, a freeware used for sound recording was used to perform signal analysis, this resulted in power distribution at specific, 
predefined frequency, not related to LVAD frequency. This might have affected the outcome, but it should not affect the area under the curve which was compared between the different recordings. This further implies that custom software, such as MATLAB is more sufficient for valid analysis.

For most studies, FFT has been used which is a solid method. If a harmonic or specific peak is shown to be associated with malfunction or thrombus in the future is yet to be determined. If that is the case, additional methods such as Continuous wavelet transform analysis, frequently used in studies on valvular disease can be a more relevant method. ${ }^{275} \mathrm{~A}$ way to compare the recording devices is if the recordings can be used to estimate pump frequency. Since the most power is in the fundamental frequency, i.e. pump speed, the amplitude of this peak should be the highest one. Yet, there is no consensus in how to asses malfunction or thrombosis of LVAD, but the use of customized software such as MATLAB further increases knowledge and facilitates characterization over the whole frequency spectrum enabling calculation of PSD. This results in that the power within a specific region can be compared between pumps with no adverse events and those with adverse events.

\section{Implication of the results}

Paper I arose from a clinical situation, which makes the studies and this thesis more applicable. It was one of the first studies on acoustic analysis of LVAD and an application of modern technology. The result was promising and showed similar results as Yost et al., but in need for technical evaluation of different devices. ${ }^{274}$ Today, the diagnosis of pump thrombosis or malfunction is based on multiple indirect measurements such as lab-results, pump parameters, $\mathrm{x}$-ray, and echocardiographic examinations. ${ }^{232}$ A pump exchange may have an impact on patient outcome as well as a substantial financial impact. ${ }^{234}$ Some of the parameters shown on the pump monitor might not be reliable, as shown in paper IV. This paper also shows the need to optimize patient factors, such as fluid status and afterload to maximize pump efficiency. These results are based on mock loop pressures and need to be validated in clinical settings or animal studies where hemodynamic alternations and vascular tonus can adapt to the different pressures. The lack of specific measurements on the monitor further increases the need of an additional method for diagnosing the presence of pump thrombosis or malfunction.

From a clinician point of view, an easy, handheld device with high sensitivity for detection would be optimal. Such a device could be an iPhone or electronic stethoscope since they both are commonly used. Despite the positive results of multiple studies on sound analysis, the clinical implication is yet low. Further studies might result in an application of artificial neuronal networks that can diagnose malfunction of the LVADs by just performing the recording. Another method might be 
by monitor pump function with a built-in sensor that reacts to changes in specific frequency regions. Another way to minimize the need for outpatient monitoring might be remote monitoring with sound recordings sent to hospital for analysis. Routinely follow-ups with telephone calls have been shown to lowering the number of adverse events, and could easily be accompanied by a sound analysis to assess pump function in relation to clinical status. ${ }^{225}$

\section{Conclusions}

The main conclusions of the thesis are as follows.

1. It is possible to record and analyze sound produced from different LVAD and the sound holds information of pump function, both in vivo and in vitro, and the frequency spectrum is similar.

2. Different devices can be used for recording, but the more dedicated equipment is superior to the more handheld devices that are easy to use. These devices might however still be used has as screening devices.

3. The sound contains of multiple peaks and harmonics that mostly are related to pump frequency.

4. The flow measurement on the monitor might not be valid. Optimization of fluid status and afterload of the patient can further increase pump efficiency.

\section{Future perspectives}

According to paper I-III, the use of acoustics as a mean to analyze pump function, and perhaps to determine thrombosis, might be an additional method to assess pump function. There are however multiple challenges. The critical point is to determine a specific change in the frequency spectrum that is due to the presence of thrombosis or malfunction. To facilitate this, the flow within the pump must be further studied to determine vortex phenomenon and its frequencies. Perhaps these frequencies are in the range of $1 \mathrm{~Hz}$.

A multicenter trial in which the aim is to study the outcome of HM3 as destination therapy within a Swedish cohort consisting of 70 patients in each study-arm is enrolling. The trial is called SweVAD and is currently ongoing with randomization to 
treatment with LVAD or optimal medical therapy. Within this trial, the sounds from the HM3 will be recorded at every outpatient follow up and at every adverse event. Data collection is ongoing at three sites, Lund, Gothenburg and Stockholm. This trial will hopefully further determine the efficacy of sound recording as a mean to find mechanical failures or pump thrombosis. If future trials of acoustic analysis show good results, the companies that provide the devices might be interested in the technology and further develop methodology.

If a specific parameter is indicative of pump thrombosis there are accelerometers that react to that specific frequency that can be used and neuronal network adopted within the device. If the total number of peaks within the spectrum seems to be more valid, the use of an accelerometer with a broader frequency spectrum can be used to alert the caregiver if an increase in peaks is found.

To further evolve the method, interdisciplinary approaches are needed, preferably with engineers with excellent knowledge in flow and signal analysis and medical doctors with knowledge of HF and LVAD treatment. One approach could be simulating thrombosis in a computer model to determine flow paths and to use these results in mock loop circuits for acoustic and vibrational analysis. 


\section{Svensk sammanfattning}

Hjärtsvikt är ett allvarligt tillstånd med konsekvenser för både patient och samhälle då 1,5-3\% av befolkningen beräknas lida av hjärtsvikt, en siffra som ökar i takt med ökad ålder. Bakomliggande orsak till hjärtsvikt kan vara många men högt blodtryck och kranskärlssjukdom är de vanligaste. Kostnaden för samhället är hög och studier har beräknat den årliga kostnaden i Sverige till 5-7 miljarder. Behandling av hjärtsvikt utgörs framför allt av medicinsk behandling i syfte att rädda liv och minska symptom genom att hämma de hormonsystem som bidrar till vätskeansamlingen och ärrbildning i hjärtat. Trots att den medicinska behandlingen är framgångsrik i praktiken och studier så är 5 års mortaliteten fortsatt 45-60\%. För patienter som uppfyller prespecificerade kriterier kan implanterbara defibrillatorer och pacemakers förbättra prognosen.

För yngre patienter med uttalad hjärtsvikt så är hjärttransplantation den enda botande behandlingen. Tyvärr är tillgängliga organ inte tillräckligt många och årligen avlider patienter i väntan på transplantation.

För vissa patienter kan behandling med långtids-assist av vänster kammare (LVAD) vara en behandling i väntan på hjärttransplantation eller som slutgiltig behandling. Behandlingen med LVAD har flertalet komplikationer såsom blödningar, infektioner och tromboser. Tromboser i LVAD har förekommit sedan starten av implantation men ökade signifikant mellan 2012-2014. Detta medförde ett ökat behov av att enkelt kunna diagnostisera dess förekomst. Flertalet parametrar, bland annat flöde och strömkonsumtion används för att diagnostisera trombos i pumpen. Idén att kunna diagnostisera blodpropp i de mekaniska hjärtpumparna med hjälp av ljud var grunden för detta avhandlingsarbete.

Syftet med denna avhandling var att utveckla och utvärdera användandet av ett konstruerat cirkulationssystem för att kunna studera ljudet från LVAD, utvärdera olika inspelningsutrustning och studera effekten av afterload på pumpens effektivitet.

Två olika cirkulationssystem skapades för att möjliggöra inspelning, införa artificiell trombos samt justera tryckförhållanden i systemet. En iPhone/ iPod ${ }^{\mathrm{TM}}$ användes som inspelningsutrustning då distansmonitorering är eftersträvad men även ett elektroniskt stetoskop utvärderades. Ljudet från HeartMate $\mathrm{II}^{\mathrm{TM}}$ studerades under olika förutsättningar och inspelningen jämfördes mot dedikerad utrustning. Även ljudet från HeartMate $3^{\mathrm{TM}}$ studerades och jämfördes med ljudet från pump implanterad i patienter. Effektiviteten och flödesförändringar vid förändringar i tryckförhållanden studerades för både HeartMate $\mathrm{II}^{\mathrm{TM}}$ och HeartMate $3^{\mathrm{TM}}$ 
Resultatet av de olika studierna visar att ett experimentellt cirkulationssystem kan användas för att simulera olika förhållanden som pumparna arbetar under och att ljudet från pumparna är liknande de som framträder vid inspelning från patienter. Detta gäller för både HeartMate $\mathrm{II}^{\mathrm{TM}}$ och HeartMate $3^{\mathrm{TM}}$. Resultaten visar att iPhone/iPod ${ }^{\mathrm{TM}}$ och elektroniskt stetoskop skiljer sig åt avseende kvalitet på inspelningarna men samtliga testade modeller kan användas. Det dedikerade systemet ger en tydligare ljudprofil medan de andra modellerna är mer lätthanterliga i den kliniska miljön I det konstruerade cirkulationssystemet kan förekomst av blodpropp simuleras samtidigt som ljudet från pumpen spelas in. Vid dessa försök sågs med iPhone/ Pod $^{\mathrm{TM}}$ förändring i amplitud av frekvensspektrumet för HeartMate $\mathrm{II}^{\mathrm{TM}}$. I det konstruerade cirkulationssystemet kan flöde samt tryck mätas och ändras vilket påverkar pumpens effektivitet. Flödet, uppvisat på monitorn, påverkas av afterload där HeartMate $3^{\mathrm{TM}}$ är mer resistent mot artificiella proppar i pumpen. Effektiviteten hos både HeartMate II ${ }^{\mathrm{TM}}$ och HeartMate $3^{\mathrm{TM}}$ är bäst om det inte föreligger något hinder i systemet. Flödet på monitorn kan vara vilseledande då det uppmätta flödet och flödet på monitorn skiljer sig åt beroende på omgivande faktorer.

Sammanfattningsvis lägger studierna i denna avhandling en grund för vidare utveckling av ljudanalys av mekaniska hjärtpumpar men det krävs ytterligare forskning för att detektera en specifik förändring som indikerar blodpropp. 


\section{Acknowledgements}

This thesis originated when I performed my scientific project concerning primary prophylactic implantable cardioverter defibrillators during medical school. When my project was almost done, my supervisor asked if I would be interested in participating in a "crazy" project in which the sounds from mechanical circulatory supports should be obtained and analyzed. We started the simulations, leading to the first paper, and after these simulations my interest in advanced heart failure rapidly increased. That was the point of no return and I accepted to become a PhD-student. That this project finally would become a thesis has felt distant but finally I'm here and I would like to thank:

My supervisor, Henrik Ahn. Thank you for sharing your experience in mechanical circulatory support, research knowledge and always believed in our ideas and pointed out the clinical applications.

My co-supervisor, Laila Hübbert for her commitment during this thesis. Without your ideas, support and frequent email conversations this thesis would never have been finished. I am full of gratitude for your support and I will always try to work under your words of wisdom; "Always put the patient first...". Without you I would not be doctor I am today.

My co supervisor, Fredrik Gustafsson. Thank you for taking care of me when I and Laila were lost in the science of engineering. Without you, this project never would been finished.

My co-supervisor Daniel Karlsson. Thank you for your support, comments and feedback on my work.

Collaborators in the scientific projects; Gabriel Fuchs, Lisa Prahl-Wittberg, Lars Broman, Hans Granfeldt, Michael Roth, Bengt Peterzén and Göran Dellgren. Thank you for your collaboration within the studies, support, and feedback on my work.

Region Östergötland. Thank you for research-time during my internship.

All my colleagues and friends at Medicin och Geriatrikkliniken, Eksjö, Region Jönköping. Thank you for giving me the possibility to continue and finish this project. Thank you for motivating comments when this thesis felt distant.

My stepmother. Thank you for supporting me throughout this project. 
My beloved parents. Thank you for supporting me throughout this project without understanding my interest in heart failure.

My sisters, Anna and Åsa. Thank you for your support. I am especially grateful towards my sister Anna for helping me with proof-reading.

My beautiful wife Caroline. Thank you for your support during this work. Thank you for taking care of our wonderful children when I've been away on conferences or working at night-time. Without you this project would not be feasible. I love you!

My children, Melker and Ellen, you are the light of my life. I love you endlessly.

"Feci guod potui, faciant meliora potentes"

- Jag har gjort vad jag kunnat, må nu de, som kan, göra bättre 


\section{References}

1. Ponikowski P, Voors AA, Anker SD, et al. 2016 ESC Guidelines for the diagnosis and treatment of acute and chronic heart failure: The Task Force for the diagnosis and treatment of acute and chronic heart failure of the European Society of Cardiology (ESC). Developed with the special contribution of the Heart Failure Association (HFA) of the ESC. European journal of heart failure 2016; 18: 891-975. 2016/05/22. DOI: 10.1002/ejhf.592.

2. Bui AL, Horwich TB and Fonarow GC. Epidemiology and risk profile of heart failure. Nature reviews Cardiology 2011; 8: 30-41. 2010/11/10. DOI: 10.1038/nrcardio.2010.165.

3. Zarrinkoub R, Wettermark B, Wandell P, et al. The epidemiology of heart failure, based on data for 2.1 million inhabitants in Sweden. European journal of heart failure 2013; 15: 995-1002. 2013/05/07. DOI: 10.1093/eurjhf/hft064. 4. McMurray JJ and Stewart S. Epidemiology, aetiology, and prognosis of heart failure. Heart 2000; 83: 596-602. 2000/04/18.

5. Agvall B, Borgquist L, Foldevi M, et al. Cost of heart failure in Swedish primary healthcare. Scandinavian journal of primary health care 2005; 23: 227-232. 2005/11/08. DOI: 10.1080/02813430500197647.

6. F. R-BTA. The health care costs of heart failure in Sweden. Journal of internal medicine 1999; 246: 275-284.

7. Neves JS, Leite-Moreira AM, Neiva-Sousa M, et al. Acute Myocardial Response to Stretch: What We (don't) Know. Frontiers in physiology 2015; 6: 408. 2016/01/19. DOI: 10.3389/fphys.2015.00408.

8. Patterson SW and Starling EH. On the mechanical factors which determine the output of the ventricles. The Journal of physiology 1914; 48: 357-379. 1914/09/08.

9. 0 F. On the dynamics of cardiac muscle. American heart journal 1959; 58: 282317. DOI: http://dx.doi.org/10.1016/0002-8703(59)90345-X.

10. Inamdar AA and Inamdar AC. Heart Failure: Diagnosis, Management and Utilization. Journal of clinical medicine 2016; 5 2016/07/02. DOI: $10.3390 /$ jcm5070062.

11. Yancy CW, Jessup M, Bozkurt B, et al. 2013 ACCF/AHA guideline for the management of heart failure: a report of the American College of Cardiology Foundation/American Heart Association Task Force on Practice Guidelines. Journal of the American College of Cardiology 2013; 62: e147-239. 2013/06/12. DOI: 10.1016/j.jacc.2013.05.019.

12. Stevenson LW, Pagani FD, Young JB, et al. INTERMACS profiles of advanced heart failure: the current picture. The Journal of heart and lung transplantation : the official publication of the International Society for Heart Transplantation 2009; 28: 535-541. 2009/06/02. DOI: 10.1016/j.healun.2009.02.015. 
13. Crespo-Leiro MG, Metra M, Lund LH, et al. Advanced heart failure: a position statement of the Heart Failure Association of the European Society of Cardiology. European journal of heart failure 2018 2018/05/29. DOI: 10.1002/ejhf.1236. 14. Mejia-Renteria HD and Nunez-Gil IJ. Takotsubo syndrome: Advances in the understanding and management of an enigmatic stress cardiomyopathy. World journal of cardiology 2016; 8: 413-424. 2016/07/29. DOI: 10.4330/wjc.v8.i7.413. 15. Krejci J, Mlejnek D, Sochorova D, et al. Inflammatory Cardiomyopathy: A Current View on the Pathophysiology, Diagnosis, and Treatment. BioMed research international 2016; 2016: 4087632. 2016/07/07. DOI: 10.1155/2016/4087632. 16. Sliwa K, Hilfiker-Kleiner D, Petrie MC, et al. Current state of knowledge on aetiology, diagnosis, management, and therapy of peripartum cardiomyopathy: a position statement from the Heart Failure Association of the European Society of Cardiology Working Group on peripartum cardiomyopathy. European journal of heart failure 2010; 12: 767-778. 2010/08/03. DOI: 10.1093/eurjhf/hfq120. 17. Laflamme MA and Murry CE. Regenerating the heart. Nature biotechnology 2005; 23: 845-856. 2005/07/09. DOI: 10.1038/nbt1117.

18. Talman V and Ruskoaho H. Cardiac fibrosis in myocardial infarction-from repair and remodeling to regeneration. Cell and tissue research 2016 2016/06/22. DOI: $10.1007 / \mathrm{s} 00441-016-2431-9$.

19. Sutton MG and Sharpe N. Left ventricular remodeling after myocardial infarction: pathophysiology and therapy. Circulation 2000; 101: 2981-2988. $2000 / 06 / 28$.

20. van den Borne SW, Diez J, Blankesteijn WM, et al. Myocardial remodeling after infarction: the role of myofibroblasts. Nature reviews Cardiology 2010; 7: 30-37. 2009/12/02. DOI: 10.1038/nrcardio.2009.199.

21. Francis Stuart SD, De Jesus NM, Lindsey ML, et al. The crossroads of inflammation, fibrosis, and arrhythmia following myocardial infarction. Journal of molecular and cellular cardiology 2016; 91: 114-122. 2016/01/08. DOI: 10.1016/j.yjmcc.2015.12.024.

22. Pinto YM, Elliott PM, Arbustini E, et al. Proposal for a revised definition of dilated cardiomyopathy, hypokinetic non-dilated cardiomyopathy, and its implications for clinical practice: a position statement of the ESC working group on myocardial and pericardial diseases. European heart journal 2016; 37: 18501858. 2016/01/23. DOI: 10.1093/eurheartj/ehv727.

23. Mirijello A, Tarli C, Vassallo GA, et al. Alcoholic cardiomyopathy: What is known and what is not known. European journal of internal medicine 2017; 43: 15. 2017/06/26. DOI: 10.1016/j.ejim.2017.06.014.

24. Michels VV, Moll PP, Miller FA, et al. The frequency of familial dilated cardiomyopathy in a series of patients with idiopathic dilated cardiomyopathy. The New England journal of medicine 1992; 326: 77-82. 1992/01/09. DOI: 10.1056/nejm199201093260201.

25. Weintraub RG, Semsarian C and Macdonald P. Dilated cardiomyopathy. Lancet 2017; 390: 400-414. 2017/02/14. DOI: 10.1016/s0140-6736(16)31713-5. 
26. Herman DS, Lam L, Taylor MR, et al. Truncations of titin causing dilated cardiomyopathy. The New England journal of medicine 2012; 366: 619-628. 2012/02/18. DOI: 10.1056/NEJMoa1110186.

27. Opie LH, Commerford PJ, Gersh BJ, et al. Controversies in ventricular remodelling. Lancet 2006; 367: 356-367. 2006/01/31. DOI: 10.1016/s01406736(06)68074-4.

28. Frohlich ED. An updated concept for left ventricular hypertrophy risk in hypertension. The Ochsner journal 2009; 9: 181-190. 2009/01/01.

29. Berenji K, Drazner MH, Rothermel BA, et al. Does load-induced ventricular hypertrophy progress to systolic heart failure? American journal of physiology Heart and circulatory physiology 2005; 289: H8-h16. 2005/06/18. DOI:

10.1152/ajpheart.01303.2004.

30 . Tomanek RJ and Torry RJ. Growth of the coronary vasculature in hypertrophy: mechanisms and model dependence. Cellular \& molecular biology research 1994; 40: 129-136. 1994/01/01.

31. Kannan A and Janardhanan R. Hypertension as a risk factor for heart failure. Current hypertension reports 2014; 16: 447. 2014/05/06. DOI: 10.1007/s11906014-0447-7.

32. Weber KT, Sun Y, Bhattacharya SK, et al. Myofibroblast-mediated mechanisms of pathological remodelling of the heart. Nature reviews Cardiology 2013; 10: 1526. 2012/12/05. DOI: $10.1038 /$ nrcardio.2012.158.

33. Arumugam S, Sreedhar R, Thandavarayan RA, et al. Angiotensin receptor blockers: Focus on cardiac and renal injury. Trends in cardiovascular medicine 2016; 26: 221-228. 2015/07/15. DOI: 10.1016/j.tcm.2015.06.004.

34. Jonsson S, Agic MB, Narfstrom F, et al. Renal neurohormonal regulation in heart failure decompensation. American journal of physiology Regulatory, integrative and comparative physiology 2014; 307: R493-497. 2014/06/13. DOI: 10.1152/ajpregu.00178.2014.

35. Chen HH. Heart failure: a state of brain natriuretic peptide deficiency or resistance or both! Journal of the American College of Cardiology 2007; 49: 10891091. 2007/03/14. DOI: 10.1016/j.jacc.2006.12.013.

36. Daniels LB and Maisel AS. Natriuretic peptides. Journal of the American College of Cardiology 2007; 50: 2357-2368. 2007/12/25. DOI: 10.1016/j.jacc.2007.09.021.

37. Maisel A, Hollander JE, Guss D, et al. Primary results of the Rapid Emergency Department Heart Failure Outpatient Trial (REDHOT). A multicenter study of Btype natriuretic peptide levels, emergency department decision making, and outcomes in patients presenting with shortness of breath. Journal of the American College of Cardiology 2004; 44: 1328-1333. 2004/09/15. DOI:

10.1016/j.jacc.2004.06.015.

38. Anand IS, Fisher LD, Chiang YT, et al. Changes in brain natriuretic peptide and norepinephrine over time and mortality and morbidity in the Valsartan Heart Failure Trial (Val-HeFT). Circulation 2003; 107: 1278-1283. 2003/03/12. 
39. Cho GW, Altamirano F and Hill JA. Chronic heart failure: $\mathrm{Ca}(2+)$, catabolism, and catastrophic cell death. Biochimica et biophysica acta 2016; 1862: 763-777. 2016/01/18. DOI: 10.1016/j.bbadis.2016.01.011.

40. Garg N, Senthilkumar A, Nusair MB, et al. Heart failure with a normal left ventricular ejection fraction: epidemiology, pathophysiology, diagnosis and management. The American journal of the medical sciences 2013; 346: 129-136. 2013/03/19. DOI: 10.1097/MAJ.0b013e31828c586e.

41. Tannenbaum S and Sayer GT. Advances in the pathophysiology and treatment of heart failure with preserved ejection fraction. Current opinion in cardiology 2015; 30: 250-258. 2015/03/26. DOI: 10.1097/hco.0000000000000163.

42. Owan TE, Hodge DO, Herges RM, et al. Trends in prevalence and outcome of heart failure with preserved ejection fraction. The New England journal of medicine 2006; 355: 251-259. 2006/07/21. DOI: 10.1056/NEJMoa052256. 43. Nanayakkara $S$ and Kaye DM. Management of heart failure with preserved ejection fraction: a review. Clinical therapeutics 2015; 37: 2186-2198. 2015/09/20. DOI: 10.1016/j.clinthera.2015.08.005.

44. van Empel V and Brunner-La Rocca HP. Inflammation in HFpEF: Key or circumstantial? International journal of cardiology 2015; 189: 259-263. 2015/04/22. DOI: 10.1016/j.ijcard.2015.04.110.

45. Cenkerova K, Dubrava J, Pokorna V, et al. Right ventricular systolic dysfunction and its prognostic value in heart failure with preserved ejection fraction. Acta cardiologica 2015; 70: 387-393. 2015/10/13.

46. Hamdani N, Franssen C, Lourenco A, et al. Myocardial titin hypophosphorylation importantly contributes to heart failure with preserved ejection fraction in a rat metabolic risk model. Circulation Heart failure 2013; 6: 1239-1249. 2013/09/10. DOI: 10.1161/circheartfailure.113.000539.

47. Tan YT, Wenzelburger F, Lee E, et al. The pathophysiology of heart failure with normal ejection fraction: exercise echocardiography reveals complex abnormalities of both systolic and diastolic ventricular function involving torsion, untwist, and longitudinal motion. Journal of the American College of Cardiology 2009; 54: 36-46. 2009/06/27. DOI: 10.1016/j.jacc.2009.03.037.

48. Telles F and Marwick TH. Imaging and Management of Heart Failure and Preserved Ejection Fraction. Current treatment options in cardiovascular medicine 2018; 20: 90. 2018/09/28. DOI: 10.1007/s11936-018-0689-9.

49. Gerull B. The Rapidly Evolving Role of Titin in Cardiac Physiology and Cardiomyopathy. The Canadian journal of cardiology 2015; 31: 1351-1359. 2015/11/01. DOI: 10.1016/j.cjca.2015.08.016.

50. Fukuda $\mathrm{N}$ and Granzier H. Role of the giant elastic protein titin in the FrankStarling mechanism of the heart. Current vascular pharmacology 2004; 2: 135139. 2004/08/24.

51. Mant J, Doust J, Roalfe A, et al. Systematic review and individual patient data meta-analysis of diagnosis of heart failure, with modelling of implications of different diagnostic strategies in primary care. Health technology assessment (Winchester, England) 2009; 13: 1-207, iii. 2009/07/10. DOI: 10.3310/hta13320. 
52. Hawkins NM, Petrie MC, Jhund PS, et al. Heart failure and chronic obstructive pulmonary disease: diagnostic pitfalls and epidemiology. European journal of heart failure 2009; 11: 130-139. 2009/01/27. DOI: 10.1093/eurjhf/hfn013. 53. Daniels LB, Clopton P, Bhalla V, et al. How obesity affects the cut-points for Btype natriuretic peptide in the diagnosis of acute heart failure. Results from the Breathing Not Properly Multinational Study. American heart journal 2006; 151: 999-1005. 2006/04/29. DOI: 10.1016/j.ahj.2005.10.011.

54. Thygesen K, Mair J, Mueller C, et al. Recommendations for the use of natriuretic peptides in acute cardiac care: a position statement from the Study Group on Biomarkers in Cardiology of the ESC Working Group on Acute Cardiac Care. European heart journal 2012; 33: 2001-2006. 2011/02/05. DOI: 10.1093/eurheartj/ehq509.

55. Eckstein J, Potocki M, Murray K, et al. Direct comparison of mid-regional proatrial natriuretic peptide with $\mathrm{N}$-terminal pro B-type natriuretic peptide in the diagnosis of patients with atrial fibrillation and dyspnoea. Heart 2012; 98: 15181522. 2012/08/07. DOI: 10.1136/heartjnl-2012-302260.

56. Roberts E, Ludman AJ, Dworzynski K, et al. The diagnostic accuracy of the natriuretic peptides in heart failure: systematic review and diagnostic metaanalysis in the acute care setting. Bmj 2015; 350: h910. 2015/03/06. DOI: 10.1136/bmj.h910.

57. Garbi M, McDonagh T, Cosyns B, et al. Appropriateness criteria for cardiovascular imaging use in heart failure: report of literature review. European heart journal cardiovascular Imaging 2015; 16: 147-153. 2015/01/01. DOI: 10.1093/ehjci/jeu299.

58. Maggioni AP, Anker SD, Dahlstrom U, et al. Are hospitalized or ambulatory patients with heart failure treated in accordance with European Society of Cardiology guidelines? Evidence from 12,440 patients of the ESC Heart Failure Long-Term Registry. European journal of heart failure 2013; 15: 1173-1184. 2013/08/28. DOI: 10.1093/eurjhf/hft134.

59. Ohlsson A, Lindahl B, Hanning M, et al. Inequity of access to ACE inhibitors in Swedish heart failure patients: a register-based study. Journal of epidemiology and community health 2016; 70: 97-103. 2015/08/12. DOI: 10.1136/jech-2015205738.

60. Danchin N, Cucherat M, Thuillez C, et al. Angiotensin-converting enzyme inhibitors in patients with coronary artery disease and absence of heart failure or left ventricular systolic dysfunction: an overview of long-term randomized controlled trials. Arch Intern Med 2006; 166: 787-796. 2006/04/12. DOI: 10.1001/archinte.166.7.787.

61. Flather MD, Yusuf S, Kober L, et al. Long-term ACE-inhibitor therapy in patients with heart failure or left-ventricular dysfunction: a systematic overview of data from individual patients. ACE-Inhibitor Myocardial Infarction Collaborative Group. Lancet 2000; 355: 1575-1581. 2000/05/23.

62. Garg R and Yusuf S. Overview of randomized trials of angiotensin-converting enzyme inhibitors on mortality and morbidity in patients with heart failure. 
Collaborative Group on ACE Inhibitor Trials. Jama 1995; 273: 1450-1456. 1995/05/10.

63. Jessup M, Abraham WT, Casey DE, et al. 2009 focused update: ACCF/AHA Guidelines for the Diagnosis and Management of Heart Failure in Adults: a report of the American College of Cardiology Foundation/American Heart Association Task Force on Practice Guidelines: developed in collaboration with the International Society for Heart and Lung Transplantation. Circulation 2009; 119: 1977-2016. 2009/03/28. DOI: 10.1161/circulationaha.109.192064. 64. Erhardt LR. A review of the current evidence for the use of angiotensinreceptor blockers in chronic heart failure. International journal of clinical practice 2005; 59: 571-578. 2005/04/29. DOI: 10.1111/j.1368-5031.2005.00513.x. 65. Loudon BL, Noordali H, Gollop ND, et al. Present and future pharmacotherapeutic agents in heart failure: an evolving paradigm. British journal of pharmacology 2016; 173: 1911-1924. 2016/03/20. DOI: 10.1111/bph.13480.

66. Effects of enalapril on mortality in severe congestive heart failure. Results of the Cooperative North Scandinavian Enalapril Survival Study (CONSENSUS). The CONSENSUS Trial Study Group. The New England journal of medicine 1987; 316: 1429-1435. 1987/06/04. DOI: 10.1056/nejm198706043162301.

67. Effect of enalapril on survival in patients with reduced left ventricular ejection fractions and congestive heart failure. The SOLVD Investigators. The New England journal of medicine 1991; 325: 293-302. 1991/08/01. DOI:

$10.1056 /$ nejm199108013250501.

68. Swedberg K and Kjekshus J. Effects of enalapril on mortality in severe congestive heart failure: results of the Cooperative North Scandinavian Enalapril Survival Study (CONSENSUS). The American journal of cardiology 1988; 62: 60A66A. 1988/07/11.

69. Yusuf S, Pitt B, Davis CE, et al. Effect of enalapril on survival in patients with reduced left ventricular ejection fractions and congestive heart failure. The New England journal of medicine 1991; 325: 293-302. 1991/08/01. DOI:

$10.1056 /$ nejm199108013250501.

70. Cleland JG, Tendera M, Adamus J, et al. The perindopril in elderly people with chronic heart failure (PEP-CHF) study. European heart journal 2006; 27: 23382345. 2006/09/12. DOI: 10.1093/eurheartj/ehl250.

71. Martin N, Manoharan K, Thomas J, et al. Beta-blockers and inhibitors of the renin-angiotensin aldosterone system for chronic heart failure with preserved ejection fraction. The Cochrane database of systematic reviews 2018; 6: CD012721. 2018/06/29. DOI: 10.1002/14651858.CD012721.pub2.

72. Ong HT, Ong LM and Ho JJ. Angiotensin-Converting Enzyme Inhibitors (ACEIs) and Angiotensin-Receptor Blockers (ARBs) in Patients at High Risk of Cardiovascular Events: A Meta-Analysis of 10 Randomised Placebo-Controlled Trials. ISRN cardiology 2013; 2013: 478597. 2013/12/07. DOI: $10.1155 / 2013 / 478597$. 
73. Granger CB, McMurray JJ, Yusuf S, et al. Effects of candesartan in patients with chronic heart failure and reduced left-ventricular systolic function intolerant to angiotensin-converting-enzyme inhibitors: the CHARM-Alternative trial. Lancet 2003; 362: 772-776. 2003/09/19. DOI: 10.1016/s0140-6736(03)14284-5. 74. Pitt B, Poole-Wilson PA, Segal R, et al. Effect of losartan compared with captopril on mortality in patients with symptomatic heart failure: randomised trial--the Losartan Heart Failure Survival Study ELITE II. Lancet 2000; 355: 1582 1587. 2000/05/23.

75. Willenheimer R. Angiotensin receptor blockers in heart failure after the ELITE II trial. Curr Control Trials Cardiovasc Med 2000; 1: 79-82. 2001/11/21. D0I: 10.1186/cvm-1-2-079.

76. Cohn JN and Tognoni G. A randomized trial of the angiotensin-receptor blocker valsartan in chronic heart failure. The New England journal of medicine 2001; 345: 1667-1675. 2002/01/05. DOI: 10.1056/NEJMoa010713.

77. Yusuf S, Pfeffer MA, Swedberg K, et al. Effects of candesartan in patients with chronic heart failure and preserved left-ventricular ejection fraction: the CHARMPreserved Trial. Lancet 2003; 362: 777-781. 2003/09/19. DOI: 10.1016/s01406736(03)14285-7.

78. Massie BM, Carson PE, McMurray JJ, et al. Irbesartan in patients with heart failure and preserved ejection fraction. The New England journal of medicine 2008; 359: 2456-2467. 2008/11/13. DOI: 10.1056/NEJMoa0805450.

79. Packer M. Pathophysiological mechanisms underlying the effects of betaadrenergic agonists and antagonists on functional capacity and survival in chronic heart failure. Circulation 1990; 82: I77-88. 1990/08/01.

80. Klapholz M. Beta-blocker use for the stages of heart failure. Mayo Clinic proceedings 2009; 84: 718-729. 2009/08/04. DOI: 10.4065/84.8.718.

81. Vedin A, Wikstrand J, Wilhelmsson C, et al. Left ventricular function and betablockade in chronic ischaemic heart failure. Double-blind, cross-over study of propranolol and penbutolol using non-invasive techniques. British heart journal 1980; 44: 101-107. 1980/07/01.

82. Packer M, Bristow MR, Cohn JN, et al. The effect of carvedilol on morbidity and mortality in patients with chronic heart failure. U.S. Carvedilol Heart Failure Study Group. The New England journal of medicine 1996; 334: 1349-1355. 1996/05/23. DOI: 10.1056/nejm199605233342101.

83. Effect of metoprolol CR/XL in chronic heart failure: Metoprolol CR/XL Randomised Intervention Trial in Congestive Heart Failure (MERIT-HF). Lancet 1999; 353: 2001-2007. 1999/06/22.

84. The Cardiac Insufficiency Bisoprolol Study II (CIBIS-II): a randomised trial. Lancet 1999; 353: 9-13. 1999/02/19.

85. Struthers AD. The clinical implications of aldosterone escape in congestive heart failure. European journal of heart failure 2004; 6: 539-545. 2004/08/11. DOI: 10.1016/j.ejheart.2004.04.013.

86. Pitt B, Pedro Ferreira J and Zannad F. Mineralocorticoid receptor antagonists in patients with heart failure: current experience and future perspectives. 
European heart journal Cardiovascular pharmacotherapy 2016 2016/08/18. DOI: 10.1093/ehjcvp/pvw016.

87. Pitt B, Zannad F, Remme WJ, et al. The effect of spironolactone on morbidity and mortality in patients with severe heart failure. Randomized Aldactone Evaluation Study Investigators. The New England journal of medicine 1999; 341: 709-717. 1999/09/02. DOI: 10.1056/nejm199909023411001.

88. Zannad F, McMurray JJ, Krum H, et al. Eplerenone in patients with systolic heart failure and mild symptoms. The New England journal of medicine 2011; 364: 11-21. 2010/11/16. DOI: 10.1056/NEJMoa1009492.

89. Pitt B, Pfeffer MA, Assmann SF, et al. Spironolactone for heart failure with preserved ejection fraction. The New England journal of medicine 2014; 370: 1383-1392. 2014/04/11. DOI: 10.1056/NEJMoa1313731.

90. Pfeffer MA, Claggett B, Assmann SF, et al. Regional variation in patients and outcomes in the Treatment of Preserved Cardiac Function Heart Failure With an Aldosterone Antagonist (TOPCAT) trial. Circulation 2015; 131: 34-42.

2014/11/20. DOI: 10.1161/circulationaha.114.013255.

91. Jhund PS and McMurray JJ. The neprilysin pathway in heart failure: a review and guide on the use of sacubitril/valsartan. Heart 2016; 102: 1342-1347. 2016/05/22. DOI: 10.1136/heartjnl-2014-306775.

92. McMurray JJ, Packer M, Desai AS, et al. Angiotensin-neprilysin inhibition versus enalapril in heart failure. The New England journal of medicine 2014; 371: 993-1004. 2014/09/02. DOI: 10.1056/NEJMoa1409077.

93. Desai AS, McMurray JJ, Packer M, et al. Effect of the angiotensin-receptorneprilysin inhibitor LCZ696 compared with enalapril on mode of death in heart failure patients. European heart journal 2015; 36: 1990-1997. 2015/05/30. DOI: 10.1093/eurheartj/ehv186.

94. Velazquez EJ, Morrow DA, DeVore AD, et al. Angiotensin-Neprilysin Inhibition in Acute Decompensated Heart Failure. The New England journal of medicine 2019; 380: 539-548. 2018/11/13. DOI: 10.1056/NEJMoa1812851.

95. Solomon SD, Claggett B, Desai AS, et al. Influence of Ejection Fraction on Outcomes and Efficacy of Sacubitril/Valsartan (LCZ696) in Heart Failure with Reduced Ejection Fraction: The Prospective Comparison of ARNI with ACEI to Determine Impact on Global Mortality and Morbidity in Heart Failure (PARADIGM-HF) Trial. Circulation Heart failure 2016; 9: e002744. 2016/02/27. DOI: 10.1161/circheartfailure.115.002744.

96. Solomon SD, McMurray JJV, Anand IS, et al. Angiotensin-Neprilysin Inhibition in Heart Failure with Preserved Ejection Fraction. The New England journal of medicine 2019 2019/09/03. DOI: 10.1056/NEJMoa1908655.

97. Damman K, Kjekshus J, Wikstrand J, et al. Loop diuretics, renal function and clinical outcome in patients with heart failure and reduced ejection fraction. European journal of heart failure 2016; 18: 328-336. 2015/12/24. DOI:

10.1002/ejhf.462.

98. Jones CD, Holmes GM, Dewalt DA, et al. Is adherence to weight monitoring or weight-based diuretic self-adjustment associated with fewer heart failure-related 
emergency department visits or hospitalizations? Journal of cardiac failure 2012; 18: 576-584. 2012/07/04. DOI: 10.1016/j.cardfail.2012.05.004.

99. Basaraba JE and Barry AR. Pharmacotherapy of heart failure with preserved ejection fraction. Pharmacotherapy 2015; 35: 351-360. 2015/04/18. DOI: 10.1002/phar.1556.

100. Nguyen E, Weeda ER and White CM. A Review of New Pharmacologic Treatments for Patients With Chronic Heart Failure With Reduced Ejection Fraction. Journal of clinical pharmacology 2016; 56: 936-947. 2015/12/03. DOI: 10.1002/jcph.677.

101. Bohm M, Swedberg K, Komajda M, et al. Heart rate as a risk factor in chronic heart failure (SHIFT): the association between heart rate and outcomes in a randomised placebo-controlled trial. Lancet 2010; 376: 886-894. 2010/08/31. DOI: $10.1016 / \mathrm{s} 0140-6736(10) 61259-7$.

102. Swedberg K, Komajda M, Bohm M, et al. Effects on outcomes of heart rate reduction by ivabradine in patients with congestive heart failure: is there an influence of beta-blocker dose?: findings from the SHIFT (Systolic Heart failure treatment with the I(f) inhibitor ivabradine Trial) study. Journal of the American College of Cardiology 2012; 59: 1938-1945. 2012/05/24. DOI:

10.1016/j.jacc.2012.01.020.

103. Tardif JC, O'Meara E, Komajda M, et al. Effects of selective heart rate reduction with ivabradine on left ventricular remodelling and function: results from the SHIFT echocardiography substudy. European heart journal 2011; 32: 2507-2515. 2011/08/31. DOI: 10.1093/eurheartj/ehr311.

104. Zannad F, Anker SD, Byra WM, et al. Rivaroxaban in Patients with Heart Failure, Sinus Rhythm, and Coronary Disease. The New England journal of medicine 2018; 379: 1332-1342. 2018/08/28. DOI: 10.1056/NEJMoa1808848. 105. Homma S, Thompson JL, Pullicino PM, et al. Warfarin and aspirin in patients with heart failure and sinus rhythm. The New England journal of medicine 2012; 366: 1859-1869. 2012/05/04. DOI: 10.1056/NEJMoa1202299.

106. Lip GY, Ponikowski P, Andreotti F, et al. Thrombo-embolism and antithrombotic therapy for heart failure in sinus rhythm. A joint consensus document from the ESC Heart Failure Association and the ESC Working Group on Thrombosis. European journal of heart failure 2012; 14: 681-695. 2012/05/23. DOI: 10.1093 /eurjhf/hfs073.

107. Farag M, Mabote T, Shoaib A, et al. Hydralazine and nitrates alone or combined for the management of chronic heart failure: A systematic review. International journal of cardiology 2015; 196: 61-69. 2015/06/16. DOI: 10.1016/j.ijcard.2015.05.160.

108. Whayne TF, Jr. Clinical Use of Digitalis: A State of the Art Review. American journal of cardiovascular drugs : drugs, devices, and other interventions 2018 2018/08/02. DOI: 10.1007/s40256-018-0292-1.

109. Gheorghiade M, Bohm M, Greene SJ, et al. Effect of aliskiren on postdischarge mortality and heart failure readmissions among patients hospitalized for heart 
failure: the ASTRONAUT randomized trial. Jama 2013; 309: 1125-1135. 2013/03/13. DOI: 10.1001/jama.2013.1954.

110. McMurray JJ, Krum H, Abraham WT, et al. Aliskiren, Enalapril, or Aliskiren and Enalapril in Heart Failure. The New England journal of medicine 2016; 374: 1521-1532. 2016/04/05. DOI: 10.1056/NEJMoa1514859.

111. McMurray JJ, Pitt B, Latini R, et al. Effects of the oral direct renin inhibitor aliskiren in patients with symptomatic heart failure. Circulation Heart failure 2008; 1: 17-24. 2008/05/01. DOI: 10.1161/circheartfailure.107.740704.

112. Packer M, Coats AJ, Fowler MB, et al. Effect of carvedilol on survival in severe chronic heart failure. The New England journal of medicine 2001; 344: 1651-1658. 2001/06/02. DOI: 10.1056/nejm200105313442201.

113. Willenheimer R, van Veldhuisen DJ, Silke B, et al. Effect on survival and hospitalization of initiating treatment for chronic heart failure with bisoprolol followed by enalapril, as compared with the opposite sequence: results of the randomized Cardiac Insufficiency Bisoprolol Study (CIBIS) III. Circulation 2005; 112: 2426-2435. 2005/09/07. DOI: 10.1161/circulationaha.105.582320. 114. McMurray JJ, Ostergren J, Swedberg K, et al. Effects of candesartan in patients with chronic heart failure and reduced left-ventricular systolic function taking angiotensin-converting-enzyme inhibitors: the CHARM-Added trial. Lancet 2003; 362: 767-771. 2003/09/19. DOI: 10.1016/s0140-6736(03)14283-3. 115. Sakata Y, Shiba N, Takahashi J, et al. Clinical impacts of additive use of olmesartan in hypertensive patients with chronic heart failure: the supplemental benefit of an angiotensin receptor blocker in hypertensive patients with stable heart failure using olmesartan (SUPPORT) trial. European heart journal 2015; 36: 915-923. 2015/02/02. DOI: 10.1093/eurheartj/ehu504.

116. Miura M, Sakata Y, Miyata S, et al. Influence of Left Ventricular Ejection Fraction on the Effects of Supplemental Use of Angiotensin Receptor Blocker Olmesartan in Hypertensive Patients With Heart Failure. Circulation journal : official journal of the Japanese Circulation Society 2016; 80: 2155-2164. 2016/09/16. DOI: 10.1253/circj.CJ-16-0577.

117. Moss AJ, Zareba W, Hall WJ, et al. Prophylactic implantation of a defibrillator in patients with myocardial infarction and reduced ejection fraction. The New England journal of medicine 2002; 346: 877-883. 2002/03/22. DOI: 10.1056/NEJMoa013474.

118. Bardy GH, Lee KL, Mark DB, et al. Amiodarone or an implantable cardioverter-defibrillator for congestive heart failure. The New England journal of medicine 2005; 352: 225-237. 2005/01/22. DOI: 10.1056/NEJMoa043399.

119. Hohnloser SH, Kuck KH, Dorian P, et al. Prophylactic use of an implantable cardioverter-defibrillator after acute myocardial infarction. The New England journal of medicine 2004; 351: 2481-2488. 2004/12/14. DOI:

10.1056/NEJMoa041489.

120. Steinbeck G, Andresen D, Seidl K, et al. Defibrillator implantation early after myocardial infarction. The New England journal of medicine 2009; 361: 14271436. 2009/10/09. DOI: 10.1056/NEJMoa0901889. 
121. Desai AS, Fang JC, Maisel WH, et al. Implantable defibrillators for the prevention of mortality in patients with nonischemic cardiomyopathy: a metaanalysis of randomized controlled trials. Jama 2004; 292: 2874-2879. 2004/12/16. DOI: 10.1001/jama.292.23.2874.

122. Kober L, Thune JJ, Nielsen JC, et al. Defibrillator Implantation in Patients with Nonischemic Systolic Heart Failure. The New England journal of medicine 2016; 375: 1221-1230. 2016/08/30. DOI: 10.1056/NEJMoa1608029.

123. Wolff G, Lin Y, Karathanos A, et al. Implantable cardioverter/defibrillators for primary prevention in dilated cardiomyopathy post-DANISH: an updated meta-analysis and systematic review of randomized controlled trials. Clinical research in cardiology : official journal of the German Cardiac Society 2017; 106: 501-513. 2017/02/19. DOI: 10.1007/s00392-017-1079-0.

124. Shun-Shin MJ, Zheng SL, Cole GD, et al. Implantable cardioverter defibrillators for primary prevention of death in left ventricular dysfunction with and without ischaemic heart disease: a meta-analysis of 8567 patients in the 11 trials. European heart journal 2017; 38: 1738-1746. 2017/03/23. DOI:

10.1093/eurheartj/ehx028.

125. Cleland JG, Daubert JC, Erdmann E, et al. The effect of cardiac resynchronization on morbidity and mortality in heart failure. The New England journal of medicine 2005; 352: 1539-1549. 2005/03/09. DOI:

10.1056/NEJMoa050496.

126. Cleland JG, Daubert JC, Erdmann E, et al. Longer-term effects of cardiac resynchronization therapy on mortality in heart failure [the CArdiac REsynchronization-Heart Failure (CARE-HF) trial extension phase]. European heart journal 2006; 27: 1928-1932. 2006/06/20. DOI: 10.1093/eurheartj/ehl099. 127. Cleland JG, Freemantle N, Erdmann E, et al. Long-term mortality with cardiac resynchronization therapy in the Cardiac Resynchronization-Heart Failure (CARE-HF) trial. European journal of heart failure 2012; 14: 628-634. 2012/05/04. DOI: 10.1093/eurjhf/hfs055.

128. Linde C, Gold MR, Abraham WT, et al. Long-term impact of cardiac resynchronization therapy in mild heart failure: 5-year results from the REsynchronization reVErses Remodeling in Systolic left vEntricular dysfunction (REVERSE) study. European heart journal 2013; 34: 2592-2599. 2013/05/04. DOI: 10.1093/eurheartj/eht160.

129. Cleland JG, Mareev Y and Linde C. Reflections on EchoCRT: sound guidance on QRS duration and morphology for CRT? European heart journal 2015; 36 : 1948-1951. 2015/07/17. DOI: 10.1093/eurheartj/ehv264.

130. Cleland JG and Ghio S. The determinants of clinical outcome and clinical response to CRT are not the same. Heart failure reviews 2012; 17: 755-766. 2011/11/15. DOI: 10.1007/s10741-011-9268-9.

131. Ali N, Keene D, Arnold A, et al. His Bundle Pacing: A New Frontier in the Treatment of Heart Failure. Arrhythm Electrophysiol Rev 2018; 7: 103-110. 2018/07/04. DOI: 10.15420/aer.2018.6.2. 
132. Huang W, Su L, Wu S, et al. Benefits of Permanent His Bundle Pacing Combined With Atrioventricular Node Ablation in Atrial Fibrillation Patients With Heart Failure With Both Preserved and Reduced Left Ventricular Ejection Fraction. Journal of the American Heart Association 2017; 6 2017/04/04. DOI: 10.1161/jaha.116.005309.

133. Mittal S, Musat DL, Hoskins MH, et al. Clinical Outcomes After Ablation of the AV Junction in Patients With Atrial Fibrillation: Impact of Cardiac Resynchronization Therapy. Journal of the American Heart Association 2017; 6 2017/11/29. DOI: 10.1161/jaha.117.007270.

134. Maack C, Eschenhagen T, Hamdani N, et al. Treatments targeting inotropy. European heart journal 2018 2018/10/09. DOI: 10.1093/eurheartj/ehy600. 135. Cuffe MS, Califf RM, Adams KF, Jr., et al. Short-term intravenous milrinone for acute exacerbation of chronic heart failure: a randomized controlled trial. Jama 2002; 287: 1541-1547. 2002/03/28.

136. Mebazaa A, Parissis J, Porcher R, et al. Short-term survival by treatment among patients hospitalized with acute heart failure: the global ALARM-HF registry using propensity scoring methods. Intensive care medicine 2011; 37: 290 301. 2010/11/19. DOI: 10.1007/s00134-010-2073-4.

137. O'Connor CM, Gattis WA, Uretsky BF, et al. Continuous intravenous dobutamine is associated with an increased risk of death in patients with advanced heart failure: insights from the Flolan International Randomized Survival Trial (FIRST). American heart journal 1999; 138: 78-86. 1999/07/01. 138. Overgaard CB and Dzavik V. Inotropes and vasopressors: review of physiology and clinical use in cardiovascular disease. Circulation 2008; 118 : 1047-1056. 2008/09/04. DOI: 10.1161/circulationaha.107.728840.

139. Tariq $S$ and Aronow WS. Use of Inotropic Agents in Treatment of Systolic Heart Failure. International journal of molecular sciences 2015; 16: 29060-29068. 2015/12/23. DOI: 10.3390/ijms161226147.

140. De Backer D, Biston P, Devriendt J, et al. Comparison of dopamine and norepinephrine in the treatment of shock. The New England journal of medicine 2010; 362: 779-789. 2010/03/05. DOI: 10.1056/NEJMoa0907118.

141. Levy B, Clere-Jehl R, Legras A, et al. Epinephrine Versus Norepinephrine for Cardiogenic Shock After Acute Myocardial Infarction. Journal of the American College of Cardiology 2018; 72: 173-182. 2018/07/07. DOI:

10.1016/j.jacc.2018.04.051.

142. Colucci WS, Wright RF, Jaski BE, et al. Milrinone and dobutamine in severe heart failure: differing hemodynamic effects and individual patient responsiveness. Circulation 1986; 73: Iii175-183. 1986/03/01.

143. Amsallem E, Kasparian C, Haddour G, et al. Phosphodiesterase III inhibitors for heart failure. The Cochrane database of systematic reviews 2005: Cd002230. 2005/01/28. DOI: 10.1002/14651858.CD002230.pub2.

144. Follath F, Cleland JG, Just H, et al. Efficacy and safety of intravenous levosimendan compared with dobutamine in severe low-output heart failure (the 
LIDO study): a randomised double-blind trial. Lancet 2002; 360: 196-202. 2002/07/23.

145. Moiseyev VS, Poder P, Andrejevs N, et al. Safety and efficacy of a novel calcium sensitizer, levosimendan, in patients with left ventricular failure due to an acute myocardial infarction. A randomized, placebo-controlled, double-blind study (RUSSLAN). European heart journal 2002; 23: 1422-1432. 2002/09/05. 146. Mebazaa A, Nieminen MS, Packer M, et al. Levosimendan vs dobutamine for patients with acute decompensated heart failure: the SURVIVE Randomized Trial. Jama 2007; 297: 1883-1891. 2007/05/03. DOI: 10.1001/jama.297.17.1883. 147. Landoni G, Biondi-Zoccai G, Greco M, et al. Effects of levosimendan on mortality and hospitalization. A meta-analysis of randomized controlled studies. Critical care medicine 2012; 40: 634-646. 2011/10/04. DOI: 10.1097/CCM.0b013e318232962a.

148. Pollesello P, Parissis J, Kivikko M, et al. Levosimendan meta-analyses: Is there a pattern in the effect on mortality? International journal of cardiology 2016; 209: 77-83. 2016/02/18. DOI: 10.1016/j.ijcard.2016.02.014.

149. Landoni G, Lomivorotov VV, Alvaro G, et al. Levosimendan for Hemodynamic Support after Cardiac Surgery. The New England journal of medicine 2017; 376: 2021-2031. 2017/03/23. DOI: 10.1056/NEJMoa1616325.

150. Mehta RH, Leimberger JD, van Diepen S, et al. Levosimendan in Patients with Left Ventricular Dysfunction Undergoing Cardiac Surgery. The New England journal of medicine 2017; 376: 2032-2042. 2017/03/21. DOI:

10.1056/NEJMoa1616218.

151. Fedele F, Bruno N, Brasolin B, et al. Levosimendan improves renal function in acute decompensated heart failure: possible underlying mechanisms. European journal of heart failure 2014; 16: 281-288. 2014/01/28. DOI: 10.1002/ejhf.9.

152. de Waha S, Desch S, Eitel I, et al. Intra-aortic balloon counterpulsation - basic principles and clinical evidence. Vascul Pharmacol 2014; 60: 52-56. 2014/01/02. DOI: $10.1016 /$ j.vph.2013.12.003.

153. Thiele H, Zeymer U, Neumann FJ, et al. Intraaortic balloon support for myocardial infarction with cardiogenic shock. The New England journal of medicine 2012; 367: 1287-1296. 2012/08/28. DOI: 10.1056/NEJMoa1208410. 154. Thiele H, Zeymer U, Neumann FJ, et al. Intra-aortic balloon counterpulsation in acute myocardial infarction complicated by cardiogenic shock (IABP-SHOCK II): final 12 month results of a randomised, open-label trial. Lancet 2013; 382: 1638-1645. 2013/09/10. DOI: 10.1016/s0140-6736(13)61783-3.

155. Estep JD. What is the role of intra-aortic balloon pump therapy in patients with acute-on-chronic heart failure and cardiogenic shock? The Journal of heart and lung transplantation : the official publication of the International Society for Heart Transplantation 2018; 37: 1301-1303. 2018/10/29. DOI: 10.1016/j.healun.2018.07.011.

156. Morine KJ and Kapur NK. Percutaneous Mechanical Circulatory Support for Cardiogenic Shock. Current treatment options in cardiovascular medicine 2016; 18: 6. 2016/01/14. DOI: 10.1007/s11936-015-0426-6. 
157. O'Neill WW, Kleiman NS, Moses J, et al. A prospective, randomized clinical trial of hemodynamic support with Impella 2.5 versus intra-aortic balloon pump in patients undergoing high-risk percutaneous coronary intervention: the PROTECT II study. Circulation 2012; 126: 1717-1727. 2012/09/01. DOI: 10.1161/circulationaha.112.098194.

158. Seyfarth M, Sibbing D, Bauer I, et al. A randomized clinical trial to evaluate the safety and efficacy of a percutaneous left ventricular assist device versus intra-aortic balloon pumping for treatment of cardiogenic shock caused by myocardial infarction. Journal of the American College of Cardiology 2008; 52: 1584-1588. 2008/11/15. DOI: 10.1016/j.jacc.2008.05.065.

159. Ouweneel DM, Eriksen E, Sjauw KD, et al. Percutaneous Mechanical Circulatory Support Versus Intra-Aortic Balloon Pump in Cardiogenic Shock After Acute Myocardial Infarction. Journal of the American College of Cardiology 2017; 69: 278-287. 2016/11/05. DOI: 10.1016/j.jacc.2016.10.022. 160. Ouweneel DM, Eriksen E, Seyfarth M, et al. Percutaneous Mechanical Circulatory Support Versus Intra-Aortic Balloon Pump for Treating Cardiogenic Shock: Meta-Analysis. Journal of the American College of Cardiology 2017; 69: 358360. 2016/11/05. DOI: 10.1016/j.jacc.2016.10.026.

161. Thiele H, Jobs A, Ouweneel DM, et al. Percutaneous short-term active mechanical support devices in cardiogenic shock: a systematic review and collaborative meta-analysis of randomized trials. European heart journal 2017; 38: 3523-3531. 2017/10/12. DOI: 10.1093/eurheartj/ehx363.

162. Ouweneel DM, de Brabander J, Karami M, et al. Real-life use of left ventricular circulatory support with Impella in cardiogenic shock after acute myocardial infarction: 12 years AMC experience. Eur Heart J Acute Cardiovasc Care 2018: 2048872618805486. 2018/11/08. DOI:

$10.1177 / 2048872618805486$.

163. Cheng A, Swartz MF and Massey HT. Impella to unload the left ventricle during peripheral extracorporeal membrane oxygenation. ASAIO journal 2013; 59: 533-536. 2013/09/03. DOI: 10.1097/MAT.0b013e31829f0e52.

164. Pappalardo F, Schulte C, Pieri M, et al. Concomitant implantation of Impella((R)) on top of veno-arterial extracorporeal membrane oxygenation may improve survival of patients with cardiogenic shock. European journal of heart failure 2017; 19: 404-412. 2016/10/07. DOI: 10.1002/ejhf.668.

165. Patel SM, Lipinski J, Al-Kindi SG, et al. Simultaneous Venoarterial Extracorporeal Membrane Oxygenation and Percutaneous Left Ventricular Decompression Therapy with Impella Is Associated with Improved Outcomes in Refractory Cardiogenic Shock. ASAIO journal 2019; 65: 21-28. 2018/03/01. DOI: $10.1097 /$ mat.0000000000000767.

166. Huang M, Ong BH, Hoo AEE, et al. Prognostic Factors for Survival After Extracorporeal Membrane Oxygenation for Cardiogenic Shock. ASAIO journal 2019 2019/03/14. DOI: 10.1097/mat.0000000000000984.

167. Ouweneel DM, Schotborgh JV, Limpens J, et al. Extracorporeal life support during cardiac arrest and cardiogenic shock: a systematic review and meta- 
analysis. Intensive care medicine 2016; 42: 1922-1934. 2016/09/21. DOI: 10.1007/s00134-016-4536-8.

168. Yusen RD, Edwards LB, Kucheryavaya AY, et al. The Registry of the International Society for Heart and Lung Transplantation: Thirty-second Official Adult Lung and Heart-Lung Transplantation Report--2015; Focus Theme: Early Graft Failure. The Journal of heart and lung transplantation : the official publication of the International Society for Heart Transplantation 2015; 34: 12641277. 2015/10/12. DOI: 10.1016/j.healun.2015.08.014.

169. Kornhall B, Nilsson J, Sigurdardottir V, et al. [More heart transplantations than ever]. Lakartidningen 2012; 109: 1743-1744. 2012/10/27.

170. Mehra MR, Canter CE, Hannan MM, et al. The 2016 International Society for Heart Lung Transplantation listing criteria for heart transplantation: A 10-year update. The Journal of heart and lung transplantation : the official publication of the International Society for Heart Transplantation 2016; 35: 1-23. 2016/01/19. DOI: 10.1016/j.healun.2015.10.023.

171. Frazier OH. Mechanical cardiac assistance: historical perspectives. Seminars in thoracic and cardiovascular surgery 2000; 12: 207-219. 2000/10/29.

172. Mihaylov D, Verkerke GJ and Rakhorst G. Mechanical circulatory support systems--a review. Technology and health care: official journal of the European Society for Engineering and Medicine 2000; 8: 251-266. 2001/02/24.

173. Moskowitz AJ, Weinberg AD, Oz MC, et al. Quality of life with an implanted left ventricular assist device. The Annals of thoracic surgery 1997; 64: 1764-1769. $1998 / 01 / 22$.

174. Frazier OH, Rose EA, Macmanus Q, et al. Multicenter clinical evaluation of the HeartMate 1000 IP left ventricular assist device. The Annals of thoracic surgery 1992; 53: 1080-1090. 1992/06/01.

175. Rose EA, Gelijns AC, Moskowitz AJ, et al. Long-term use of a left ventricular assist device for end-stage heart failure. The New England journal of medicine 2001; 345: 1435-1443. 2002/01/17. DOI: 10.1056/NEJMoa012175.

176. Park SJ, Tector A, Piccioni W, et al. Left ventricular assist devices as destination therapy: a new look at survival. The Journal of thoracic and cardiovascular surgery 2005; 129: 9-17. 2005/01/06. DOI:

10.1016/j.jtcvs.2004.04.044.

177. Griffith BP, Kormos RL, Borovetz HS, et al. HeartMate II left ventricular assist system: from concept to first clinical use. The Annals of thoracic surgery 2001; 71: S116-120; discussion S114-116. 2001/03/27.

178. Bourque K, Gernes DB, Loree HM, 2nd, et al. HeartMate III: pump design for a centrifugal LVAD with a magnetically levitated rotor. ASAIO journal 2001; 47: 401-405. 2001/08/03.

179. Westaby S, Katsumata T, Evans R, et al. The Jarvik 2000 Oxford system: increasing the scope of mechanical circulatory support. The Journal of thoracic and cardiovascular surgery 1997; 114: 467-474. 1997/09/26. DOI: 10.1016/s0022-5223(97)70195-8. 
180. Slaughter MS, Sobieski MA, 2nd, Tamez D, et al. HeartWare miniature axialflow ventricular assist device: design and initial feasibility test. Texas Heart Institute journal / from the Texas Heart Institute of St Luke's Episcopal Hospital, Texas Children's Hospital 2009; 36: 12-16. 2009/05/14.

181. Frazier OH, Delgado RM, 3rd, Kar B, et al. First clinical use of the redesigned HeartMate II left ventricular assist system in the United States: a case report. Texas Heart Institute journal / from the Texas Heart Institute of St Luke's Episcopal Hospital, Texas Children's Hospital 2004; 31: 157-159. 2004/06/24.

182. Burke DJ, Burke E, Parsaie F, et al. The Heartmate II: design and development of a fully sealed axial flow left ventricular assist system. Artificial organs 2001; 25: 380-385. 2001/06/14.

183. Frazier OH, Gemmato C, Myers TJ, et al. Initial clinical experience with the HeartMate II axial-flow left ventricular assist device. Texas Heart Institute journal / from the Texas Heart Institute of St Luke's Episcopal Hospital, Texas Children's Hospital 2007; 34: 275-281. 2007/10/20.

184. Miller LW, Pagani FD, Russell SD, et al. Use of a continuous-flow device in patients awaiting heart transplantation. The New England journal of medicine 2007; 357: 885-896. 2007/09/01. DOI: 10.1056/NEJMoa067758.

185. Pagani FD, Miller LW, Russell SD, et al. Extended mechanical circulatory support with a continuous-flow rotary left ventricular assist device. Journal of the American College of Cardiology 2009; 54: 312-321. DOI:

10.1016/j.jacc.2009.03.055.

186. Slaughter MS, Rogers JG, Milano CA, et al. Advanced heart failure treated with continuous-flow left ventricular assist device. The New England journal of medicine 2009; 361: 2241-2251. 2009/11/19. DOI: 10.1056/NEJMoa0909938. 187. Lahpor J, Khaghani A, Hetzer R, et al. European results with a continuousflow ventricular assist device for advanced heart-failure patients. European journal of cardio-thoracic surgery : official journal of the European Association for Cardio-thoracic Surgery 2010; 37: 357-361. DOI: 10.1016/j.ejcts.2009.05.043. 188. Struber M, Sander K, Lahpor J, et al. HeartMate II left ventricular assist device; early European experience. European journal of cardio-thoracic surgery: official journal of the European Association for Cardio-thoracic Surgery 2008; 34: 289-294. 2008/06/24. DOI: 10.1016/j.ejcts.2008.05.011.

189. John R, Kamdar F, Liao K, et al. Improved survival and decreasing incidence of adverse events with the HeartMate II left ventricular assist device as bridge-totransplant therapy. The Annals of thoracic surgery 2008; 86: 1227-1234; discussion 1234-1225. 2008/09/23. DOI: 10.1016/j.athoracsur.2008.06.030. 190. Loforte A, Montalto A, Ranocchi F, et al. Long-term mechanical support with the HeartMate II LVAS. Transplantation proceedings 2009; 41: 1357-1359. 2009/05/23. DOI: 10.1016/j.transproceed.2009.03.020.

191. Pagani FD, Miller LW, Russell SD, et al. Extended mechanical circulatory support with a continuous-flow rotary left ventricular assist device. Journal of the American College of Cardiology 2009; 54: 312-321. 2009/07/18. DOI: 10.1016/j.jacc.2009.03.055. 
192. Granfeldt H, Peterzen B, Hubbert L, et al. A single center experience with the HeartMate II left ventricular assist device (LVAD). Scandinavian cardiovascular journal : SCJ 2009; 43: 360-365. 2009/06/23. DOI:

10.1080/14017430903019553.

193. Jorde UP, Kushwaha SS, Tatooles AJ, et al. Results of the destination therapy post-food and drug administration approval study with a continuous flow left ventricular assist device: a prospective study using the INTERMACS registry (Interagency Registry for Mechanically Assisted Circulatory Support). Journal of the American College of Cardiology 2014; 63: 1751-1757. 2014/03/13. DOI: 10.1016/j.jacc.2014.01.053.

194. Loforte A, Montalto A, Lilla della Monica P, et al. Mechanical circulatory support in advanced heart failure: single-center experience. Transplantation proceedings 2014; 46: 1476-1480. 2014/06/18. DOI:

10.1016/j.transproceed.2014.01.016.

195. Kyo S, Ono M, Sawa Y, et al. Results of the prospective multicenter Japanese bridge to transplant study with a continuous-flow left ventricular assist device. Journal of artificial organs : the official journal of the Japanese Society for Artificial Organs 2014; 17: 142-148. 2014/01/29. DOI: 10.1007/s10047-013-0752-y. 196. Lim CP, Sivathasan C, Tan TE, et al. Use of left ventricular assist device (HeartMate II): a Singapore experience. Artificial organs 2014; 38: 543-548. 2014/01/08. DOI: 10.1111/aor.12247.

197. Ertugay S, Engin C, Nalbantgil S, et al. Postoperative Outcomes of the Largest HeartMate-II Experience in Turkey. Transplantation proceedings 2015; 47: 14991502. 2015/06/22. DOI: 10.1016/j.transproceed.2015.04.046.

198. Morgan JA, Go PH, Xuereb L, et al. Outcomes on Continuous Flow Left Ventricular Assist Devices: A Single Institutional 9-Year Experience. The Annals of thoracic surgery 2016 2016/05/14. DOI: 10.1016/j.athoracsur.2016.03.026. 199. John R, Pagani FD, Naka Y, et al. Post-cardiac transplant survival after support with a continuous-flow left ventricular assist device: impact of duration of left ventricular assist device support and other variables. The Journal of thoracic and cardiovascular surgery 2010; 140: 174-181. DOI: 10.1016/j.jtcvs.2010.03.037.

200. Rogers JG, Aaronson KD, Boyle AJ, et al. Continuous flow left ventricular assist device improves functional capacity and quality of life of advanced heart failure patients. Journal of the American College of Cardiology 2010; 55: 18261834. 2010/04/24. DOI: 10.1016/j.jacc.2009.12.052.

201. John R. Current axial-flow devices--the HeartMate II and Jarvik 2000 left ventricular assist devices. Seminars in thoracic and cardiovascular surgery 2008; 20: 264-272. 2008/11/29. DOI: 10.1053/j.semtcvs.2008.08.001. 202. John R, Kamdar F, Eckman P, et al. Lessons learned from experience with over 100 consecutive HeartMate II left ventricular assist devices. The Annals of thoracic surgery 2011; 92: 1593-1599; discussion 1599-1600. 2011/11/05. DOI: 10.1016/j.athoracsur.2011.06.081. 
203. Kirklin JK, Naftel DC, Kormos RL, et al. Fifth INTERMACS annual report: risk factor analysis from more than 6,000 mechanical circulatory support patients. The Journal of heart and lung transplantation : the official publication of the International Society for Heart Transplantation 2013; 32: 141-156. DOI: 10.1016/j.healun.2012.12.004. 204. Tuzun E, Roberts $\mathrm{K}$, Cohn WE, et al. In vivo evaluation of the HeartWare centrifugal ventricular assist device. Texas Heart Institute journal / from the Texas Heart Institute of St Luke's Episcopal Hospital, Texas Children's Hospital 2007; 34: 406-411. 2008/01/04.

205. Park SJ, Milano CA, Tatooles AJ, et al. Outcomes in advanced heart failure patients with left ventricular assist devices for destination therapy. Circulation Heart failure 2012; 5: 241-248. 2012/01/28. DOI:

10.1161/circheartfailure.111.963991.

206. Kirklin JK, Naftel DC, Pagani FD, et al. Seventh INTERMACS annual report: 15,000 patients and counting. The Journal of heart and lung transplantation : the official publication of the International Society for Heart Transplantation 2015; 34: 1495-1504. 2015/11/02. DOI: 10.1016/j.healun.2015.10.003.

207. Kirklin JK, Pagani FD, Kormos RL, et al. Eighth annual INTERMACS report: Special focus on framing the impact of adverse events. The Journal of heart and lung transplantation : the official publication of the International Society for Heart Transplantation 2017; 36: 1080-1086. 2017/09/26. DOI:

10.1016/j.healun.2017.07.005.

208. Kormos RL, Cowger J, Pagani FD, et al. The Society of Thoracic Surgeons Intermacs database annual report: Evolving indications, outcomes, and scientific partnerships. The Journal of heart and lung transplantation : the official publication of the International Society for Heart Transplantation 2019; 38: 114126. 2019/01/30. DOI: 10.1016/j.healun.2018.11.013. 209. Moreno SG, Novielli N and Cooper NJ. Cost-effectiveness of the implantable HeartMate II left ventricular assist device for patients awaiting heart transplantation. The Journal of heart and lung transplantation : the official publication of the International Society for Heart Transplantation 2012; 31: 450458. 2011/11/26. DOI: 10.1016/j.healun.2011.10.017.

210. Neyt M, Van den Bruel A, Smit Y, et al. Cost-effectiveness of continuous-flow left ventricular assist devices. International journal of technology assessment in health care 2013; 29: 254-260. 2013/06/15. DOI: 10.1017/s0266462313000238. 211. Sutcliffe P, Connock M, Pulikottil-Jacob R, et al. Clinical effectiveness and cost-effectiveness of second- and third-generation left ventricular assist devices as either bridge to transplant or alternative to transplant for adults eligible for heart transplantation: systematic review and cost-effectiveness model. Health technology assessment (Winchester, England) 2013; 17: 1-499, v-vi. 2013/11/28. DOI: $10.3310 /$ hta17530.

212. Sundbom P, Hedayati E, Peterzen B, et al. Young woman with breast cancer and cardiotoxicity with severe heart failure treated with a HeartMate IITM for 
nearly 6 years before heart transplantation. ASAIO journal 2014; 60: e3-4. 2014/09/19. DOI: 10.1097/mat.0000000000000138.

213. Schmitto JD, Hanke JS, Rojas S, et al. Circulatory support exceeding five years with a continuous-flow left ventricular assist device for advanced heart failure patients. Journal of cardiothoracic surgery 2015; 10: 107. 2015/08/09. DOI: 10.1186/s13019-015-0306-x.

214. Farrar DJ, Bourque K, Dague CP, et al. Design features, developmental status, and experimental results with the Heartmate III centrifugal left ventricular assist system with a magnetically levitated rotor. ASAIO journal 2007; 53: 310-315. 2007/05/23. DOI: 10.1097/MAT.0b013e3180536694.

215. Schmitto JD, Hanke JS, Rojas SV, et al. First implantation in man of a new magnetically levitated left ventricular assist device (HeartMate III). The Journal of heart and lung transplantation : the official publication of the International Society for Heart Transplantation 2015; 34: 858-860. 2015/04/30. DOI:

10.1016/j.healun.2015.03.001.

216. Netuka I, Sood P, Pya Y, et al. Fully Magnetically Levitated Left Ventricular Assist System for Treating Advanced HF: A Multicenter Study. Journal of the American College of Cardiology 2015; 66: 2579-2589. 2015/12/17. DOI: 10.1016/j.jacc.2015.09.083.

217. Hanke JS, Dogan G, Rojas SV, et al. First experiences with HeartMate 3 followup and adverse events. The Journal of thoracic and cardiovascular surgery 2017; 154: 173-178. 2017/03/08. DOI: 10.1016/j.jtcvs.2017.01.045.

218. Hanke JS, Dogan G, Zoch A, et al. One-year outcomes with the HeartMate 3 left ventricular assist device. The Journal of thoracic and cardiovascular surgery 2018; 156: 662-669. 2018/03/12. DOI: 10.1016/j.jtcvs.2018.01.083.

219. Schmitto JD, Pya Y, Zimpfer D, et al. Long-term evaluation of a fully magnetically levitated circulatory support device for advanced heart failure-twoyear results from the HeartMate 3 CE Mark Study. European journal of heart failure 2018 2018/07/28. DOI: 10.1002/ejhf.1284.

220. Mehra MR, Uriel N, Naka Y, et al. A Fully Magnetically Levitated Left Ventricular Assist Device - Final Report. The New England journal of medicine 2019; 380: 1618-1627. 2019/03/19. DOI: 10.1056/NEJMoa1900486.

221. Thoratec. HeartMate II, LVAS, Operating manual. 2007.

222. Bourque K, Cotter C, Dague C, et al. Design Rationale and Preclinical Evaluation of the HeartMate 3 Left Ventricular Assist System for Hemocompatibility. ASAIO journal 2016; 62: 375-383. 2016/05/20. DOI: $10.1097 /$ mat.0000000000000388.

223. Wiegmann L, Thamsen B, de Zelicourt D, et al. Fluid dynamics in the HeartMate 3: Influence of the artificial pulse feature and residual cardiac pulsation. Artificial organs 2018 2018/08/22. DOI: 10.1111/aor.13346. 224. Feldman D, Pamboukian SV, Teuteberg JJ, et al. The 2013 International Society for Heart and Lung Transplantation Guidelines for mechanical circulatory support: executive summary. The Journal of heart and lung transplantation : the 
official publication of the International Society for Heart Transplantation 2013; 32: 157-187. 2013/01/29. DOI: 10.1016/j.healun.2012.09.013.

225. Schloglhofer T, Horvat J, Moscato F, et al. A Standardized Telephone Intervention Algorithm Improves the Survival of Ventricular Assist Device Outpatients. Artificial organs 2018; 42: 961-969. 2018/05/26. DOI:

10.1111/aor.13155.

226. Bouchez S, Van Belleghem Y, De Somer F, et al. Haemodynamic management of patients with left ventricular assist devices using echocardiography: the essentials. European heart journal cardiovascular Imaging 2019; 20: 373-382. 2019/02/05. DOI: 10.1093/ehjci/jez003.

227. Meyer AL, Kuehn C, Weidemann J, et al. Thrombus formation in a HeartMate II left ventricular assist device. The Journal of thoracic and cardiovascular surgery 2008; 135: 203-204. 2008/01/09. DOI: 10.1016/j.jtcvs.2007.08.048.

228. Bashir J, Cheung A, Kaan A, et al. Thrombosis and failure of a HeartMate II device in the absence of alarms. The Journal of heart and lung transplantation : the official publication of the International Society for Heart Transplantation 2011; 30: 1197-1199. 2011/07/19. DOI: 10.1016/j.healun.2011.05.008.

229. Boyle AJ, Russell SD, Teuteberg JJ, et al. Low thromboembolism and pump thrombosis with the HeartMate II left ventricular assist device: analysis of outpatient anti-coagulation. The Journal of heart and lung transplantation : the official publication of the International Society for Heart Transplantation 2009; 28 : 881-887. DOI: 10.1016/j.healun.2009.05.018.

230. Menon AK, Gotzenich A, Sassmannshausen H, et al. Low stroke rate and few thrombo-embolic events after HeartMate II implantation under mild anticoagulation. European journal of cardio-thoracic surgery: official journal of the European Association for Cardio-thoracic Surgery 2012; 42: 319-323; discussion 323. 2012/03/09. DOI: $10.1093 /$ ejcts/ezr312.

231. Netuka I, Litzler PY, Berchtold-Herz M, et al. Outcomes in HeartMate II Patients With No Antiplatelet Therapy: 2-Year Results From the European TRACE Study. The Annals of thoracic surgery 2017; 103: 1262-1268. 2016/10/17. DOI: 10.1016/j.athoracsur.2016.07.072.

232. Goldstein DJ, John R, Salerno C, et al. Algorithm for the diagnosis and management of suspected pump thrombus. The Journal of heart and lung transplantation : the official publication of the International Society for Heart Transplantation 2013; 32: 667-670. 2013/06/26. DOI:

10.1016/j.healun.2013.05.002.

233. Taghavi S, Ward C, Jayarajan SN, et al. Surgical technique influences HeartMate II left ventricular assist device thrombosis. The Annals of thoracic surgery 2013; 96: 1259-1265. DOI: 10.1016/j.athoracsur.2013.05.081. 234. Kirklin JK, Naftel DC, Kormos RL, et al. Interagency Registry for Mechanically Assisted Circulatory Support (INTERMACS) analysis of pump thrombosis in the HeartMate II left ventricular assist device. The Journal of heart and lung transplantation : the official publication of the International Society for Heart Transplantation 2014; 33: 12-22. DOI: 10.1016/j.healun.2013.11.001. 
235. Mehra MR, Stewart GC and Uber PA. The vexing problem of thrombosis in long-term mechanical circulatory support. The Journal of heart and lung transplantation : the official publication of the International Society for Heart Transplantation 2014; 33: 1-11. DOI: 10.1016/j.healun.2013.12.002. 236. Starling RC, Moazami N, Silvestry SC, et al. Unexpected abrupt increase in left ventricular assist device thrombosis. The New England journal of medicine 2014; 370: 33-40. 2013/11/29. DOI: 10.1056/NEJMoa1313385.

237. Kirklin JK, Naftel DC, Pagani FD, et al. Sixth INTERMACS annual report: a 10,000-patient database. The Journal of heart and lung transplantation: the official publication of the International Society for Heart Transplantation 2014; 33: 555-564. DOI: 10.1016/j.healun.2014.04.010.

238. McCarthy FH, Kobrin D, Rame JE, et al. Increasing Frequency of Left Ventricular Assist Device Exchanges in the United States. The Annals of thoracic surgery 2015; 100: 1660-1664; discussion 1665. 2015/07/26. DOI:

10.1016/j.athoracsur.2015.04.072.

239. Uriel N, Han J, Morrison KA, et al. Device thrombosis in HeartMate II continuous-flow left ventricular assist devices: a multifactorial phenomenon. The Journal of heart and lung transplantation : the official publication of the International Society for Heart Transplantation 2014; 33: 51-59. DOI: 10.1016/j.healun.2013.10.005.

240. Whitson BA, Eckman P, Kamdar F, et al. Hemolysis, pump thrombus, and neurologic events in continuous-flow left ventricular assist device recipients. The Annals of thoracic surgery 2014; 97: 2097-2103. 2014/04/30. DOI:

10.1016/j.athoracsur.2014.02.041.

241. Kirklin JK, Naftel DC, Pagani FD, et al. Pump thrombosis in the Thoratec HeartMate II device: An update analysis of the INTERMACS Registry. The Journal of heart and lung transplantation : the official publication of the International Society for Heart Transplantation 2015; 34: 1515-1526. 2015/12/19. DOI: 10.1016/j.healun.2015.10.024.

242. Soltani S, Kaufmann F, Vierecke J, et al. Design changes in continuous-flow left ventricular assist devices and life-threatening pump malfunctions. European journal of cardio-thoracic surgery : official journal of the European Association for Cardio-thoracic Surgery 2015; 47: 984-989. 2014/09/12. DOI:

10.1093/ejcts/ezu347.

243. Klodell CT, Massey HT, Adamson RM, et al. Factors Related to Pump Thrombosis With the Heartmate II Left Ventricular Assist Device. Journal of cardiac surgery 2015; 30: 775-780. 2015/08/19. DOI: 10.1111/jocs.12607. 244. Maltais S, Kilic A, Nathan S, et al. PREVENtion of HeartMate II Pump Thrombosis Through Clinical Management: The PREVENT multi-center study. The Journal of heart and lung transplantation : the official publication of the International Society for Heart Transplantation 2017; 36: 1-12. 2016/11/21. DOI: 10.1016/j.healun.2016.10.001.

245. Chiu WC, Slepian MJ and Bluestein D. Thrombus formation patterns in the HeartMate II ventricular assist device: clinical observations can be predicted by 
numerical simulations. ASAIO journal 2014; 60: 237-240. 2014/01/09. DOI: $10.1097 /$ mat.0000000000000034.

246. Najjar SS, Slaughter MS, Pagani FD, et al. An analysis of pump thrombus events in patients in the HeartWare ADVANCE bridge to transplant and continued access protocol trial. The Journal of heart and lung transplantation : the official publication of the International Society for Heart Transplantation 2014; 33: 23-34. 2014/01/15. DOI: 10.1016/j.healun.2013.12.001.

247. Smedira NG, Blackstone EH, Ehrlinger J, et al. Current risks of HeartMate II pump thrombosis: Non-parametric analysis of Interagency Registry for Mechanically Assisted Circulatory Support data. The Journal of heart and lung transplantation : the official publication of the International Society for Heart Transplantation 2015; 34: 1527-1534. 2015/12/19. DOI: 10.1016/j.healun.2015.10.027.

248. Krabatsch T, Netuka I, Schmitto JD, et al. Heartmate 3 fully magnetically levitated left ventricular assist device for the treatment of advanced heart failure -1 year results from the Ce mark trial. Journal of cardiothoracic surgery 2017; 12 : 23. 2017/04/06. DOI: 10.1186/s13019-017-0587-3.

249. Mehra MR, Goldstein DJ, Uriel N, et al. Two-Year Outcomes with a Magnetically Levitated Cardiac Pump in Heart Failure. The New England journal of medicine 2018 2018/03/13. DOI: 10.1056/NEJMoa1800866.

250. Mehra MR, Naka Y, Uriel N, et al. A Fully Magnetically Levitated Circulatory Pump for Advanced Heart Failure. The New England journal of medicine 2017; 376: 440-450. 2016/12/14. DOI: 10.1056/NEJMoa1610426.

251. Itzhaki Ben Zadok O, Ben-Avraham B, Shaul A, et al. An 18-month comparison of clinical outcomes between continuous-flow left ventricular assist devices. European journal of cardio-thoracic surgery : official journal of the European Association for Cardio-thoracic Surgery 2019 2019/10/01. DOI: 10.1093 /ejcts/ezz268.

252. Florisson DS, Conte SM, De Bono JA, et al. Do patients with the centrifugal flow HeartMate 3 or HeartWare left ventricular assist device have better outcomes compared to those with axial flow HeartMate II? Interactive cardiovascular and thoracic surgery 2019 2019/08/23. DOI:

10.1093/icvts/ivz202.

253. Duero Posada JG, Moayedi Y, Alhussein M, et al. Outflow Graft Occlusion of the HeartMate 3 Left Ventricular Assist Device. Circulation Heart failure 2017; 10 2017/08/31. DOI: 10.1161/circheartfailure.117.004275.

254. Uriel N, Morrison KA, Garan AR, et al. Development of a novel echocardiography ramp test for speed optimization and diagnosis of device thrombosis in continuous-flow left ventricular assist devices: the Columbia ramp study. Journal of the American College of Cardiology 2012; 60: 1764-1775. DOI: 10.1016/j.jacc.2012.07.052.

255. Makino T, Okamoto E, Tanaka S, et al. Estimation of early-stage malfunction using implantable artificial heart sound in animal experiments. Artificial organs 2006; 30: 360-364. 2006/05/11. DOI: 10.1111/j.1525-1594.2006.00226.x. 
256. Slaughter MS, Feldman CM, Sobieski MA, et al. Utilization of acoustic signatures to identify HeartMate XVE device end-of-life. The Journal of heart and lung transplantation : the official publication of the International Society for Heart Transplantation 2007; 26: 579-583. 2007/06/05. DOI:

10.1016/j.healun.2007.03.009.

257. Bowles CT, Borhani M, van der Horst A, et al. 44: Analysis of Implantable Left Ventricular Assist Device (LVAD) Acoustic Waveform by Fourier Transform and Empirical Mode Decomposition: Dependence on Rotation Speed, Device Design and Left Ventricular Interaction. The Journal of Heart and Lung Transplantation 2009; 28: S80. DOI: http://dx.doi.org/10.1016/i.healun.2008.11.050.

258. Bowles C.T NM, Schmidt A, Hedger M.E, Banner N.R, Parker K.H, Simon A. Successful Treatment of Implantable Rotary Left Ventricular Assist Device (LVAD) Thrombus Is Associated with Normalisation of Acoustic Properties. The Journal of Heart and Lung Transplantation 2011; 30: S98.

259. Hubbert L JU, Peterzén B, Granfeldt H, Kornhall B, Morrison K, Ahn H. Early Results from the SoundMate Study. Acoustic Analysis of a Thromboembolic Event in a Patient Treated with HeartMate II ${ }^{\mathrm{TM}}$, Mechanical Circulatory Support. The Journal of Heart and Lung Transplantation 2012; 31: S134-S135.

260. Markey P DK, Gupta S, Woldendorp K, Robson D, Hayward C, Lovell N. The Value of Pump Audiosignals in Patients with Left Ventricular Assist Devices. The Journal of Heart and Lung Transplantation 2013; 32: S30.

261. Kaufmann F, Hormandinger C, Stepanenko A, et al. Acoustic spectral analysis for determining pump thrombosis in rotary blood pumps. ASAIO journal 2014; 60: 502-507. 2014/05/13. DOI: 10.1097/mat.0000000000000097.

262. Bull D, Markey P, Vickers D, et al. The Harmonic Pattern of Ventricular Assist Device Audiosignals: Correlation to Pump Speed and Aortic Valve Opening. The Journal of Heart and Lung Transplantation 2015; 34: S196. DOI:

10.1016/j.healun.2015.01.536.

263. Yost GL, Royston TJ, Bhat G, et al. Acoustic Characterization of Axial Flow Left Ventricular Assist Device Operation In Vitro and In Vivo. ASAIO journal 2015 2015/11/05. DOI: $10.1097 /$ mat.0000000000000307.

264. Feldmann C, Deniz E, Stomps A, et al. An acoustic method for systematic ventricular assist device thrombus evaluation with a novel artificial thrombus model. Journal of thoracic disease 2018; 10: S1711-S1719. 2018/07/24. DOI: 10.21037/jtd.2018.04.11.

265. Fuchs G, Berg N, Eriksson A, et al. Detection of Thrombosis in the Extracorporeal Membrane Oxygenation Circuit by Infrasound: Proof of Concept. Artificial organs 2017; 41: 573-579. 2016/09/23. DOI: 10.1111/aor.12782. 266. Gustafson F, Ljung L and Millnert M. Signal processing. Lund: Studentlitteratur, 2013.

267. The physics of sound, https://homepages.wmich.edu/ hillenbr/206/ac.pdf (accessed 2018-10-16). 
268. Shure. Product Specifications PG58,

http://cdn.shure.com/specification sheet/upload/66/us pro pg58 specsheet.pd $\underline{\mathrm{f}}(2008$, accessed 0312 2015).

269. Behringer. Firepower FCA1616 /FCA610,

http://www.behringer.com/assets/FCA610 FCA1616 WebBrochure.pdf (2013, accessed 0312 2015).

270. Mathworks. (accessed 0312 2015).

271. Hubbert L, Sundbom P, Loebe M, et al. Acoustic analysis of a mechanical

circulatory support. Artificial organs 2014; 38: 593-598. DOI: 10.1111/aor.12244. 272. Sundbom P, Roth M, Granfeldt H, et al. Sound analysis of a left ventricular assist device: A technical evaluation of iOS devices. The International journal of artificial organs 2018: 391398818762352. 2018/03/10. DOI:

$10.1177 / 0391398818762352$.

273. Sundbom P, Roth M, Granfeldt H, et al. Sound analysis of the magnetically levitated left ventricular assist device HeartMate 3(). The International journal of artificial organs 2019: 391398819857443. 2019/06/30. DOI:

10.1177/0391398819857443.

274. Yost GL. Acoustic Characterization of Left Ventricular Assisst Device Function. Cornell University, Ithaca, New York, 2012.

275. Debbal SM and Bereksi-Reguig F. Filtering and classification of phonocardiogram signals using wavelet transform. Journal of medical engineering \& technology 2008; 32: 53-65. 2008/01/10. DOI: 10.1080/03091900600750348. 


\section{Papers}

The papers associated with this thesis have been removed for copyright reasons. For more details about these see:

http://urn.kb.se/resolve?urn=urn:nbn:se:liu:diva-161902 


\section{FACULTY OF MEDICINE AND HEALTH SCIENCES}

Linköping University Medical Dissertation No. 1707, 2019

Department of Medicine and Health

Linköping University

SE-581 83 Linköping, Sweden

www.liu.se
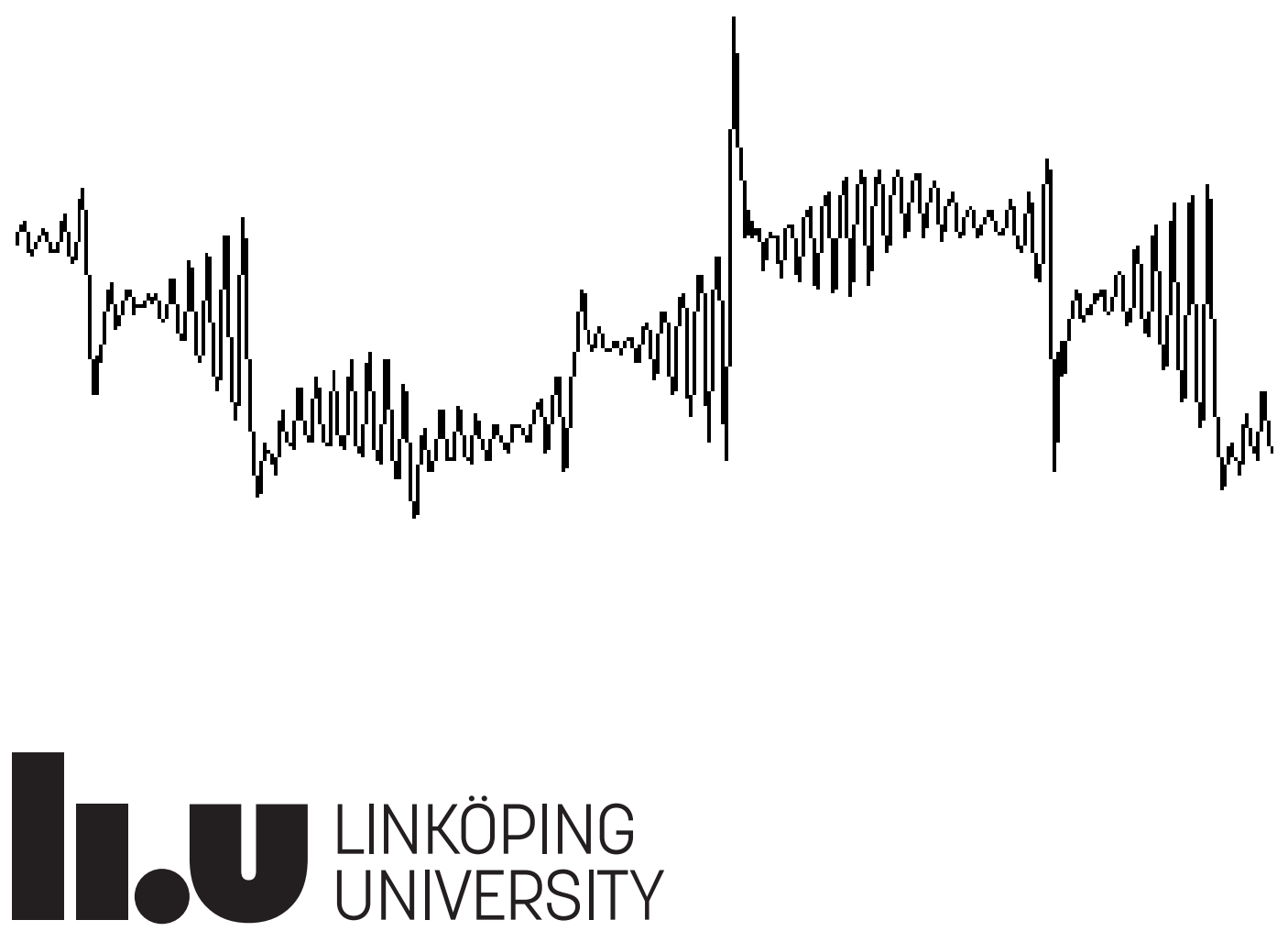